
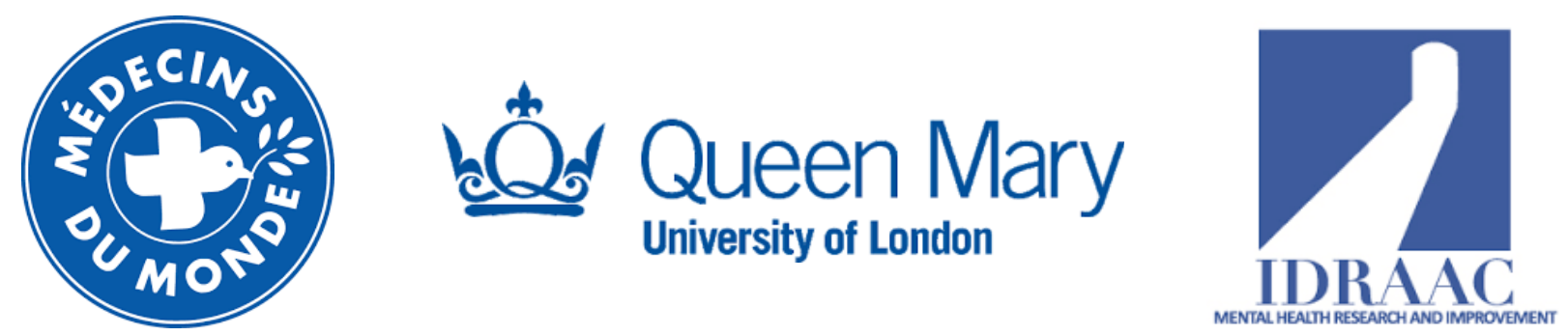

\title{
Validating Screening Questionnaires for Internalizing and Externalizing Disorders against Clinical Interviews in 8 to 17 -Year-Old Syrian Refugee Children
}

Fiona S. McEwen ${ }^{1}$, Patricia Moghames ${ }^{2}$, Tania Bosqui ${ }^{3,4}$, Vanessa Kyrillos ${ }^{2}$, Nicolas Chehade $^{2}$, Stephanie Saad ${ }^{2}$, Diana Abdul Rahman², Cassandra Popham ${ }^{1}$, Dahlia Saab $^{5}$, Georges Karam ${ }^{5,6,7,8}$, Elie Karam ${ }^{5,6,7,9}$, \& Michael Pluess ${ }^{1}$

${ }^{1}$ Queen Mary University of London

${ }^{2}$ Médecins du Monde

${ }^{3}$ American University of Beirut

${ }^{4}$ Centre for Public Health, Queen's University Belfast

${ }^{5}$ Institute for Development, Research, Advocacy \& Applied Care (IDRAAC)

${ }^{6}$ St. George Hospital University Medical Centre/Faculty of Medicine, University of Balamand

${ }^{7}$ Medical Institute for Neuropsychological Disorders (MIND)

${ }^{8}$ President of Alzheimer's Association Lebanon (AAL)

${ }^{9}$ Chairman of the WPA Epidemiology and Public Health Section

Technical Working Paper

Draft January 2020

Note:

This report contains evidence on a suite of screening tools tested by study authors for use with Syrian refugee children ages 8-17 years old in Lebanon. Information on the Center for Epidemiological Studies Depression Scale for Children (CES-DC: 10-item version) can be found in the summary tables below as well as in sections 1.1.1, 2.4.2, 3.1.1, 3.2.2, and 5.1.1 of the report. We strongly encourage the reader to carefully and fully review the introduction, methods, summary and recommendations of the entire report to facilitate accurate interpretation of the results.

Correspondence and requests for technical appendices should be addressed to Dr. Fiona McEwen at f.mcewen@qmul.ac.uk 


\begin{abstract}
Syrian children affected by the civil war are at increased risk of mental health problems, including depression, anxiety, post-traumatic stress disorder (PTSD), and externalizing behaviour problems. Screening questionnaires are designed to identify individual children who require further assessment and treatment, and also estimate the need for mental health services in a population. However, few questionnaires have been rigorously tested in this population. This study examined the reliability and validity of questionnaires for depression (Center for Epidemiological Studies Depression Scale for Children, CES-DC, self-report, 10item version), anxiety (Screen for Child Anxiety Related Emotional Disorders, SCARED, self-report, 18-item version), PTSD (Child PTSD Symptom Scale, CPSS, self-report), and internalizing and externalizing behavior problems (Strengths and Difficulties Questionnaire, SDQ, parent-report version) in a population sample of 8-17 year old Syrian children living in Informal Tented Settlements (ITS) in the Beqaa region of Lebanon. In addition, several ways of measuring functional impairment due to mental health problems were compared. These included self- and parent-report questionnaires (World Health Organization Disability Assessment Schedule, WHODAS-Child; SDQ Impact supplement, parent-report only) and an interviewer rating of severity (Clinical Global Impression-severity, CGI-s).
\end{abstract}

Questionnaires were translated into Arabic and modified based on pilot testing with Syrian children. Responses from $N=1006$ children and caregivers were used for analysis, a subset of whom had additional clinical interview data (MINI KID + clinical judgement; $N=119$ ). The self-report questionnaires showed good internal consistency reliability with alpha $>.80$, though the parent-report SDQ and WHODAS-Child fell below this level. In terms of validity, the SDQ externalizing scale performed well in differentiating children with conduct problems from those without and it was possible to achieve a fair balance between sensitivity ( $82 \%)$ and specificity (71\%). The CES-DC, CPSS, SDQ total difficulties, and WHODAS-Child (selfreport) achieved an acceptable level of validity, though it was harder to achieve a good balance between sensitivity and specificity. In most cases, at least $50 \%$ of those screening positive were false positives, meaning that a more in-depth follow up assessment would be required if these tools were used as screeners in a clinical setting. Furthermore, correction would be needed if used to estimate prevalence rates for mental disorders in this population. There was moderate convergent validity between measures of functional impairment, with self-report WHODAS-Child showing greater agreement with interviewer ratings when compared to parent-report measures (WHODAS and SDQ Impact). Measuring functional impairment and distress due to mental health problems should help to differentiate children with clinically significant mental health problems from those with subthreshold problems; however, more work will be required to establish how helpful the tools used here are in achieving that aim. 
This technical working paper was developed by Fiona S. McEwen, Patricia Moghames, Tania Bosqui, Vanessa Kyrillos, Nicolas Chehade, Stephanie Saad, Diana Abdul Rahman, Cassandra Popham, Dahlia Saab, Georges Karam, Elie Karam, \& Michael Pluess as members of the 3EA | MENAT Measurement Consortium, and reviewed by NYU Global Ties for Children.

Suggested citation: McEwen, F. S., Moghames, P., Bosqui, T., Kyrillos, V., Chehade, N., Saad, S., Abdul Rahman, D., Popham, C., Saab, D., Karam, G., Karam, E., \& Pluess, M. (2020, January). Validating screening questionnaires for internalizing and externalizing disorders against clinical interviews in 8-17 year-old Syrian refugee children. Technical working paper. London, UK: QMUL.

The report and copies of the validated measures can be accessed at https://inee.org/measurement-library 


\title{
Validating screening questionnaires for internalising and externalising disorders against clinical interviews in 8-17 year-old Syrian refugee children
}

Fiona S. McEwen, Patricia Moghames, Tania Bosqui, Vanessa Kyrillos, Nicolas Chehade, Stephanie Saad, Diana Abdul Rahman, Cassandra Popham, Dahlia Saab, Georges Karam, Elie Karam, Michael Pluess

\begin{abstract}
Syrian children affected by the civil war are at increased risk of mental health problems, including depression, anxiety, post traumatic stress disorder (PTSD), and externalising behaviour problems. Screening questionnaires are designed to identify individual children who require further assessment and treatment, and also estimate the need for mental health services in a population. However, few questionnaires have been rigorously tested in this population. This study examined the reliability and validity of questionnaires for depression (Center for Epidemiological Studies Depression Scale for Children, CES-DC, self-report, 10-item version), anxiety (Screen for Child Anxiety Related Emotional Disorders, SCARED, self-report, 18-item version), PTSD (Child PTSD Symptom Scale, CPSS, self-report), and internalising and externalising behaviour problems (Strengths and Difficulties Questionnaire, SDQ, parent-report version) in a population sample of 8-17 year old Syrian children living in Informal Tented Settlements (ITS) in the Beqaa region of Lebanon. In addition, several ways of measuring functional impairment due to mental health problems were compared. These included self- and parent-report questionnaires (World Health Organisation Disability Assessment Schedule, WHODAS-Child; SDQ Impact supplement, parent-report only) and an interviewer rating of severity (Clinical Global Impression-severity, CGI-s). Questionnaires were translated into Arabic and modified based on pilot testing with Syrian children. Responses from $\mathrm{N}=1006$ children and caregivers were used for analysis, a subset of whom had additional clinical interview data (MINI KID + clinical judgement; $\mathrm{N}=119$ ). The self-report questionnaires showed good internal consistency reliability with alpha>.80, though the parent-report SDQ and WHODAS-Child fell below this level. In terms of validity, the SDQ externalising scale performed well in differentiating children with conduct problems from those without and it was possible to achieve a fair balance between sensitivity (82\%) and specificity (71\%). The CES-DC, CPSS, SDQ total difficulties, and WHODAS-Child (self-report) achieved an acceptable level of validity, though it was harder to achieve a good balance between sensitivity and specificity. In most cases, at least $50 \%$ of those screening positive were false positives, meaning that a more in-depth follow up assessment would be required if these tools were used as screeners in a clinical setting. Furthermore, correction would be needed if used to estimate prevalence rates for mental disorders in this population.

There was moderate convergent validity between measures of functional impairment, with self-report WHODASChild showing greater agreement with interviewer ratings when compared to parent-report measures (WHODAS and SDQ Impact). Measuring functional impairment and distress due to mental health problems should help to differentiate children with clinically significant mental health problems from those with subthreshold problems; however, more work will be required to establish how helpful the tools used here are in achieving that aim.
\end{abstract}

\section{Introduction}

This report describes an evaluation of the reliability and validity of a number of screening tools for internalizing and externalizing behaviour problems in 8-17 year old Syrian children. The tools were evaluated in children who are currently displaced due to the war in Syria and are living in Informal Tented Settlements (ITS) in Lebanon. The measures evaluated are culturally-adapted versions of the Center for Epidemiological Studies Depression Scale for Children (CES-DC; [1, 2]), Screen for Child Anxiety Related Emotional Disorders (SCARED; [3-5]), and Child PTSD Symptom Scale (CPSS; [6]). Evaluation of the published version of the Strengths and Difficulties Questionnaire (SDQ; $[7,8]$ ) is also reported. These questionnaires have been evaluated against diagnosis of common mental disorders, ascertained using a structured clinical interview (MINI KID 6.0, Arabic for Lebanon version; [9]) and clinical judgement.

Additionally, the convergent validity of measures of functional impairment in children is reported, including selfreport, parent-report, and observer-report measures. This includes an adapted version of the World Health 
Organisation Disability Assessment Schedule (WHODAS-Child; [10]), the SDQ Impact supplement [11], and rating of severity of symptoms and impairment made by assessor, the Clinical Global Impression - severity score [12]. The tools evaluated are widely used in mental health research and clinical settings. However, they have mostly been developed in Western populations and have not been extensively studied in the MENAT region or in the context of war and displacement. Differences in the experience or expression of mental health problems between different cultures may mean that the checklists of symptoms reported here do not correspond with the way that psychopathology is expressed in Syrian children. Moreover, efficacy in one population (e.g., the US or UK) does not necessarily imply efficacy in another with different level of risk (e.g., post-conflict settings), or low levels of education and literacy. Therefore evaluation in the population and context in which they are to be used is critical in establishing their likely efficacy for both clinical and research purposes, including: (i) identifying individual children in need of services, (ii) establishing the prevalence of mental health problems to facilitate service planning, and (iii) conducting research that helps develop theory and evaluate interventions.

\subsection{Previous work on adaptation and validation}

\subsubsection{CES-DC}

The CES-DC is intended to be used to screen for depression and as a measure of depressive symptoms. Initial development and validation in US samples showed good internal consistency $(\alpha=.84-.89)$, and moderate testretest reliability $(r=.51)$, though less than optimal balance between sensitivity and specificity $[1,2]$. The adult version, the CES-D, has been used in Arabic speaking young women in the United Arab Emirates [13], showing good reliability ( $\alpha=.88$, test-retest ICC $=.59$ ) and validity, discriminating between those with and without depression (cut-off of 21 : $A U C=.84$, sensitivity $=.82$, specificity=.83). The CES-DC has performed similarly in Iranian schoolchildren and adolescents [14]. It may lack specificity in US populations [2] though it has performed well in other countries such as Rwanda [15]. A higher cut-off (e.g., of 21) may be required in Arabic speaking populations as using the lower cut-off of 15 leads to higher than expected prevalence of depression (e.g., 41.9\% [16]).

\subsubsection{SCARED}

The SCARED was designed to screen children with anxiety disorders and in a US sample was shown to be reliable $(\alpha=.90-.93$; test-retest reliability, ICC $=.86$; parent-child agreement, $r=.32-.33$ ) with acceptable validity ( $A U C=.68$ .78). It was tested in Lebanon in a clinical population of children referred to a psychiatric clinic [5]. Child-report SCARED showed moderate to good reliability ( $\alpha=.65-.85$ for subscales) and agreement with parent-report ( $r=.56$ .66), but modest discrimination of children with and without anxiety disorders (cut-off $26, A \cup C=.63$, sensitivity=.66, specificity=.56).

\subsubsection{CPSS}

The CPSS was designed to measure the severity of DSM-IV PTSD symptoms and to screen for PTSD diagnosis in children exposed to trauma. It was validated in US children affected by an earthquake and showed moderate to good reliability ( $\alpha=.70-.89$; test-retest coefficient $=.63-.85$ ) and good convergent validity (correlation with Child Posttraumatic Stress Reaction Index, $r=.80$ ); however, there was no confirmation of diagnosis using clinical interview [6]. Similar psychometric properties were seen in Turkish adolescents, but again no clinical interview was used [17]. The Hebrew version of the CPSS showed similar performance in a clinical sample of Israeli children and adolescents, with modest convergent validity against the K-SADS- $R$ clinical interview $(r=.54)$ [18]. It has also been validated with a war-exposed population - child soldiers in Nepal - and showed good reliability ( $\alpha=.86$, testretest $=.85$ ) and moderate-good validity ( $\mathrm{AUC}=.77$, sen $=.68$, spec=.73, PPV=.35, NPV=.92) [19].

\subsubsection{SDQ}

The SDQ is designed as a brief screen for child psychiatric disorders. The parent-report version of the Arabic SDQ was validated in 5-12 year-old children in Yemen, including clinical and community samples [8]. This version showed good discrimination of children from clinic and community samples ( $A \cup C=.70-.84)$ and between children with emotional, conduct or hyperactivity disorders and psychiatric controls ( $A \cup C=.76-.89$ ). However, no data was presented on reliability. In a UK sample there was only moderate internal consistency for the five subscales of the parent-report version ( $\alpha=.58-.77 ; 19)$, but better performance for broader internalising and externalising subscales $(\alpha=.73-.78)$. Self-report data from Omani children demonstrated that a number of items did not load onto the expected subscales [20]. Similarly, teacher-reported SDQ data from Syrian refugee children in Lebanon 
and Iraq suggested a different factor structure than the five published subscales, and some items did not load onto any of the proposed subscales [21].

\subsubsection{WHODAS-Child}

The WHODAS-Child was designed as a measure of disability due to health problems that could be used in both clinical and epidemiological work, including measuring response to interventions. Self- and parent-report versions have been validated in Rwandan children, most of whom had been referred for psychosocial problems, showing good test-retest $(r=.83)$ and inter-rater reliability $(I C C=.88)$, but only modest agreement between parent and child report ( $r=.32$ ). It was modestly correlated with symptoms of common mental health problems ( $r=.18-.42)$ [10].

\section{Methods}

\subsection{Sample}

Data is drawn from a large, longitudinal cohort study of Syrian children living in Lebanon, Biological Pathways of Risk and Resilience in Syrian Refugee Children (BIOPATH). All children were living in Informal Tented Settlements (ITS) in West and Central Bekaa and were eligible to participate if they were: (i) aged 8-16 years at recruitment (late 2017); (ii) had left Syria because of the war in the past four years at the time of recruitment (left Syria approx. 2013-2017); (iii) the caregiver gave informed consent and the child gave assent to participate. Purposive cluster sampling was used with small to medium sized settlements in west and central Bekaa selected from UNHCR listings to represent a range of levels of vulnerability. $\mathrm{N}=88$ settlements were sampled during October 2017 - January 2018 and all eligible families in these settlements were offered inclusion $(N=2,300)$; the resulting sample size was $\mathrm{N}=1,596$ child-caregiver dyads at baseline ( $69.4 \%$ response rate). A follow up assessment was conducted 12 months later during October 2018 - January 2019; N=1006 families were interviewed (funding constraints meant that only $63 \%$ of families could be followed up).

A subsample of the BIOPATH sample also took part in a structured clinical interview through one of two related studies. The first is a pilot clinical trial (Development, Piloting and Evaluation of a Phone-Delivered Psychological Intervention [t-CETA] for Syrian Refugee Children in Lebanon), and children were eligible if (i) they or their caregiver had indicated interest in accessing mental health services for problems that the child had, and (ii) they had evidence of common mental health problems through scoring in the top $40 \%$ of the distribution of at least one of the self-report screening questionnaires (SCARED, CES-DC, or CPSS) and the top 40\% of the parent-report SDQ. During the trial, recruitment was also opened to children from the same region who had not taken part in BIOPATH. Children were excluded if they had evidence of disorders for which the intervention is not suitable (e.g., psychosis) or serious risk issues that would make inclusion inappropriate (e.g., child protection issues). A second group of children was recruited specifically for the study reported here (Validating screening questionnaires for internalising and externalising disorders against clinical interviews in 8-16 year-old Syrian refugee children [VaST]). Children were eligible if they had not participated in the t-CETA study and the sample was weighted to reflect the rest of the BIOPATH sample in terms of risk of mental health problems (based on whether or not they indicated that they child needed mental health services and their questionnaire scores). Where children were assessed as part of the VaST study and found to have clinically significant mental health problems, they were offered inclusion in the t-CETA study. In cases where they took up this offer, their data from the VaST study was used. A total of $\mathrm{N}=119$ children had both questionnaire and clinical interview data, four of whom were not BIOPATH participants. At the time the subsample was selected, this sample was representative of the BIOPATH sample in terms of age, gender, and scores on mental health screening questionnaires, though a greater proportion attended school (see Section 2.3). Figure 1 shows the relationship between the three study populations.

\subsection{Data collection}

Local Lebanese Arabic-speaking interviewers conducted all data collection, after appropriate training. Training involved all aspects of data collection, including specific training on each measurement tool and a focus on adjusting phrasing to account for differences in Arabic dialects and approaching culturally sensitive issues in an appropriate way. See associated training materials and instructions for more information. 


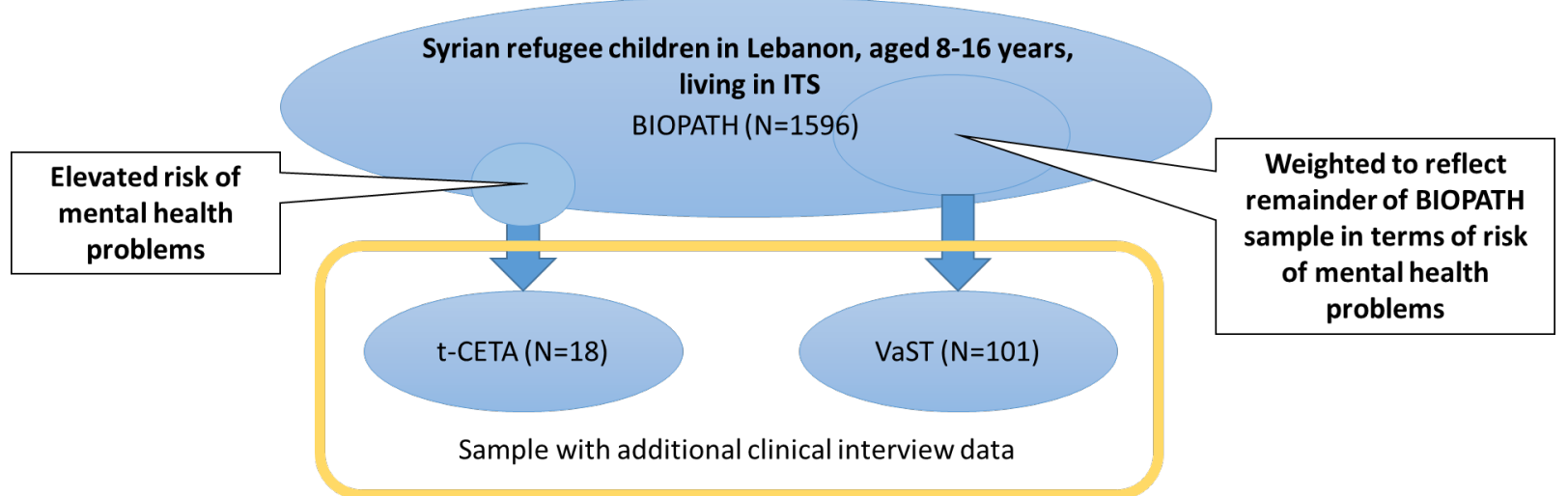

Figure 1. Relationship between BIOPATH study, t-CETA study, and VaST study.

ITS, Informal Tented Settlements. BIOPATH baseline sample ( $N=1596)$; follow up sample of $\mathrm{N}=1006$ of this cohort used for main analyses of reliability; combined t-CETA and VaST samples used for analyses of validity. $\mathrm{N}=4$ children in the $\mathrm{t}$-CETA sample were recruited from outside the BIOPATH cohort.

Questionnaire data was collected in interview format either in person in the settlements (BIOPATH and VaST) or via phone interview (t-CETA). One child from each participating family and their main caregiver were interviewed, either by different interviewers (BIOPATH) or by the same interviewer (t-CETA and VaST). Steps were taken to ensure privacy where possible: by asking other family members to leave the shelter or move to another room, by interviewing the child and caregiver simultaneously in different rooms (if more than one was available) or at opposite ends of the room (if only one room was available), talking in a quiet voice, and using visual aids that allowed the participant to point to an answer rather than verbalise it if they chose to do so. For phone interviews, the interviewer went through a checklist to establish if the participant was in a safe and quiet place and caregivers were asked to help ensure that the child had privacy when completing the call. Despite these steps, it is possible that perceived lack of privacy may have impacted data collection and this is discussed further below (see Section 4).

The clinical interview (MINI KID) was conducted either in a clinic (t-CETA) or in settlements (t-CETA and VaST; in the t-CETA study, families were given the choice of attending the clinic or being visited at home). For children aged 12 or under, the interview was generally conducted with the child and caregiver together. The interview was primarily completed with the child, but the caregiver was asked to provide information in areas where it was likely that the child's reporting was incomplete (e.g., conduct problems). In children older than 12 , the interview was generally completed with the child alone, with subsequent follow up with the caregiver as above. In all cases, decisions about whether to interview the child alone or with the caregiver was made jointly with the family to ensure that they were comfortable with the arrangement.

Demographic data was collected during BIOPATH, at both baseline and follow up, and was checked in families who also participated in t-CETA or VaST. Financial compensation was provided for families who participated in BIOPATH and VaST (for BIOPATH, \$15 per family [the study involved interviews and collection of biological samples]; for VaST, LBP10,000 per family, approx. $\$ 6.60$ at the time of the study). Participants in the t-CETA study were offered mental health services free of charge and reimbursement of travel expenses if required.

All data was entered directly into two online platforms, either via tablet device running offline apps or using the online version on a laptop computer. REDCap is a secure system designed for clinical trials and was used to enter all identifying data. Qualtrics is a secure online platform designed for surveys and was used to enter all questionnaire and interview data (data was pseudonymous, participants were identified using an internal study code ID). Data was uploaded to the servers daily, and was regularly exported and processed by the team based at Queen Mary University of London (QMUL), who conducted quality control checks. Issues with data entry were thus quickly identified and the Field Work Coordinator in Lebanon was notified so that problems could be addressed.

\subsection{Demographics}

Demographic data for the baseline and follow up BIOPATH samples (Waves 1 and 2) and the subsample from $t$ - 
CETA/VaST with clinical interview data is shown in Table 1. Those with clinical interview data did not differ from those without on age and gender, though a greater proportion attended school. Based on BIOPATH Wave 2 data (the subsample invited for clinical interview were selected from those who completed Wave 2), those with clinical interview data did not differ from those without on the SCARED $(t(d f)=0.58(1004), p=.560)$, the CES-DC $(t(d f)=1.90(152.8), p=.059)$, the CPSS $(t(d f)=0.77(1003), p=.444)$, SDQ total difficulties $(t(d f)=-0.14(994), p=.892)$, or the SDQ Impact score $(t(d f)=0.06(120), p=.951)$. Those with clinical interview data had significantly lower scores for the WHODAS self-report $(t(d f)=3.39(170.7), p=.001)$, and WHODAS parent-report $(t(d f)=3.32(163.8), p=.001)$, albeit of small effect size ( $d=.27$ and .26 , respectively). Despite the fact that the subsample who completed clinical interviews was broadly representative of the BIOPATH Wave 2 sample at the time at the time of BIOPATH data collection, at the time of data collection to complete clinical interviews and questionnaires for validity analysis (210 months later) there was evidence of an increased level of symptoms of mental health problems compared to mean scores during BIOPATH data collection. Scores for CES-DC $(t(d f)=5.91(119), p<.001)$, CPSS $(t(d f)=6.42(118)$, $p<.001)$, SDQ total difficulties $(t(d f)=4.42(119), p<.001)$, WHODAS self-report $(t(d f)=5.53(119), p<.001)$, and WHODAS parent-report $(t(d f)=7.58(118), p<.001)$ were all higher with medium effect sizes $(d=0.40-0.69)$. Scores for SCARED ( $(\mathrm{df})=0.13(118), p=.894)$ and SDQ Impact $(\mathrm{t}(\mathrm{df})=1.26(42), p=.216)$ did not differ. The possible reasons for this increase, as well as implications for evaluating the measurement tools, are considered in the Discussion.

\subsection{Measures}

\subsubsection{Screen for Child Anxiety Related Emotional Disorders (SCARED; child self-report)}

This is a child self-report (or parent-report) instrument used to screen for childhood anxiety disorders including general anxiety disorder, separation anxiety disorder, panic disorder, social phobia, and school phobia [3-5]. The original version consists of 41 items and 5 factors that parallel the DSM-IV classification of anxiety disorders. We shortened the scale to 15 items, using qualitative feedback and factor analysis of pilot data from Syrian refugee children in Lebanon to make decisions about items to remove. We removed items that were not understood by the majority of children. Items relating to school anxiety were also removed, because a significant proportion of children in the target population do not attend school. We retained items across the following scales: panic disorder, generalised anxiety disorder, separation anxiety, and social anxiety that both loaded onto specific factors but also onto one general anxiety factor. Following use of the 15-item version for Wave 1 of the BIOPATH study, and due to concerns that many items were endorsed at very high frequency, we added three items back in to make an 18-item scale. Items are scored from 0 (Not true or hardly ever true) to 2 (Very true or often true), resulting in total scores from 0-36 for the 18-item version included in this report.

\subsubsection{Center for Epidemiological Studies Depression Scale for Children (CES-DC; child self-report)}

This is a 20-item questionnaire that assesses the frequency and duration of the symptoms associated with depression in children and adolescents [1,2]. The measure was reduced to 10 items following pilot testing in Syrian refugee children in Lebanon. Factor analysis and qualitative feedback was used to choose items that were understandable to Syrian children and that loaded most strongly onto one factor. Based on qualitative feedback, items where children commonly asked for examples were modified to provide standardised examples. For example, It was hard to get started doing things, was modified to It was hard to get started doing things (e.g., homework, playing, watching TV, doing chores). Items are scored from 0 (Not at all or only at one time) to 3 (Almost always), resulting in a total ranging from 0-30 for the 10-item version.

\subsubsection{Child PTSD Symptom Scale (CPSS; child self-report)}

The CPSS is a self-report questionnaire designed to assess the severity of DSM-IV PTSD symptoms in children aged 8-18 [6]. There are 17 items that measure the presence of symptoms, each of which is rated on a scale from 0 (Not at all or only at one time) to 3 (5 or more times a week/almost always), resulting in a total ranging from 0-51. The authors recommended a clinical cutoff score of greater or equal to 11 on the basis of inspecting the distribution of total scale scores for children with high and low PTSD symptoms, which yielded $95 \%$ sensitivity and $96 \%$ specificity [6]. However, a cut-off of 20 was established in a study of child soldiers in Nepal, suggesting that a higher cut-off may be approriate in war-exposed populations [19]. Some items were modified to be appropriate to the context, for example the symptom Having trouble falling or staying asleep was supplemented with excluding times when you were disturbed by other people or noise. The instructions were also supplemented to ensure that children were referring to an event that was very scary, dangerous, or violent and that still bothers 


\begin{tabular}{|c|c|c|c|c|c|}
\hline & & $\begin{array}{l}\text { BIOPATH } \\
\text { Wave } 1 \\
(\mathrm{~N}=1596)\end{array}$ & $\begin{array}{l}\text { BIOPATH } \\
\text { Wave } 2 \\
(\mathrm{~N}=1006)\end{array}$ & $\begin{array}{l}\text { t-CETA/VaST } \\
\text { subsample } \\
(\mathrm{N}=120)^{\mathrm{A}}\end{array}$ & $\begin{array}{l}\text { Comparison of } \\
\text { subsample with } \\
\text { BIOPATH }\end{array}$ \\
\hline Child gender & $\%$ female & $52.8 \%$ & $53.5 \%$ & $45.0 \%$ & $\chi^{2}(1)=2.96, p=.086$ \\
\hline \multicolumn{2}{|c|}{$\begin{array}{l}\text { Child age: mean (SD), } \\
\text { median [range] }\end{array}$} & $\begin{array}{c}10.99(2.29), \\
11[8-16]\end{array}$ & $\begin{array}{c}11.79(2.28), \\
12[7-17]^{\mathrm{A}}\end{array}$ & $\begin{array}{c}11.95(2.45) \\
12[8-19]^{A}\end{array}$ & $t(119)=0.73, p=.466$ \\
\hline Attends school & $\%$ yes & $43.6 \%$ & $37.1 \%$ & $57.1 \%$ & $\chi^{2}(1)=20.58, p<.001$ \\
\hline Caregiver gender & $\%$ female & $94.1 \%$ & $96.3 \%$ & $/^{\mathrm{B}}$ & \\
\hline \multirow{7}{*}{$\begin{array}{l}\text { Caregiver } \\
\text { relationship to } \\
\text { child, } \mathbf{N}(\%)\end{array}$} & Mother & 1405 (88.4\%) & 912 (91.7\%) & \multirow[t]{7}{*}{$/^{\mathrm{B}}$} & \\
\hline & Father & $83(5.2 \%)$ & $24(2.4 \%)$ & & \\
\hline & Stepmother & $24(1.5 \%)$ & $17(1.7 \%)$ & & \\
\hline & Aunt & $14(0.9 \%)$ & $7(0.7 \%)$ & & \\
\hline & Grandmother & 24 (1.5\%) & $13(1.3 \%)$ & & \\
\hline & Sister & $20(1.3 \%)$ & $7(0.7 \%)$ & & \\
\hline & Other & $20(1.3 \%)$ & $15(1.5 \%)$ & & \\
\hline \multirow[t]{4}{*}{ Nationality, N (\%) } & Syrian & 1568 (98.4\%) & 992 (98.6\%) & \multirow[t]{4}{*}{ NA } & \\
\hline & Lebanese & $13(0.8 \%)$ & $3(0.3 \%)$ & & \\
\hline & Palestinian & $10(0.6 \%)$ & $9(0.9 \%)$ & & \\
\hline & Other & $2(0.1 \%)$ & $2(0.2 \%)$ & & \\
\hline \multirow{3}{*}{$\begin{array}{l}\text { Child married, } \\
\mathrm{N}(\%)\end{array}$} & Yes & $15(0.9 \%)$ & $23(2.3 \%)$ & \multirow[t]{3}{*}{ NA } & \\
\hline & Engaged & $11(0.7 \%)$ & $6(0.6 \%)$ & & \\
\hline & No & 1565 (98.4\%) & 977 (97.1\%) & & \\
\hline \multirow{4}{*}{$\begin{array}{l}\text { Parents live in } \\
\text { another country, } \\
\mathbf{N}(\%)\end{array}$} & Yes & $244(15.3 \%)$ & 119 (11.9\%) & \multirow[t]{4}{*}{ NA } & \\
\hline & Mother & 45 & 23 & & \\
\hline & Father & 206 & 96 & & \\
\hline & No & 1347 (84.7\%) & 881 (88.1\%) & & \\
\hline \multirow{5}{*}{$\begin{array}{l}\text { Weekly reported } \\
\text { family income, } \\
\mathrm{N}(\%)\end{array}$} & $\$ 0-15$ & 754 (48.3\%) & 436 (45.8\%) & \multirow[t]{5}{*}{ NA } & \\
\hline & $\$ 16-30$ & $432(27.7 \%)$ & $255(26.8 \%)$ & & \\
\hline & $\$ 31-50$ & 240 (15.4\%) & 165 (17.3\%) & & \\
\hline & $\$ 51-100$ & 97 (6.2\%) & 59 (6.2\%) & & \\
\hline & $>\$ 100$ & $38(2.4 \%)$ & $37(3.9 \%)$ & & \\
\hline \multirow{5}{*}{$\begin{array}{l}\text { Caregiver literacy, } \\
\text { N (\%) }\end{array}$} & Not at all & $326(20.5 \%)$ & $206(20.7 \%)$ & \multirow[t]{5}{*}{ NA } & \\
\hline & A little & 577 (36.3\%) & 322 (32.3\%) & & \\
\hline & More or less & 341 (21.5\%) & $212(21.3 \%)$ & & \\
\hline & Mostly & 226 (14.2\%) & $128(12.9 \%)$ & & \\
\hline & Fully literate & $118(7.4 \%)$ & 128 (12.9\%) & & \\
\hline \multicolumn{2}{|c|}{$\begin{array}{l}\text { Caregiver currently employed, } \\
\mathrm{N}(\%)\end{array}$} & $206(13.0 \%)$ & 175 (17.6\%) & NA & \\
\hline \multicolumn{2}{|c|}{ Child in school, $\mathbf{N}(\%)$} & 696 (43.5\%) & 374 (37.2\%) & NA & \\
\hline
\end{tabular}

Table 1. Demographic data for participants in BIOPATH sample and t-CETA/VaST subsample with clinical interview data. ${ }^{A}$ During Wave 2 some discrepancies in reported age between Waves 1 and 2 were discovered, including 3 children who are aged 18-19; these are being investigated and resolved; ${ }^{B}$ Where data were available, the caregiver was the same as in BIOPATH in $97 \%$ of cases; NA Not asked, questions were not repeated during VaST or t-CETA studies.

them today, and a description of events and their timing (before the war, during the war, since leaving Syria) were recorded. There are also 7 items that measure functional impairment, that were not used in this study. 


\subsubsection{Strengths and Difficulties Questionnaire + Impact Supplement (SDQ; parent-report)}

The SDQ is a brief behavioural screening questionnaire about 3-16 year olds [7]. It includes 25 items on psychological attributes, some positive and others negative. These 25 items are divided between 5 scales: (1) emotional symptoms; (2) conduct problems; (3) hyperactivity/inattention; 4) peer relationship problems; 5) prosocial behaviour. Parent-report, self-report and teacher-report versions are available; only parent-report was used for this study. In low-risk or general population samples, it may be better to use an alternative threesubscale division of the SDQ into 'internalising problems' (emotional + peer symptoms, 10 items), 'externalising problems' (conduct + hyperactivity symptoms, 10 items) and the prosocial scale (5 items) [22]. An Impact Supplement is also available, which asks whether the respondent thinks the young person has a problem, and if so, enquires further about chronicity, distress, social impairment, and burden to others [11]. No modifications were made to the SDQ (modifications are not permitted). Some items are culturally sensitive (e.g., stealing) and were reported to be offensive by some respondants; interviewers clarified that these are standard items asked to all families to reduce the risk of causing offence.

\subsubsection{World Health Organization Disability Assessment Schedule for Children (WHODAS-Child; self- and} parent-report)

The WHODAS-Child is a 36-item instrument designed to measure disability or functional impairment and that has been adapted for low resource settings [10]. It is based on the WHO's International Classification of Functioning, Disability and Health for children and youth and covers six domains: understanding and communicating, getting around (mobility), self-care (personal hygiene and safety), getting along with people, life activities (ability to carry out responsibilities at home, work and school), and participation in society (engagement in community, civil and recreational activities). A 24-item version including the scales Getting along with people, Life activities, and Participation in society, as well as items about overall health and the number of days when usual activities were impaired, was used in this study [23]. Each subscale score is calculated as a percentage of the maximum possible score, and then a global disability score is created by averaging all subscales (range 0-100).

\subsection{Translation and refinement}

Where an Arabic translation was not available, questionnaires (other than the WHODAS; see below) were translated using a standard protocol (see Appendix 1). Two local clinical psychology students independently completed forward translation from English to Modern Standard Arabic (MSA). The two versions were synthesized into one version, which was then back translated from Arabic to English by two different students. This back translated version was compared to the original version to check for discrepancies and refine the Arabic translation. The translated version was then reviewed independently by three local experts with knowledge of the target community and the constructs measured in the questionnaires (e.g., clinical psychologists working with Syrian refugees). Where necessary, the MSA version was supplemented with alternative dialect words to improve comprehensibility.

Following translation, the questionnaires were piloted during Focus Group Discussions (FGD) with Syrian children and caregivers, and then during a series of pilot studies (sample size $\mathrm{N}=30-100$ for each questionnaire). This was used to further refine questions (by adjusting language or providing examples) and to guide modifications to the scales (deciding which items to remove when abridging scales).

The WHODAS was introduced later in the project and was forward translated by a professional translator, back translated by two local clinical psychology students, and then reviewed by three local clinical staff. Interviewers reported any difficulties during its administration and this feedback was used to refine the language (e.g., adding appropriate dialect words) where necessary.

\subsection{Visual aids}

Visual aids were available for all questionnaires, which participants could choose to use. During piloting it was clear that some participants found the Likert scale response format difficult, spontaneously answering using a dichotomous format (yes/no). A range of different visual aids were developed and piloted, and a version portraying water glasses was selected. See Figure 2 for an example.

The versions used to support phone interviews in the t-CETA study were presented in a laminated booklet that the family kept at home. To support participants with lower literacy, pages were identified using colour and 
pattern, as well as page numbers; response options were additionally identified using small line drawings of common objects (e.g., tree, car) printed directly under the response option. This approach was piloted and was found to be easy to use, effective, and there was no evidence of any biases in response (e.g., based on children's favourite objects).

\section{Child: Anxiety}

I'm going to read you a list of sentences that describe how people feel. Listen to each phrase and decide if it is "Not True or Hardly Ever True" or "Somewhat True or Sometimes True" or "Very True or Often True" for you. Then, for each sentence, tell me which response seems to describe you for the last month.

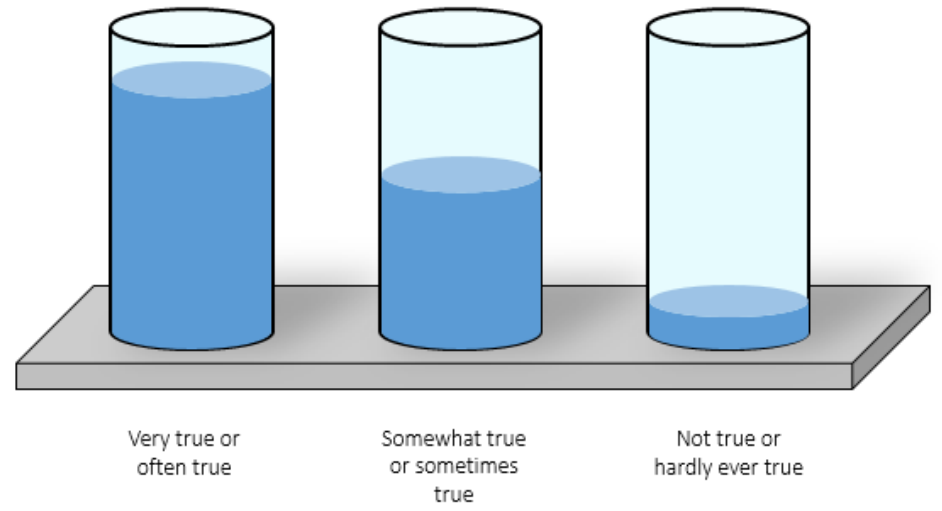

\section{Figure 2. Visual aid for use with the SCARED}

The versions used in the study were in Arabic, with glass order moving from right to left with the response options.

\subsection{Measure to assess validity}

The MINI International Neuropsychiatric Interview for Children and Adolescents (MINI KID), version 6 (DSM-IV version; [24]), was used to gather information about symptoms of mental disorders. Additional information was gathered in order to gain sufficient information to assign DSM-5 diagnoses. The context of families living in informal tented settlements and culture of the participants needed to be taken into account by, for example, rephrasing questions about behaviour in school to ask about behaviour in community settings (because less than half the BIOPATH cohort attended school), being aware of culturally sensitive issues, and asking parents for follow up information about sensitive issues (including potentially traumatic events) that the child might not want to disclose due to perceived lack of privacy [25]. A Clinical Global Impression - severity (CGI-s) score [12] was also assigned to capture severity of presentation, including functional impairment and distress experienced by the child. Ratings ranged from 1-7 and the process of assigning a score was operationalised to assist clinical judgement (see Appendix 2 for details). All cases were discussed with an experienced clinical psychologist before final diagnosis and CGI-s score were agreed: final consensus diagnosis thus relied on clinical judgement as well as the MINI KID. Again, the culture and context was taken into account by attempting to establish to what extent difficulties were more severe and causing greater impairment and/or distress than seen in other children in the same community. For example, children with a presentation involving frequent praying for the safety of their family and repeatedly checking if doors were locked were only considered for a diagnosis of Obsessive Compulsive Disorder (OCD) if it was significantly more pronounced than similar behaviour in other children, and clearly causing impairment and/or distress. Criteria for being a 'case' were (i) definite diagnosis of a mental disorder assigned based on information from the MINI KID and clinical judgement, and (ii) CGI-s score $\geq 4$, indicating moderate to severe functional impairment and/or distress. Children with evidence of symptoms but not meeting criteria for a mental disorder, for example with CGI-s score $<4$, were classified as having subclinical difficulties.

In 10 cases a second rater observed and independently coded the interview and assigned a CGI-s score to check reliability. Interrater reliability was good to excellent for most ratings including the CGIs score (intraclass correlation [single measures] $=.78, p=.002$ ) and diagnostic judgements (kappa=.47-1.00, all $p<.035$; where it was not possible to calculate kappa because there was no variance for one rater [they had rated all cases as $0=$ unaffected], there was perfect agreement with the other rater in $90 \%$ of cases [i.e., the second rater had rated 
$90 \%$ as $0=$ unaffected]). Agreement for conduct disorder / oppositional defiant disorder (CD/ODD) was poorer ( $k a p p a=.41, p=.084$ ); this reflected a need to adjust for the context, where fighting between children and other low-level conduct issues were relatively common, and this was a particular focus during consensus discussions. All discrepancies in administration or coding that were highlighted during double coding were further discussed in joint supervision sessions to improve consistency in administration and coding.

The MINI KID was either completed on the same day as the questionnaires ( $N=101$ cases) or on different days ( $\mathrm{N}=18$; median gap=19.5 days, interquartile range=21.5 days). Cases in which the gap between MINI KID and questionnaires was greater than 2 months were excluded from analysis.

\subsection{Data analysis}

\subsubsection{Calculating scales}

There was little missing data: $>97 \%$ of cases in BIOPATH and $>93 \%$ of the subsample with clinical interview data had complete data for each scale and where data were missing, this was typically only 1-2 items. This small amount of missing data was mostly not associated with age, gender, or evidence of mental disorder. The exception was the WHODAS, where children who were not in school were missing data on the subscale relating to school. The WHODAS is calculated as a percentage score using the subscales available, so the total score was calculated minus the school subscale in children who did not attend school. See Appendix 3 for details on missing data.

All scales and subscales were calculated by multiplying the mean item score by the maximum possible number of items in the scale, providing at least $90 \%$ of items were available. This thus corrected for missing data by replacing missing items with the mean item score. If greater than $10 \%$ of items were missing, the scale total was also missing.

\subsubsection{Reliability}

Internal consistency for each scale and subscale was examined using Cronbach's alpha. Exploratory factor analysis was also conducted on each scale to establish whether the factor structure fitted the proposed subscales. Wave 2 BIOPATH data $(\mathrm{N}=1006)$ was used for these analyses.

\subsubsection{Validity}

Each psychopathology questionnaire is designed to measure symptoms of mental disorders, and to identify likely clinical cases by the application of a cut-off score. The efficacy of each scale in identifying clinical cases was explored by comparing each questionnaire to cases of the relevant disorder in the subsample with clinical interview data $(\mathrm{N}=119)$. For example, the SCARED was compared to current diagnosis of any anxiety disorder and the CES-DC to current diagnosis of major depressive disorder/episode. Receiver Operating Characteristics (ROC) Curve analysis was used to summarise the overall diagnostic accuracy of each questionnaire in correctly classifying cases and non-cases (using the Area Under the Curve; AUC). An AUC of 0.5 suggests no discrimination, 0.7-0.8 is considered acceptable, 0.8-0.9 is considered excellent, and $>0.9$ is considered outstanding [26]. The ROC curve was used to select a cut-off that would achieve an optimal balance between sensitivity and specificity (with priority given to sensitivity when a balance was difficult to achieve). Sensitivity (the proportion of true cases correctly identified), specificity (the proportion of non-cases correctly identified), Positive Predictive Value (PPV; the proportion of individuals above cut-off that are true cases), and Negative Predictive Value (NPV; the proportion of individuals below cut-off that are true non-cases) were calculated using previously established cutoffs and/or new cut-offs established for this population [27]. Values range from 0-1.0 (or are expressed as a percentage), with higher values indicating better performance. Sensitivity and specificity are in balance, such that increasing sensitivity for a scale results in decreasing specificity. The values that are considered to be acceptable depend on the purpose that the scale is to be used for (i.e., is it more important to prioritise sensitivity or specificity), so there are no published standard criteria as to 'good' sensitivity or specificity. The values for sensitivity, specificity, PPV and NPV should be considered together when making decisions about whether to use a scale for a particular purpose and interpreting results [28].

Construct validity was examined for the WHODAS-Child by examining patterns of convergent and discriminant validity using self- and parent-report versions, both in the BIOPATH sample $(\mathrm{N}=1006)$ and the subsample $(\mathrm{N}=119)$ ( $N$ varies slightly by analysis, see Appendix 4, Tables A4.7 and A4.8). Convergent validity for measures of 
functional impairment was examined using correlational analysis between different measurement tools (WHODAS, SDQ Impact, and CGI-s score), and between different raters (WHODAS-Child self-report and parentreport), in the BIOPATH sample and the subsample ( $\mathrm{N}$ varies by measure, see Table 6 ). The ability of the WHODAS and the screening question of the SDQ Impact supplement to predict any mental disorder or more severe disorder was also explored, using ROC Curve analysis as described above. Further analysis was conducted to examine the effect of the skip rule in the SDQ Impact supplement by comparing children whose caregiver answered Yes or No to the screening question at the start of the SDQ Impact supplement on (i) WHODAS and CGIs scores, and (ii) diagnosis of any disorder.

\section{Results}

\subsection{Psychopathology screening tools}

\subsubsection{CES-DC}

Exploratory factor analysis: Exploratory factor analysis resulted in one factor being extracted, with item factor loadings all >.6 (see Appendix 4, p1). This may be an artefact of the way the scale was shortened, as items that loaded most strongly onto one factor were selected for inclusion in the brief version. However, the brief scale contains items from all three factors identified by the original study in a US sample [1] and the amount of variance explained by the one factor in our study $(51 \%)$ is similar to that explained by the three factors in the original study (44\%).

Reliability: The 10-item version showed good internal consistency: Cronbach's $\alpha=.89$.

Distribution: The distribution was positively skewed (see Appendix 4, Figures A4.2-3), as expected for a measure of psychopathology, and all items showed a similar distribution.
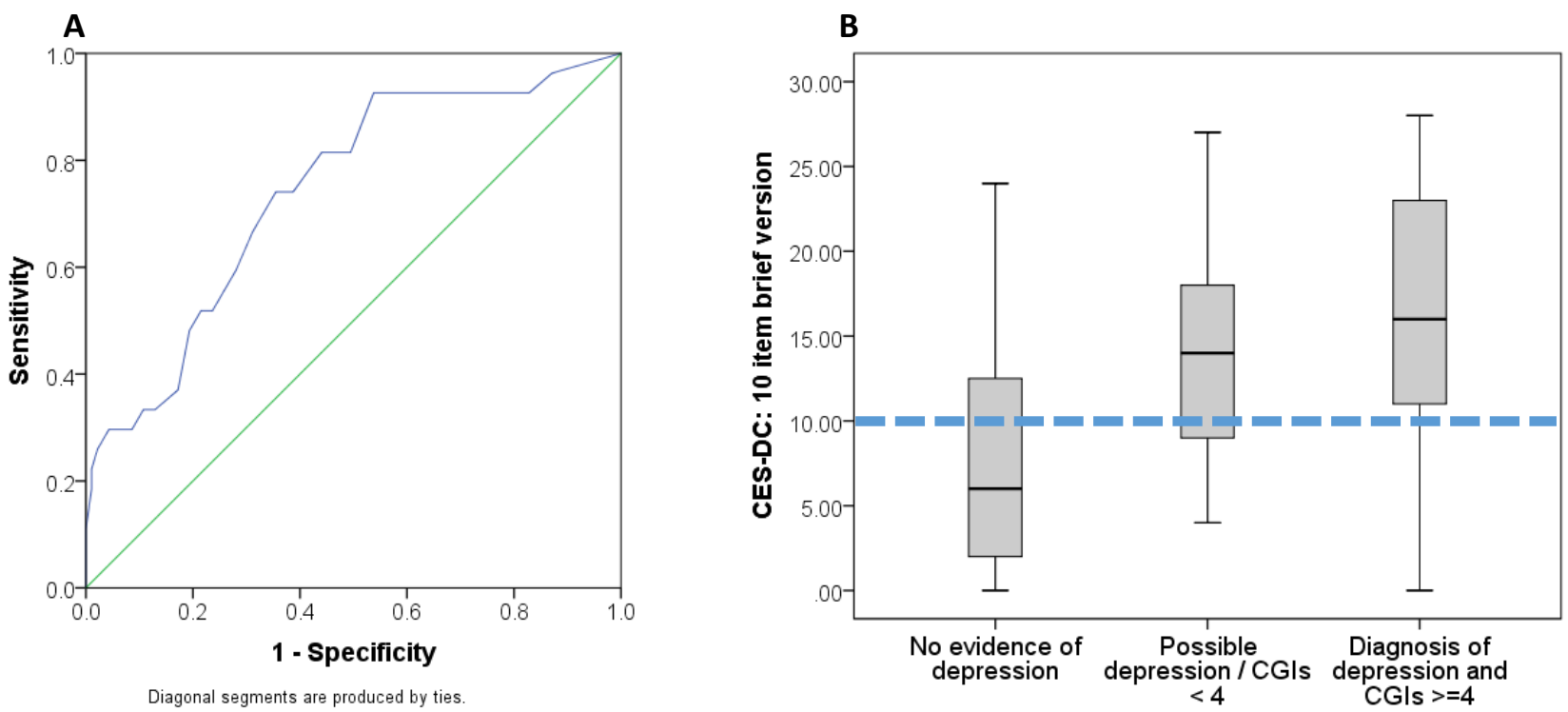

Figure 7. CES-DC (10 item) predicting major depressive disorder/episode

(A) ROC curve analysis, AUC=.74, $p<.001$. (B) Distribution of CES-DC scores in non-cases (left), subthreshold cases (depressive symptoms but little impairment or distress; middle), and cases with diagnosis of depression and moderate to severe impairment/distress (right); blue dashed line represents cut-off of 10, estimated to be optimal based on ROC curve.

Validity: ROC curve analysis showed that the Area Under the Curve was acceptable (AUC=.74, $p<.001$; Figure 7, panel A). The distribution of CES-DC scores is shown in Figure 7, panel B, for cases, non-cases, and subthreshold cases. For ROC curve analysis, only those children with a definite diagnosis of current major depressive disorder or major depressive episode and moderate to severe impairment or distress (CGI-s score $\geq 4$ ) were counted as cases (shown in right hand boxplot in Figure 7, panel B). A cut-off of 10 or above on the 10-item scale was selected based on the ROC curve. Sensitivity was good with $81 \%$ of cases being identified, but specificity was lower (56\%) with around half of non-cases being misclassified. This is due to the majority of subthreshold cases scoring greater than 10 , suggesting that the CES-DC does not differentiate well between children with major 
depressive disorder / episode and those with some evidence of depressive symptoms but little impairment or distress. PPV was low with only $35 \%$ of children who screened positive being true cases. NPV was better: $91 \%$ of children who scored under 10 were true non-cases. Overall, $61.7 \%$ of cases were correctly classified using this cutoff.

\subsubsection{SCARED}

Exploratory factor analysis: Four factors were extracted, which explained $53.5 \%$ of the variance and partially replicated the subscale structure (see Appendix 4, p3). The Panic disorder and Generalised anxiety disorder (GAD) subscales were replicated, other than the two items that were phrased 'People tell me that...' which loaded on their own factor, suggesting that this may be driven by question style. Interviewers reported that these questions were difficult for some children, perhaps because others did not comment on the child's symptoms to them. All but one of the Separation anxiety and Social anxiety items loaded on one factor, though the Separation anxiety items cross-loaded on the Panic disorder factor. Forcing all items onto one factor resulted in factor loadings $>.4$ for all items, other than 'I follow my mother or father wherever they go'.

Reliability: The 18-item version of the SCARED showed good internal consistency: Cronbach's $\alpha=.84$. Internal consistency for subscales was more variable, ranging from $\alpha=.52-.78$ (see Table 2). Internal consistency was repeated using empirically derived scales: the item 'I follow my mother or father wherever they go' was removed from the total score; the items phrased 'People tell me that...' were removed from Panic disorder and GAD subscales; the remaining Separation and Social anxiety items were analysed together. While this improved internal consistency for Separation and Social anxiety, change to the total scale was negligible. Further analyses use the 18-item scale with no further modification.

Distribution: The distribution of total SCARED score for the 18-item version was approximately normal (see Appendix 4, Figure A4.4). Typically, measures of psychopathology show a positive skew: the majority of children have low scores and relatively few children have high scores. The Panic disorder and GAD subscales were positively skewed, while Separation anxiety was normally distributed and Social anxiety was negatively skewed (see Appendix 4, Figure A4.4). Examination of the distribution of individual items showed that several of the items that contribute to the latter scales were endorsed at very high frequency, with the majority of children responding Very true or often true (e.g., I get scared if I sleep away from home [Separation anxiety], I feel shy with people I don't know well [Social anxiety]).

\begin{tabular}{|l|c|c|c|c|}
\hline \multirow{2}{*}{ Scale } & \multicolumn{2}{|c|}{$\begin{array}{c}\text { Using items / subscales as defined in } \\
\text { original measure }\end{array}$} & \multicolumn{2}{|c|}{$\begin{array}{c}\text { Using items as defined in empirically } \\
\text { derived scales }\end{array}$} \\
\cline { 2 - 5 } & N items & Cronbach's alpha & N items & Cronbach's alpha \\
\hline Anxiety total & 18 & .84 & 17 & .85 \\
\hline Panic disorder & 6 & .78 & 5 & .80 \\
\hline $\begin{array}{l}\text { Generalised anxiety } \\
\text { disorder }\end{array}$ & 6 & .73 & 5 & .72 \\
\hline $\begin{array}{l}\text { Separation anxiety } \\
\text { disorder }\end{array}$ & 3 & .52 & 5 & .71 \\
\hline Social anxiety disorder & 3 & .69 & & \\
\hline
\end{tabular}

Table 2. Internal consistency for SCARED scale and subscales

Validity: ROC curve analysis showed that the AUC fell just short of acceptable criteria ( $A \cup C=.69, p<.001$; Figure 5 , panel A). The distribution of SCARED scores is shown in Figure 5, panel B, for cases, non-cases, and subthreshold cases. Only those children with a definite diagnosis of an anxiety disorder and moderate to severe impairment or distress (CGI-s score $\geq 4$ ) were counted as cases (shown in right hand boxplot in Figure 5, panel B). A cut-off of 12 or above on the 18 -item scale was selected based on the ROC curve. Sensitivity was good with $80 \%$ of cases being identified, but specificity was lower (53\%) with around half of non-cases being misclassified. This is due to a sizeable proportion of non-cases scoring greater than 12. PPV was moderate $-63 \%$ of children who screened positive were true cases - and NPV was $72 \%$, with the majority who scored under 12 being true non-cases. 
A

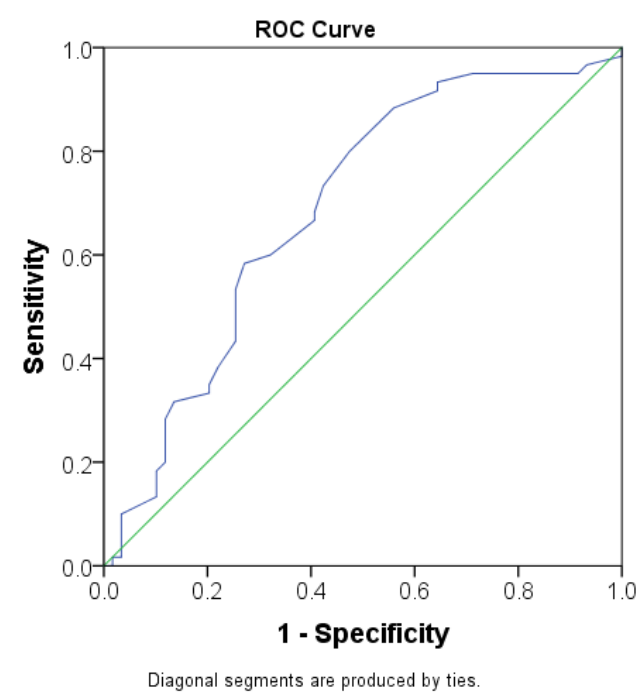

B

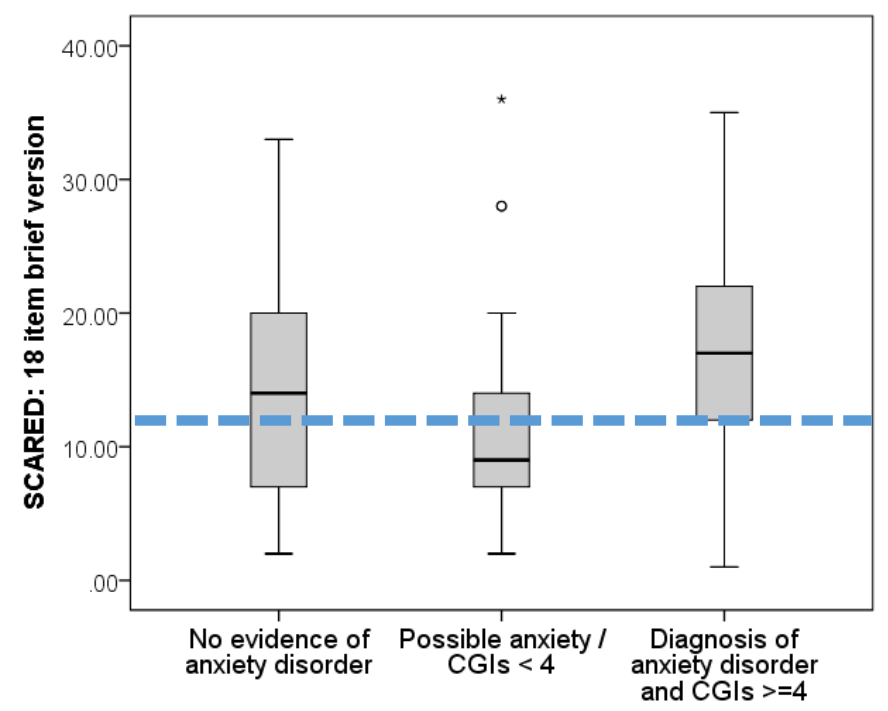

Figure 5. SCARED (18 item) predicting any anxiety disorder

(A) ROC curve analysis, AUC=.69, $\mathrm{p}<.001$. (B) Distribution of SCARED scores in non-cases (left), subthreshold cases (anxiety symptoms but little impairment or distress; middle), and cases with a diagnosis of anxiety disorder and moderate to severe impairment and/distress (right); blue dashed line represents cut-off of 12, estimated to be optimal based on ROC curve.

\subsubsection{CPSS}

Exploratory factor analysis: Two factors were extracted, which explained $59.8 \%$ of the variance, though the scree plot suggested that a one factor solution may be acceptable (see Appendix 4, p5). The first factor consisted of items broadly from the following DSM-5 criteria: Criterion B, Intrusion Symptoms; Criterion C, Avoidance; and Criterion E, Alterations in Arousal and Reactivity. This factor also maps onto the three Criteria from ICD 11: Criterion B, Re-experiencing; Criterion C, Avoidance; and Criterion D, Hyperarousal. The second factor consisted broadly of items from DSM-5 Criterion D, Negative Alterations in Cognitions and Mood. This may suggest that the 'core' PTSD items were represented by the first factor, and those that are less specific (e.g., also associated with depression) were represented by the second factor. However, the scree plots suggest that a one-factor solution is also acceptable; forcing all items onto one factor results in all items having a factor loading of at least .56.

Distribution: Just over a quarter of children (27.2\%) in the BIOPATH sample reported at least one event that still bothers them today. Just over half of reported events occurred during the war in Syria, but approximately $40 \%$ of reported events occurred after displacement in Lebanon (e.g., fires in settlements, road accidents, and interpersonal violence). During the later data collection for VaST, the number of children reporting an event had increased to $58.8 \%$. Again, over half were events that occured in Syria, and around $40 \%$ occured in Lebanon.

The total CPSS score was calculated from symptom items only and was positively skewed (see Appendix 4, Figure A4.6), as expected for a measure of psychopathology. This was true for the BIOPATH sample and the subsample with clinical interviews, although there was an upwards shift of the distribution in the subsample with an increase in mean score from 10.80 to 17.51 (data collection took place 3-10 months later); this seemed to be driven by an approximate doubling of mean scores in those who did not report an event. As predicted, the mean score was higher in those reporting an event than those who did not report an event (Appendix 4, Figure A4.6, panels B-C and E-F). In the BIOPATH sample, $7.5 \%$ of children were estimated to meet DSM-5 criteria for PTSD based on applying an algorithm to CPSS responses (this required children to have reported a potentially traumatic event [Criterion A] and endorsed the minimum number of required symptoms from Criteria B-E). This had increased to $25.4 \%$ during data collection in the subsample.

Reliability: The CPSS showed excellent internal consistency: Cronbach's $\alpha=.94$. Interviewers reported that younger children (aged approx. 8-10 years) found it hard to understand what was meant by an 'event', which made it difficult to complete the symptom checklist in some cases. 
A

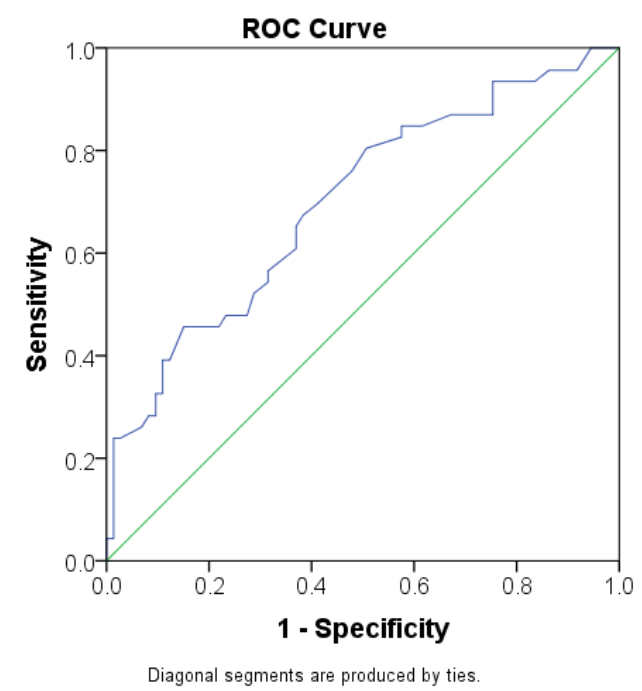

B

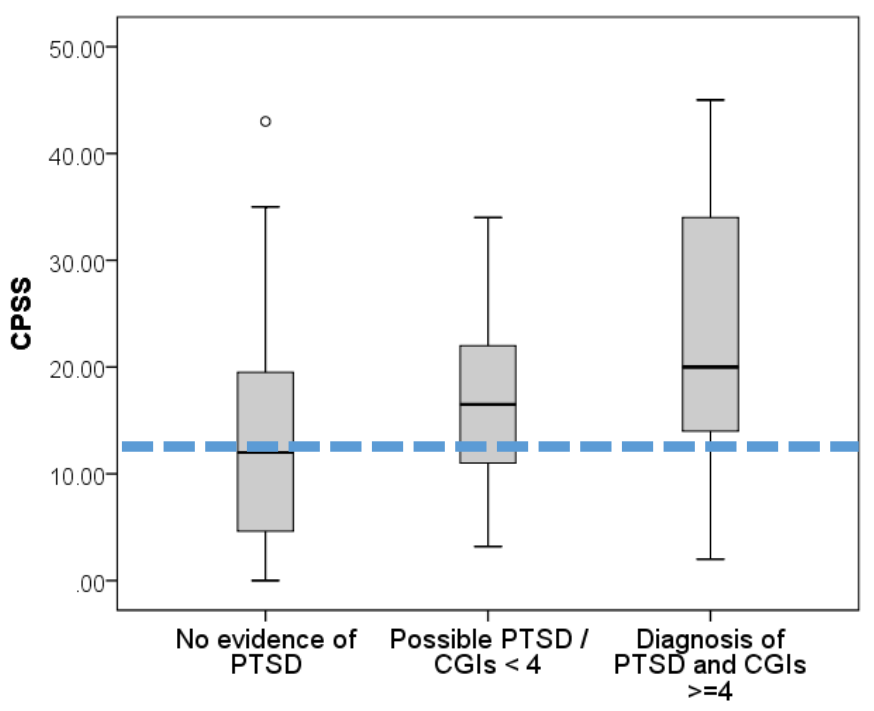

Figure 9. CPSS predicting PTSD

(A) ROC curve analysis, AUC=.70, $p<.001$. (B) Distribution of CPSS scores in non-cases (left), subthreshold cases (PTSD symptoms but little impairment or distress; middle), and cases with diagnosis of PTSD and moderate to severe impairment/distress (right); blue dashed line represents cut-off of 12, estimated to be optimal based on ROC curve.

Validity: ROC curve analysis showed that the AUC was sigificantly different from chance $(A \cup C=.70, p<.001$; Figure 9, panel A) and reached an acceptable level. The distribution of CPSS scores is shown in Figure 9, panel B, for cases, non-cases, and subthreshold cases. For ROC curve analysis, only those children with a definite diagnosis of PTSD and moderate to severe impairment or distress (CGI-s score $\geq 4$ ) were counted as cases (shown in right hand boxplot in Figure 9, panel B). A cut-off of 12 or above was selected based on the ROC curve. Sensitivity was high with $83 \%$ of cases being identified, but specificity was only $43 \%$ with many non-cases being misclassified. This is due to the majority of children with subthreshold symptoms and half of non-cases scoring greater than 12 . PPV was moderate with $48 \%$ of children who screened positive being true cases. NPV was better with $79 \%$ of children who scored under 12 being true non-cases. As an alternative to applying a cut-off to the total score, an algorithm based on DSM-5 criteria was applied to questionnaire responses (as described above). This resulted in a lower sensitivity of $33 \%$ but a much improved specificity of $88 \%$; while two thirds of cases were missed, this approach significantly reduced the risk of misclassifying non-cases. PPV was slightly improved at $62 \%$, and NPV was $69 \%$.

\subsubsection{SDQ and Impact supplement}

Exploratory factor analysis: For the 25 symptom items of the SDQ, seven factors were extracted, which explained $49.6 \%$ of the variance (see Appendix 4, p7-8). The Prosocial scale was represented by one factor and four items from the Emotional problems subscale loaded onto another factor with one item from the Peer problems scale (Rather solitary, tends to play alone). Two items from the Conduct problems scale loaded on a factor with two Hyperactivity items and one Emotional problems item. The other three items from the Conduct problems scale loaded on a factor with one Peer problems item (Picked on or bullied by other children). The three inattention items from the Hyperactivity scale loaded on a factor by themselves. The Peer problems items loaded across four separate factors. Finally, the Peer problems item Gets on better with adults than other children loaded on a factor by itself, but with some evidence of cross-loading on the Prosocial subscale. This item was negatively correlated with other items in the Peer problems scale and was endorsed at a high frequency, suggesting that it does not index social difficulties in this population. In summary, the original subscale structure was only partially reproduced, and internalising and externalising items did not clearly separate.

For the Impact supplement there was a one factor solution, explaining $54.0 \%$ of the variance and all items had a factor loading of .58 or greater (see Appendix 4, p7\&9).

Reliability: Internal consistency was acceptable for SDQ total difficulties: Cronbach's $\alpha=.76$; and for the Impact supplement: $\alpha=.78$. However, it was low for the five subscales and the internalising and externalising scales (see Table 3). 


\begin{tabular}{|l|c|c|}
\hline Scale & N items & Cronbach's alpha \\
\hline SDQ total difficulties & 20 & .76 \\
\hline SDQ emotional problems & 5 & .66 \\
\hline SDQ peer problems & 5 & .26 \\
\hline SDQ conduct problems & 5 & .48 \\
\hline SDQ hyperactivity & 5 & .46 \\
\hline SDQ prosocial & 5 & .50 \\
\hline SDQ internalising & 10 & .65 \\
\hline SDQ externalising & 10 & .64 \\
\hline SDQ Impact & 5 & .78 \\
\hline
\end{tabular}

Table 3. Internal consistency for SDQ scale and subscales

Distribution: The SDQ total difficulties scale was normally distributed, as were the internalising and externalising scales (see Appendix 4, Figure A4.9). Twelve percent of caregivers in the BIOPATH sample reported that their child had difficulties when asked the screening question for the SDQ Impact supplement, whereas in the subsample with clinical interviews, this was $35 \%$. The Impact score was normally distributed in those with a score.

A

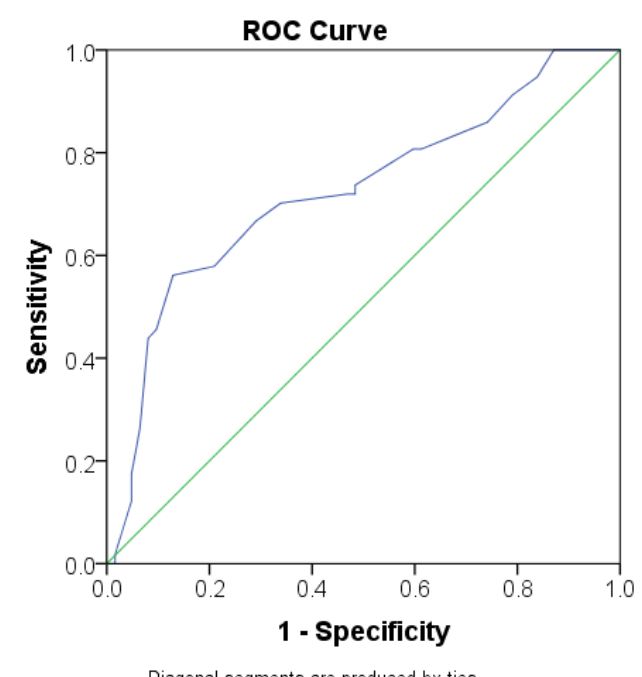

B

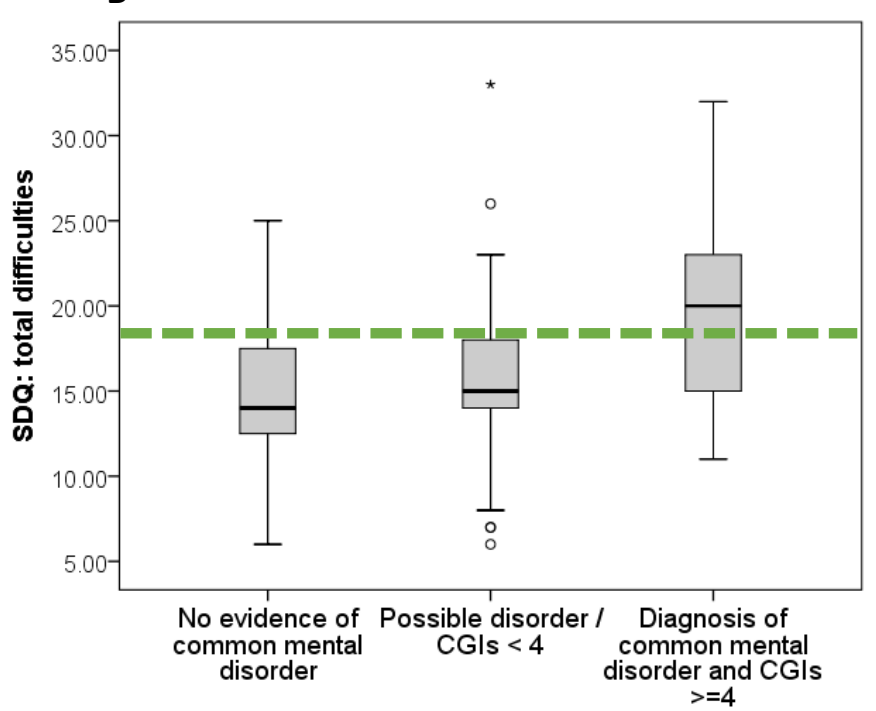

Figure 10. SDQ total difficulties predicting any common disorder

(A) ROC curve analysis, AUC=.72, $p<.001$. (B) Distribution of SDQ scores in non-cases (left), subthreshold cases (symptoms but little impairment or distress; middle), and cases with a diagnosis of any common disorder and moderate to severe impairment and/distress (right); green dashed line represents published cut-off of 17.

Validity: For SDQ total difficulties, ROC curve analysis showed that the AUC was acceptable $(A \cup C=.72, p<.001$; Figure 10, panel A). The distribution of SDQ scores is shown in Figure 10, panel B, for cases, non-cases, and subthreshold cases. Only those children with a definite or probable diagnosis of any common mental disorder (depression, anxiety, PTSD, CD/ODD) and moderate to severe impairment or distress (CGI-s score $\geq 4$ ) were counted as cases (shown in right hand boxplot in Figure 10, panel B). The published cut-off of 17 or above was used. Sensitivity was moderate with $70 \%$ of cases being identified, and specificity was also moderate with $66 \%$ of non-cases correctly classified. PPV was moderate with $66 \%$ of children who screened positive were true cases. NPV was similar at $71 \%$ showing that the majority of children who scored under 17 were true non-cases.

For SDQ internalising problems, ROC curve analysis did not reach an acceptable level (AUC=.62, $p<.001$; Figure 11, panel A). The distribution of SDQ internalising scores is shown in Figure 11, panel B, for cases, non-cases, and subthreshold cases. A cut-off of 7 or above was selected based on the ROC curve. Sensitivity was good with $80 \%$ 
of cases being identified, but specificity was very poor with only $22 \%$ of non-cases being correctly classified. The majority of both cases and non-cases scored above the cut-off (Figure 11, panel B). PPV was $48 \%$ and NPV was $56 \%$.

For SDQ externalising problems, the $A \cup C$ was excellent $(A \cup C=.82, p<.001$; Figure 12 , panel $A$ ). The distribution of SDQ externalising scores is shown in Figure 12, panel B, for cases, non-cases, and subthreshold cases. A cut-off of 9 or above was selected based on the ROC curve. Sensitivity was good with $82 \%$ of cases being identified, and specificity was also fair with $71 \%$ of non-cases correctly classified. PPV was $54 \%$ and NPV $91 \%$.

A

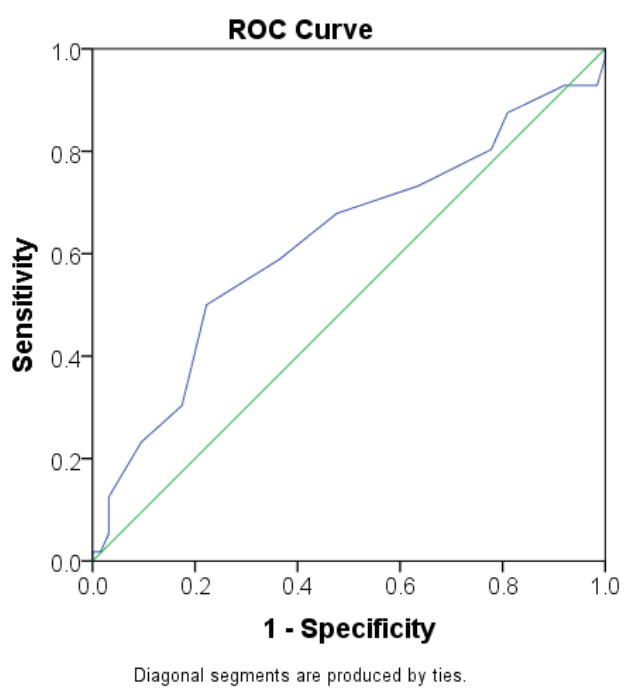

B

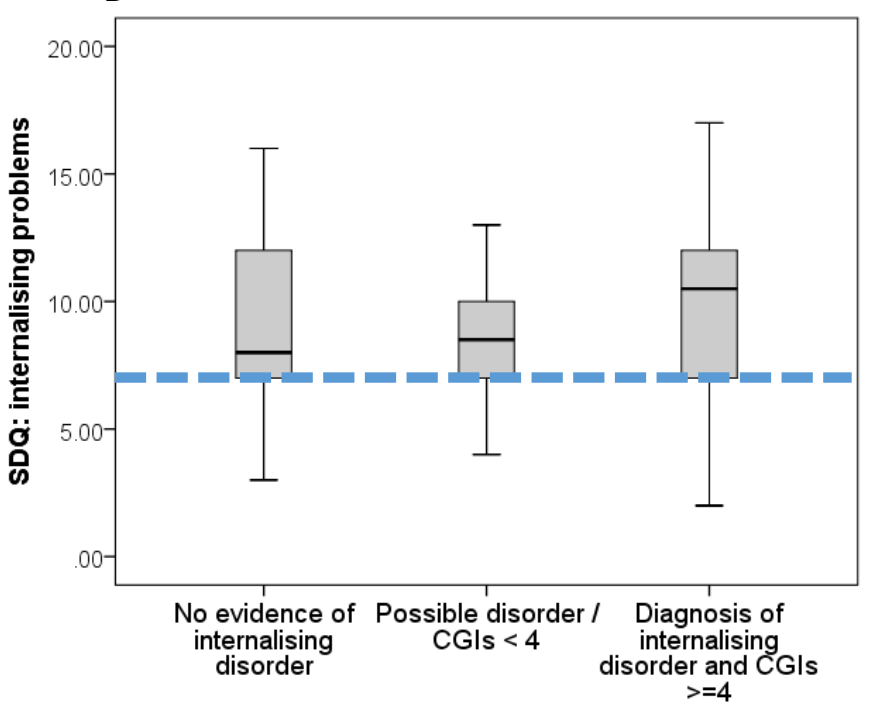

Figure 11. SDQ internalising score predicting any internalising disorder

(A) ROC curve analysis, AUC=.62, $\mathrm{p}<.001$. (B) Distribution of SDQ internalising scores in non-cases (left), subthreshold cases (symptoms but little impairment or distress; middle), and cases with a diagnosis of any internalising disorder and moderate to severe impairment and/distress (right); blue dashed line represents cut-off of 12, based on ROC curve.

A

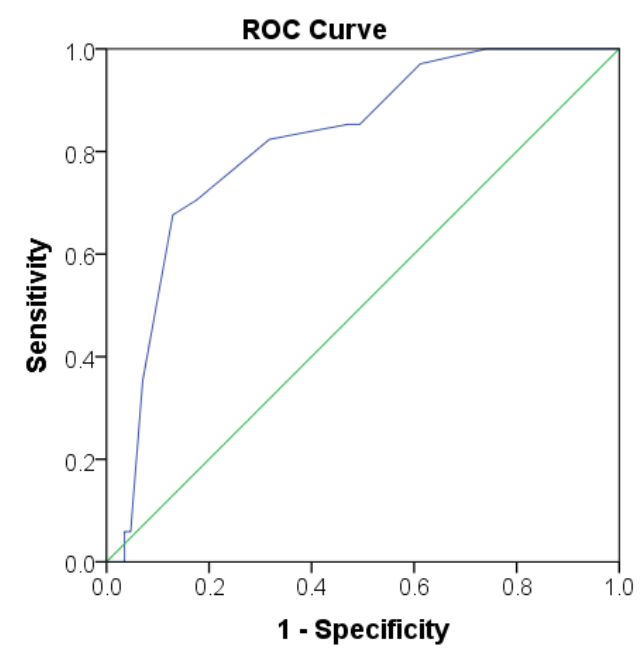

B

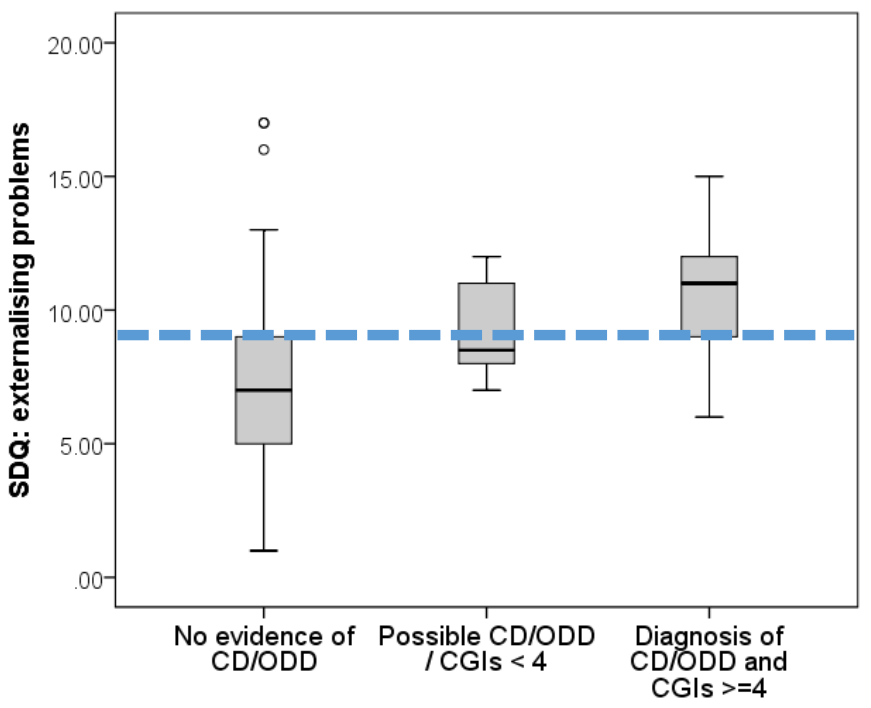

Figure 12. SDQ externalising score predicting any externalising disorder

(A) ROC curve analysis, AUC=.82, $p<.001$. (B) Distribution of SDQ externalising scores in non-cases (left), subthreshold cases (symptoms but little impairment or distress; middle), and cases with a diagnosis of any externalsing disorder and moderate to severe impairment and/distress (right); blue dashed line represents cut-off of 9, based on ROC curve.

For the SDQ Impact score, the effect of the screening question (Overall, do you think that your child has difficulties in one or more of the following areas: emotions, concentration, behaviour or being able to get on with other 
people?) was examined. Endorsement of this item by a parent was associated with significantly higher disability scores on WHODAS, both self-report $(\mathrm{t}[\mathrm{df}]=4.90[77.3], \mathrm{p}<.001, \mathrm{~d}=0.95)$ and parent-report $(\mathrm{t}[\mathrm{df}]=6.16[74.0]$, $p<.001, d=1.21$ ), as well as higher severity scores (CGls: $t[d f]=3.79[117], p<.001, d=0.70$ ). It was also tested as a predictor of any common mental disorder. Taking any endorsement of this item as an indicator of disorder, sensitivity was modest with $53 \%$ of cases being identified, and specificity was good with $76 \%$ of non-cases being correctly classified. PPV was $67 \%$ and NPV was $64 \%$. The screening question was also tested as a predictor of CGI$s \geq 4$, resulting in sensitivity of $50 \%$, specificity of $80 \%$, PPV of $78 \%$ and NPV of $53 \%$.

\subsection{Functional impairment measures}

\subsubsection{WHODAS Child}

Exploratory factor analysis: Self-report. A large amount of missing data on the five items relating to school precluded analysis and so these items were omitted from EFA. Using the remaining items, four factors were extracted, which explained $64.0 \%$ of the variance (see Appendix 4, p13-14) and broadly replicated the subscale structure. Six items, including overall health, overall impairment, and the number of days the difficulties had an impact loaded onto one factor. The five items from the scale Getting along with others loaded onto a second factor together with an item about community activities and an item on the impact on family members. The four items from the Life activities (non-school) loaded onto a third factor. Finally, there was one factor that covered the number of days absent/late for school. Parent-report. Six factors were extracted, which explained $72.3 \%$ of the variance (see Appendix 4, p13\&15) and broadly replicated the subscale structure. Four items including overall health and overall impairment loaded onto one factor. The five items from the scale Getting along with others loaded onto a second factor. The four items from the Life activities (non-school) loaded onto a third factor and the five items from Life activities (school) loaded onto a factor along with the item Difficulties joining in community activities (this item also showed some cross-loading on Getting along with others). Finally, there were two factors that covered the number of days that the child was affected by these difficulties and the number of days absent/late for school.

Distribution: A global difficulties score calculated using the available subscales (i.e., excluding Life activities (school) for those not in school) was positively skewed for both self- and parent-report versions (see Appendix 4, Figure A4.12).

Reliability: The scales showed good to excellent internal reliability: Cronbach's $\alpha>.76$ for all scales other than Participation in society, which was $\alpha=.63$. The Global disability score, which combines the scores for each of the scales, also showed good to excellent internal consistency. See Table 4.

There was only modest agreement between self-report and parent-report WHODAS-Child global disability scores in the BIOPATH sample $(r h o=.23, p<.001)$, though there was stronger agreement in the subsample ( $r h o=.58$, $\mathrm{p}<.001)$. In the former, different interviewers completed the questionnaires with the child and caregiver, whereas in the latter it was typically the same interviewer. Therefore the lower figure represents inter-rater reliability for both different interviewers and different respondents, whereas the higher figure represents different respondents only. For subscales, there was again stronger agreement between self- and parent-report in the subsample than from the BIOPATH sample (see Appendix 4, Tables A4.7 and A4.8).

Validity: Cross-subscale cross-respondent correlations were examined to test construct validity (the multitraitmultimethod approach [29]). In the subsample, there was evidence of both convergent and discriminant validity (Appendix 4, Table A4.8); the correlations between raters for the same subscale were stronger than those between raters for different scales (e.g., there was a stronger correlation between self- and parent-report for Getting along with others, than between self-report Getting along with others and parent-report on the other subscales). In the BIOPATH sample the evidence for convergent and discriminant validity was less consistent (Appendix 4, Table A4.7); this may reflect the fact that different interviewers completed the measures with child and parent in the BIOPATH sample. 


\begin{tabular}{|l|c|c|c|}
\hline Scale & N items & $\begin{array}{c}\text { Self-report version } \\
\text { Cronbach's alpha }\end{array}$ & $\begin{array}{c}\text { Parent-report version } \\
\text { Cronbach's alpha }\end{array}$ \\
\hline WHODAS global disability & 5 subscales $^{\mathrm{A}}$ & $.82^{\mathrm{B}}$ & $.76^{\mathrm{B}}$ \\
\hline WHODAS getting along with others & 5 & .76 & .81 \\
\hline WHODAS life activities (non-school) & 4 & .91 & .93 \\
\hline WHODAS life activities (school) & 5 & .88 & .94 \\
\hline WHODAS participation in society & 3 & .68 & .63 \\
\hline WHODAS overall health & 1 & $\mathrm{~N} / \mathrm{A}$ & $\mathrm{N} / \mathrm{A}$ \\
\hline WHODAS overall impairment & 1 & N/A & N/A \\
\hline
\end{tabular}

Table 4. Internal consistency for WHODAS Child self- and parent-report subscales and total score calculated from subscale scores

${ }^{A}$ Cronbach's alpha was calculated using subscale scores, to reflect the way that the global disability score is calculated from subscales; ${ }^{B}$ When restricted to those in school (with Life activities (school) subscale score), $\alpha=.83 / .76$

The efficacy of the WHODAS in predicting any common mental disorder and then CGI-s score $\geq 4$ was examined. When predicting any common disorder, the self-report version fell just short of acceptable, with $A \cup C=.67, p=.002$. The distribution of WHODAS-child global disability scores is shown in Figure 13, panel B, for cases, non-cases, and subthreshold cases. A cut-off of $\geq 17$ was selected based on the ROC curve, resulting in sensitivity of $77 \%$ and specificity of $52 \%$. PPV was $59 \%$ and NPV was $71 \%$. When predicting CGI-s score $\geq 4$, indicating more severe symptoms associated with greater levels of impairment and distress (Figure 15), AUC was acceptable (AUC=.70, p<.001), with sensitivity of $77 \%$ and specificity of $59 \%$, PPV of $73 \%$ and NPV of $64 \%$.

A

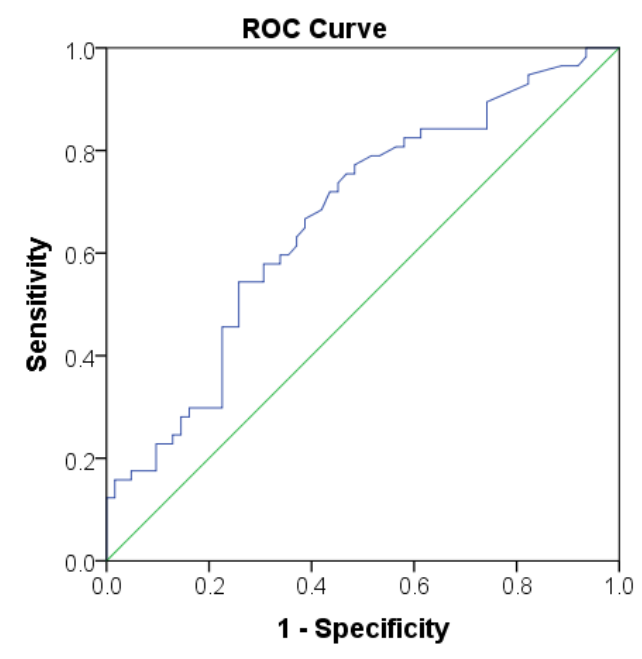

B

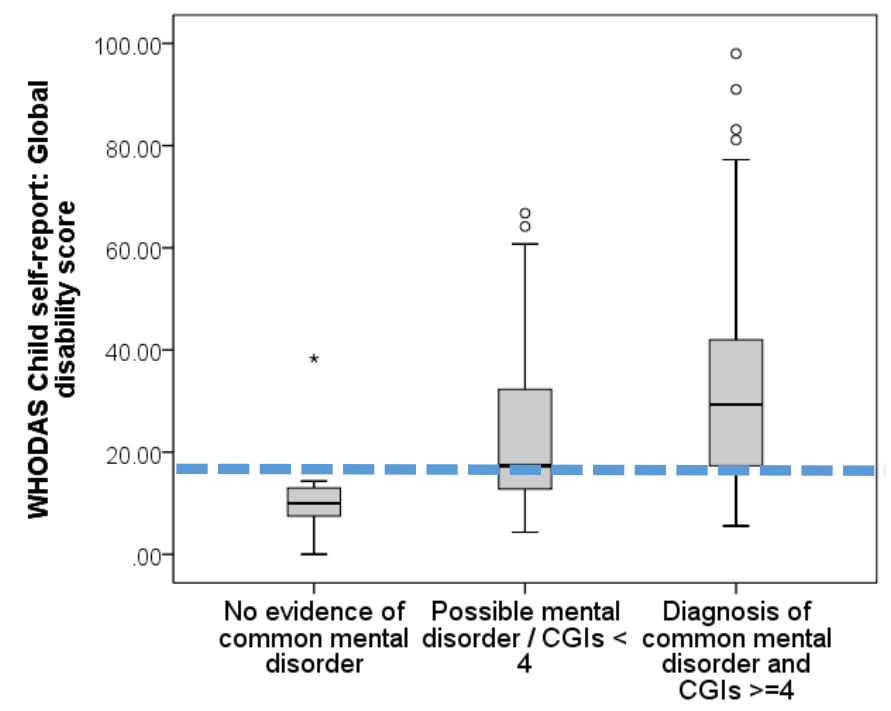

Figure 13. WHODAS-Child self-report version predicting any common mental disorder

(A) ROC curve analysis, $A \cup C=.67, p=.002$. (B) Distribution of WHODAS-Child global disability scores in non-cases (left hand boxplot), definite cases (right hand boxplot), and subthreshold cases (symptoms of mental disorder but little impairment or distress; middle boxplot); blue dashed line represents cut-off of 17 estimated to be optimal based on ROC curve.

The parent-report version only weakly predicted the presence of mental disorder ( $A \cup C=.61, p=.041$ ). The distribution of WHODAS-child global disability scores is shown in Figure 14, panel B, for cases, non-cases, and subthreshold cases. Using a cut-off of $\geq 17$ based on the ROC curve, sensitivity was $75 \%$, specificity was $47 \%$, PPV was $56 \%$ and NPV was $67 \%$. Predicting CGI-s score $\geq 4$, prediction was no better than chance (AUC=.59, $p=.115$ ). Sensitivity was $70 \%$, specificity was $45 \%$, PPV was $64 \%$ and NPV $51 \%$. 


\subsubsection{Convergent validity of measures of functional impairment}

Correlations between WHODAS-Child, SDQ Impact, and CGI-s scores are presented in Table 5. The CGI-s score was assigned by interviewer based on information gathered during the MINI KID and confirmed during supervision. In the subsample with clinical interview data (below the diagonal in Table 5), there was moderate agreement between CGI-s and WHODAS self-report and parent-report scores, with the correlation with self-report being double the magnitude of that with parent-report. The correlation with parent-report SDQ Impact score was not significant. SDQ Impact score correlated with parent-report WHODAS, but not self-report (this was replicated in the BIOPATH sample). Correlations in the BIOPATH sample (where different interviewers completed the questionnaires with child and caregiver) were consistently of smaller magnitude that those seen in the subsample (where the same interviewer worked with child and caregiver).

A

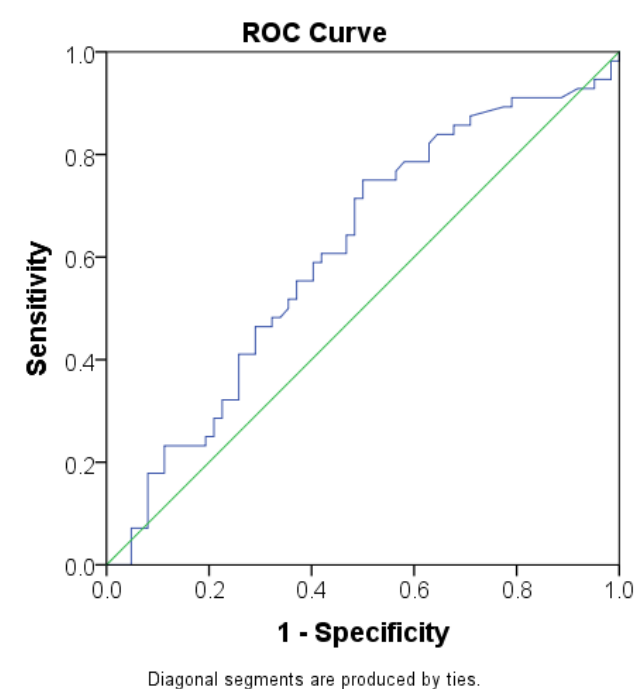

B

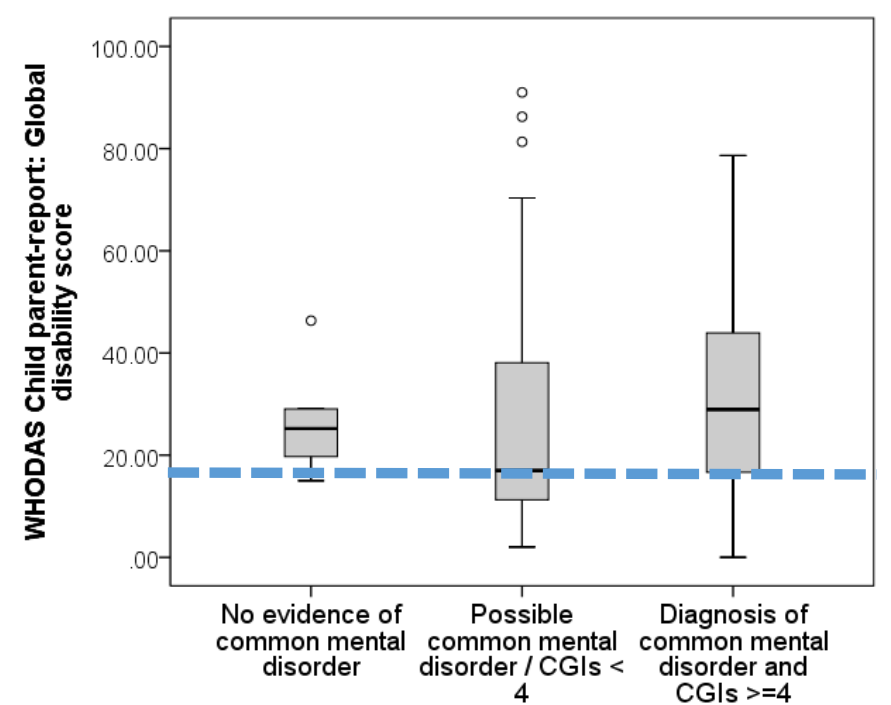

Figure 14. WHODAS-Child parent-report version predicting any common mental disorder

(A) ROC curve analysis, AUC=.61, p=.041. (B) Distribution of WHODAS-Child global disability scores in non-cases (left hand boxplot), definite cases (right hand boxplot), and subthreshold cases (symptoms of mental disorder but little impairment or distress; middle boxplot); blue dashed line represents cut-off of 17 estimated to be optimal based on ROC curve.

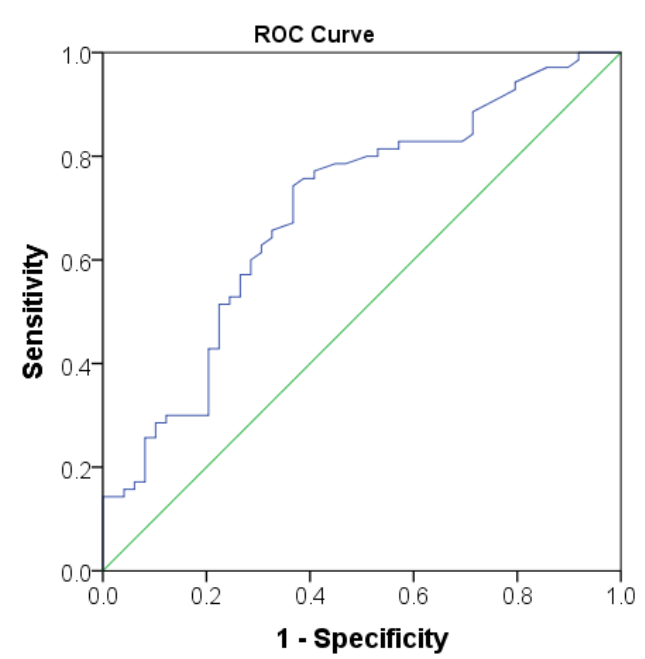

Diagonal segments are produced by ties

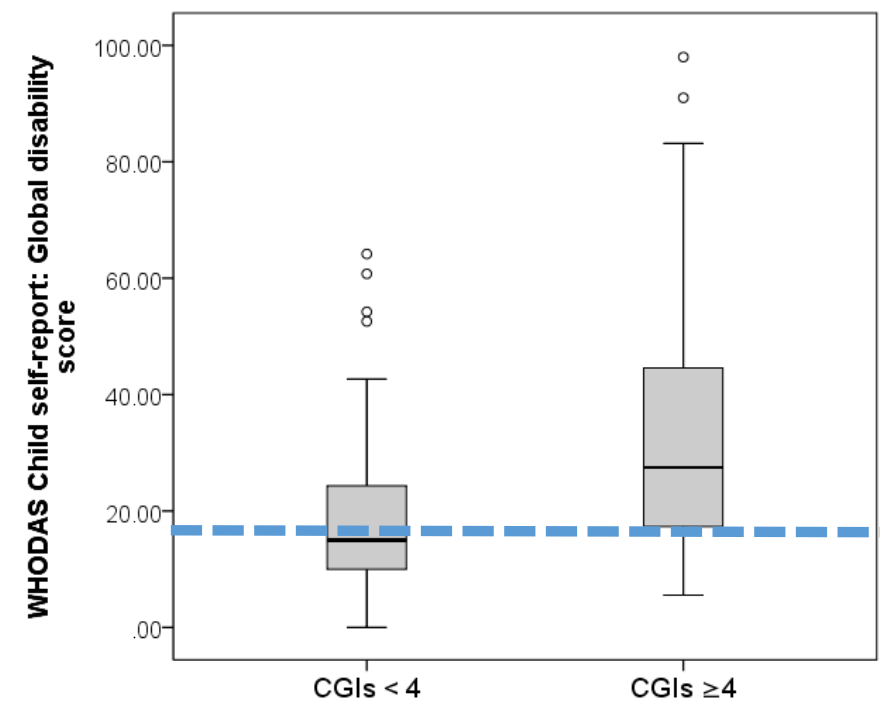

Figure 15. WHODAS Child self-report version predicting CGI-s score $\geq 4$

(A) ROC curve analysis, AUC=.70, p<.001. (B) Distribution of WHODAS Child global disability scores in non-cases (CGI-s score<4; left hand boxplot) and definite cases (CGI-s score $\geq 4$; right hand boxplot); blue dashed line represents cut-off of 17 estimated to be optimal based on ROC curve. 
This pattern of associations suggests that shared method variance may, at least in part, account for associations, i.e., caregivers report difficulties that are picked up by different caregiver measures, but this only partially overlaps with the difficulties reported by children. However, the significant correlations between child- and parent-report WHODAS, and between both child- and parent-report WHODAS and interviewer assigned CGI-s score provides some evidence of convergent validity. Combined with the findings above showing that child-report WHODAS is a stronger predictor of mental health problems than parent-report, these results suggest that childreport of difficulties in the WHODAS may be a better reflection of clinically significant problems than caregivers' reports.

Table 6 shows correlations between measures of functional impairment and symptom measures in the BIOPATH sample and subsample with clinical interview data. Both self- and parent-report WHODAS are consistently associated with measures of symptoms, suggesting that both reflect impairment due to mental health problems. The SDQ Impact score shows a less consistent pattern of associations with symptom scores; however, the skip rule means that only a minority of parents completed the impact supplement and this limits power to detect significant associations. The CGI-s score is consistently associated with symptom scores. This is expected given that the score is designed to summarise severity as shown through both symptoms and level of associated impairment/distress.

\begin{tabular}{|l|c|c|c|c|}
\hline & $\begin{array}{c}\text { WHODAS Global } \\
\text { disability, self- } \\
\text { report }\end{array}$ & $\begin{array}{c}\text { WHODAS Global } \\
\text { disability, } \\
\text { parent-report }\end{array}$ & $\begin{array}{c}\text { SDQ Impact, } \\
\text { parent-report }\end{array}$ & $\begin{array}{c}\text { CGI-s, assigned } \\
\text { by interviewer }\end{array}$ \\
\hline $\begin{array}{l}\text { WHODAS Global disability } \\
\text { score, self-report }\end{array}$ & $1.00(119 / 1002)$ & $.23^{* *}(989)$ & $.15(122)$ & N/A \\
\hline $\begin{array}{l}\text { WHODAS Global disability } \\
\text { score, parent-report }\end{array}$ & $.58^{* *}(118)$ & $1.00(118)$ & $.33^{* *}(122)$ & N/A \\
\hline $\begin{array}{l}\text { SDQ Impact score, parent- } \\
\text { report }\end{array}$ & $.25(42)$ & $.49^{*}(41)$ & $1.00(42)$ & N/A \\
\hline $\begin{array}{l}\text { CGI-s, assigned by } \\
\text { interviewer }\end{array}$ & $.39^{* *}(119)$ & $.19^{*}(118)$ & $.25(42)$ & $1.00(119 / \mathrm{N} / \mathrm{A})$ \\
\hline
\end{tabular}

Table 5. Correlations between measures of functional impairment

Spearman's rho (N) presented for each pairwise comparison. Above the diagonal shows correlations from BIOPATH sample (CGI-s score was not available), below the diagonal shows correlations from the subsample with clinical interviews. $\mathrm{N}$ is smaller for SDQ Impact score because the skip rule means that subsequent questions were not asked if the screening question was answered in the negative. CGI-s, Clinical Global Impression - severity score. ${ }^{* *} p<.01,{ }^{*} p<.05$ (2-tailed).

\section{Limitations}

Before discussing the results, there are a number of limitations that should be considered. Data that contributed to these analyses were collected through three research studies, the BIOPATH, t-CETA and VaST studies. While all attempts were made to ensure consistency in methods of data collection as far as was practicable, there were some differences that were unavoidable. For example, the MINI KID was conducted in either a clinic (t-CETA) or in settlements (VaST and some t-CETA cases), potentially leading to differences in the level of privacy during the interview. While the interviewer made all attempts to ensure privacy (e.g., by asking others to leave), it's possible that this led to differences in the quality of the data. The level of experience of the interviewers also differed, with a clinical psychologist conducting interviewers for VaST and mental health trained case managers doing so for t-CETA. We aimed to ensure consistency in administration and coding through training, supervision on every case by an experienced clinical psychologist, a joint supervision structure (the same supervisor for all interviewers and joint meetings), and double coding of $10 \%$ of interviews. It should be noted that the majority of interviews were conducted by the clinical psychologist $(85 \%)$ and where interviews were double coded there was generally good to excellent agreement between interviewers (see section 2.7). There were also some differences in the way that questionnaire data was collected, either through interview in person (BIOPATH and VaST) or over the phone ( $t$-CETA). The relatively small number of cases where phone administration was used $(n=18)$ precludes comparison of different methods. It was also not possible to look at test-retest reliability; delay in starting data 
collection in the subsample and difficulties in scheduling assessments with refugee families meant that there was an insufficient number with repeated assessments within an appropriate time window (see Appendix 5). Testretest reliability and comparison of different methods of administration (phone versus in person) should be a focus of future research.

\begin{tabular}{|c|c|c|c|c|c|c|c|}
\hline & \multicolumn{2}{|c|}{$\begin{array}{l}\text { WHODAS Global } \\
\text { disability, self-report }\end{array}$} & \multicolumn{2}{|c|}{$\begin{array}{l}\text { WHODAS Global } \\
\text { disability, parent- } \\
\text { report }\end{array}$} & \multicolumn{2}{|c|}{$\begin{array}{l}\text { SDQ Impact, parent- } \\
\text { report }\end{array}$} & \multirow{2}{*}{$\begin{array}{c}\text { CGI-s, } \\
\text { assigned by } \\
\text { interviewer } \\
\text { Subsample }\end{array}$} \\
\hline & BIOPATH & Subsample & BIOPATH & Subsample & BIOPATH & Subsample & \\
\hline $\begin{array}{l}\text { SCARED, self- } \\
\text { report }\end{array}$ & $\begin{array}{l}.42 * * \\
(1002)\end{array}$ & $\begin{array}{l}.61^{* *} \\
(118)\end{array}$ & $\begin{array}{l}.15^{* *} \\
(993)\end{array}$ & $\begin{array}{l}.45^{* *} \\
(117)\end{array}$ & $\begin{array}{c}.06 \\
(122)\end{array}$ & $\begin{array}{l}-.02 \\
(41)\end{array}$ & $\begin{array}{l}.36^{* *} \\
(118)\end{array}$ \\
\hline $\begin{array}{l}\text { CES-DC, self- } \\
\text { report }\end{array}$ & $\begin{array}{l}.57^{* *} \\
(1002)\end{array}$ & $\begin{array}{l}.62^{* *} \\
(119)\end{array}$ & $\begin{array}{l}.24^{* *} \\
(993)\end{array}$ & $\begin{array}{l}.36 * * \\
(118)\end{array}$ & $\begin{array}{l}.18^{*} \\
(122)\end{array}$ & $\begin{array}{l}.19 \\
(42)\end{array}$ & $\begin{array}{l}.43^{* *} \\
(119)\end{array}$ \\
\hline CPSS, self-report & $\begin{array}{l}.22^{* *} \\
(1001)\end{array}$ & $\begin{array}{l}.57^{* *} \\
(118)\end{array}$ & $\begin{array}{l}.16^{* *} \\
(992)\end{array}$ & $\begin{array}{l}.36 * * \\
(117)\end{array}$ & $\begin{array}{l}.22 * \\
(122)\end{array}$ & $\begin{array}{l}.16 \\
(42)\end{array}$ & $\begin{array}{l}.41^{* *} \\
(118)\end{array}$ \\
\hline $\begin{array}{l}\text { SDQ total } \\
\text { difficulties, } \\
\text { parent-report }\end{array}$ & $\begin{array}{l}.13^{* *} \\
(991)\end{array}$ & $\begin{array}{l}.27^{* *} \\
(119)\end{array}$ & $\begin{array}{l}.40 * * \\
(993)\end{array}$ & $\begin{array}{l}.45^{* *} \\
(118)\end{array}$ & $\begin{array}{l}.38^{* *} \\
(122)\end{array}$ & $\begin{array}{l}.45^{* *} \\
(42)\end{array}$ & $\begin{array}{l}.43^{* *} \\
(119)\end{array}$ \\
\hline $\begin{array}{l}\text { SDQ } \\
\text { internalising, } \\
\text { parent-report }\end{array}$ & $\begin{array}{l}.17^{* *} \\
(991)\end{array}$ & $\begin{array}{l}.28 * * \\
(119)\end{array}$ & $\begin{array}{l}.37^{* *} \\
(993)\end{array}$ & $\begin{array}{l}.46^{* *} \\
(118)\end{array}$ & $\begin{array}{l}.33^{* *} \\
(122)\end{array}$ & $\begin{array}{c}.42 * * \\
(42)\end{array}$ & $\begin{array}{l}.29 * * \\
(119)\end{array}$ \\
\hline $\begin{array}{l}\text { SDQ } \\
\text { externalising, } \\
\text { parent-report }\end{array}$ & $\begin{array}{l}.05 \\
(991)\end{array}$ & $\begin{array}{c}.18^{*} \\
(119)\end{array}$ & $\begin{array}{l}.33^{* *} \\
(993)\end{array}$ & $\begin{array}{c}.23^{*} \\
(118)\end{array}$ & $\begin{array}{l}.27^{* *} \\
(122)\end{array}$ & $\begin{array}{l}.24 \\
(42)\end{array}$ & $\begin{array}{l}.44^{* *} \\
(119)\end{array}$ \\
\hline
\end{tabular}

Table 6. Correlations between measures of functional impairment and symptom measures

Spearman's rho (N). N is smaller for SDQ Impact score because the skip rule means that subsequent questions were not asked if the screening question was answered in the negative. CGI-s, Clinical Global Impression - severity score. ${ }^{* *} p<.01,{ }^{*}$ $\mathrm{p}<.05$ (2-tailed).

A further limitation is a smaller sample size than anticipated in the t-CETA study. This is because of challenges to recruiting children to a clinical trial (which required multiple visits / study contacts) in a refugee setting when there are numerous barriers to research participation, such as limited transport, difficulties getting time away from work, and stigma associated with accessing mental health services. However, power analyses suggest that all analyses reported here were adequately powered (see Appendix 5).

While we made all efforts to modify questionnaires based on pilot testing to ensure that questions were adapted to the target population, it was not possible to modify the SDQ because of licensing conditions. Some questions were perceived to be offensive or were not optimally phrased because of differences in Arabic dialects, thus this may have impacted the quality of these data.

\section{Discussion}

A summary of the findings is presented first (Table 7), followed by discussion of specific measures, and then general discussion about using these measures in crisis contexts.

Before discussing each measure, there will be a brief discussion about the selection of optimal cut-offs and the use of tools as dimensional symptom measures. Typically, the aim is to select a cut-off that maximises both sensitivity and specificity - to identify as many cases as possible while minimising the number of non-cases that are misclassified. Because sensitivity and specificity are in balance, selecting a cut-off that maximises one will decrease the other. Using a ROC curve, the point closest to the top left corner of the chart should represent the optimal balance between sensitivity and specificity. However, where the AUC $<.80$ this approach can result in both sensitivity and specificity that are less than optimal. If the purpose of a screening tool is to identify children who may have disorder while minimising missed cases (e.g., for selection into a clinical service) then it may be more appropriate to select a cut-off that prioritises sensitivity (while avoiding specificity that is unacceptably low). 
If this approach is taken the tool should only be used as a first step to identify children, who will then undergo further assessment to distinguish true from false positives. The PPV should be noted to determine what proportion of false positives are expected, and this may help guide decisions about whether the tool has the potential to form part of a cost-effective way to determine eligibility for a service. (See [28] for discussion of these issues.)

If a tool is to be used to estimate prevalance of a disorder in a population, then the rate of false positives and false negatives needs to be taken into account. A tool that is sensitive (so identifying most cases) but has a high rate of false positives will overestimate prevalence. A tool that has good specificity (so avoiding too many false positives) may have a high rate of false negatives, so underestimating prevalence. In reality, a tool is likely to produce both false positives and false negatives but in differing proportions. Selecting a cut-off that balances the numbers of false positives and false negatives can help to provide a more accurate estimate of prevalence, as the number of false positives will effectively cancel out the number of false negatives. However, it should be noted that the frequency of false positives and false negatives may not be apparent from the proportions expressed as PPV/NPV, because the frequencies also depend on the prevalence of the disorder in the population under study. For example, in a sample of $\mathrm{N}=100$ and a disorder with prevalence of $25 \%$, a test with perfect sensitivity but PPV of $50 \%$ would identify $n=50$ children, $n=25$ of whom would be false positives. With a prevalence of $5 \%, n=10$ children would screen positive, $n=5$ of whom would be false positives. Therefore if validation data has been generated from a population that may have a different prevalence rate, care should be taken in attempting to correct prevalence estimates using the PPV and NPV.

In this report, where a cut-off was selected based on the ROC curve and it was not possible to achieve a high value for both sensitivity and specificity, sensitivity was prioritised. Further work will be required to establish cutoffs that provide more accurate estimates of prevalence.

There are circumstances in which the purpose of a tool is to provide a dimensional symptom measure and therefore a cut-off is less relevant. This includes research focused on individual differences between children and that measuring change in symptom level following intervention. In this study, all questionnaire measures of psychopathology were correlated with measures of impairment (WHODAS self- and parent-report and CGI-s score), suggesting that they are capturing the severity of mental health problems. The lack of specificity may limit claims that they are measuring particular psychopathology in the Syrian refugee context; rather, they could be acting as a more general index of mental distress.

\subsection{Measures: summary and recommendations for use}

\subsubsection{CES-DC}

The 10-item CES-DC was internally consistent, but it was not possible to achieve the same sensitivity and specificity as has been demonstrated previously [2]. Selecting a cut-off that achieved good sensitivity resulted in low specificity and a high rate of false positives, with about two thirds of children scoring above cut-off being false positives. If used in a clinical setting, a second stage of screening or assessment would be required to discriminate true from false positives. The CES-DC differentiated poorly between true cases and subclinical cases (with little impairment or distress), so further assessment could focus on functional impairment. The high rate of false positives means that this is unlikely to be a cost effective way to identify children for in-depth clinical assessment. However, the rate of false negatives was low so scoring below cut-off may help to rule out a diagnosis of depressive disorder. Further work is required to establish test-retest and interrater reliability, and to establish sensitivity to change; the latter is important if it is used to measure response to intervention.

If used in epidemiological research, the high rate of false positives using this cut-off would need to be taken into account when estimating prevalence of depressive disorder. Further work is required to establish a cut-off that is likely to yield a more accurate prevalence estimate in this context.

\subsubsection{SCARED}

The 18-item SCARED showed similar performance to that previously demonstrated in a Lebanese clinical population [5]. The subscales showed moderate internal consistency and the total score showed modest ability to discriminate between children with and without anxiety disorders. While sensitivity was higher in our study, specificity was modest with about half of non-cases being misclassified. 


\begin{tabular}{|c|c|c|c|c|c|c|}
\hline $\begin{array}{c}\text { Is scale } \\
\text { internally } \\
\text { consistent? }\end{array}$ & $\begin{array}{c}\text { Does scale } \\
\text { predict } \\
\text { disorder } \\
\text { better than } \\
\text { chance? (AUC) }\end{array}$ & $\begin{array}{l}\text { What } \% \text { of cases } \\
\text { are detected? } \\
\text { (SENSITIVITY) }\end{array}$ & $\begin{array}{l}\text { What \% of } \\
\text { non-cases are } \\
\text { identified? } \\
\text { (SPECIFICITY) }\end{array}$ & $\begin{array}{l}\text { What \% of } \\
\text { positive } \\
\text { results true? } \\
\text { (PPV) }\end{array}$ & $\begin{array}{l}\text { What \% of } \\
\text { negative } \\
\text { results } \\
\text { true? } \\
\text { (NPV) }\end{array}$ & $\begin{array}{c}\text { Are there any other } \\
\text { concerns? }\end{array}$ \\
\hline
\end{tabular}

\begin{tabular}{|c|c|c|c|c|c|c|c|c|}
\hline CES-DC (depression) & Cut-off 10 & .89 & .74 & $81 \%$ & $56 \%$ & $35 \%$ & $91 \%$ & \\
\hline SCARED (anxiety) & Cut-off 12 & .84 & .6 & $80 \%$ & $53 \%$ & $63 \%$ & $72 \%$ & $\begin{array}{l}\text { Some items endorsed at } \\
\text { very high frequency; two } \\
\text { subscales did not have } \\
\text { expected distribution }\end{array}$ \\
\hline \multirow{2}{*}{$\begin{array}{l}\text { CPSS } \\
\text { (PTSD) }\end{array}$} & Cut-off 12 & \multirow{2}{*}{.94} & \multirow{2}{*}{.70} & $83 \%$ & $43 \%$ & $48 \%$ & $79 \%$ & \\
\hline & Algorithm & & & $33 \%$ & $88 \%$ & $62 \%$ & $69 \%$ & \\
\hline SDQ total difficulties & Cut-off 17 & .76 & .72 & $70 \%$ & $66 \%$ & $66 \%$ & $71 \%$ & \multirow{3}{*}{$\begin{array}{l}\text { Cronbach's alpha for } \\
\text { subscales below } \\
\text { acceptable level; factor } \\
\text { analysis did not replicate } \\
\text { subscale structure }\end{array}$} \\
\hline SDQ internalising & Cut-off 7 & .65 & & $80 \%$ & $22 \%$ & $48 \%$ & $56 \%$ & \\
\hline SDQ externalising & Cut-off 9 & .64 & .82 & $82 \%$ & $71 \%$ & $54 \%$ & $91 \%$ & \\
\hline SDQ impact & $\begin{array}{l}\text { Screening } \\
\text { question }\end{array}$ & .78 & N/A & $53 \%$ & $76 \%$ & $67 \%$ & $64 \%$ & \\
\hline \multirow{2}{*}{$\begin{array}{l}\text { WHODAS self- } \\
\text { report }\end{array}$} & $\begin{array}{l}\text { Predicting } \\
\text { disorder }\end{array}$ & & & $77 \%$ & $52 \%$ & $59 \%$ & $71 \%$ & \multirow{4}{*}{$\begin{array}{l}\text { Agreement between self- } \\
\text { and parent-report good } \\
\text { when same interviewer } \\
\text { completed with child and } \\
\text { parent, reduced when } \\
\text { different interviewers; } \\
\text { some evidence of } \\
\text { construct validity when } \\
\text { same interviewer } \\
\text { completed with child and } \\
\text { parent, inconsistent } \\
\text { evidence when different } \\
\text { interviewers. }\end{array}$} \\
\hline & $\begin{array}{l}\text { Predicting } \\
\text { severity / } \\
\text { impairment }\end{array}$ & .82 & .70 & $77 \%$ & $59 \%$ & $73 \%$ & $64 \%$ & \\
\hline \multirow{2}{*}{$\begin{array}{l}\text { WHODAS } \\
\text { parent-report }\end{array}$} & $\begin{array}{l}\text { Predicting } \\
\text { disorder }\end{array}$ & \multirow{2}{*}{.76} & & $75 \%$ & $47 \%$ & $56 \%$ & $67 \%$ & \\
\hline & $\begin{array}{l}\text { Predicting } \\
\text { severity / } \\
\text { impairment }\end{array}$ & & & $70 \%$ & $45 \%$ & $64 \%$ & $51 \%$ & \\
\hline
\end{tabular}

\section{Table 7. Summary of reliability and validity statistics}

Green highlighting shows results considered to be excellent, yellow to be acceptable, and red to be poor; note that decisions about what constitutes acceptable sensitivity, specificity, PPV, and NPV for a measure depends on the purpose for which it is to be used. 
A number of SCARED items were endorsed at very high frequency and the 3-item subscales for Social and Separation anxiety did not show the expected distribution. It is possible that some questions are confounded by the context of displacement. For example, being scared about being separated from parents, sleeping away from home, being alone in the house, or worrying about the future may be common reactions in children who have been displaced. Furthermore, some items may reflect living in informal tented settlements (ITS) where there are sometimes hostilities, such as reporting being shy or nervous with people the child doesn't know well. However, similarly elevated scores have been found in a school-based study involving Lebanese and Syrian students, suggesting that there may be broader cultural factors that influence the performance of the SCARED in Lebanon and that require further exploration (Karam, E., Karam, G., Saab, D., unpublished data). These issues may increase the level of reported anxiety symptoms across the whole sample, and contribute to the difficultly in separating children with clinically-significant anxiety from those without. More than half of children with no evidence of anxiety disorder at clinical interview nevertheless had SCARED scores above the cut-off, confirming that, in this population of displaced Syrian children, the SCARED has limited value in identifying cases. Apparently elevated prevalence of anxiety shown by the SCARED should therefore be interpreted with caution. Further work will be required to determine if the same items are endorsed at high frequency in other populations in the Middle East, and in a range of contexts, to understand the extent to which cultural and contextual factors may influence children's responses. A clearer understanding will be required in order to identify those symptoms that provide better discrimination of anxiety disorders from feelings or behaviour that are normative in the context. These concerns mean that this 18-item version of the SCARED is not currently recommended for the purpose of screening for anxiety disorders in clinical settings in the Syrian refugee context.

\subsection{CPSS}

The CPSS was internally consistent, but it was difficult to achieve a good balance between sensitivity and specificity. With sensitivity of $83 \%$, specificity was only $42 \%$ and the false positive rate was $52 \%$. The one previous study in a war-exposed population also failed to achieve both good sensitivity and specificity (reporting moderate values for each and using a higher cut-off than used here) and had a very high false positive rate [19]. One possibility is that the lack of specificity means that children with other difficulties (e.g., depression) are picked up by the CPSS. Examining data from the false positives, nearly half met criteria for an internalising or externalising disorder. Applying an algorithm aligned to DSM- 5 criteria for PTSD to the CPSS responses addressed this by increasing specificity to $88 \%$; however, the trade off was very low sensitivity, with two thirds of cases being missed using this approach. If used to screen in a clinical setting, applying a cut-off would identify most cases but further assessment would be required to separate true from false positives, and to assess for a range of other difficulties that may be present in those who do not meet criteria for PTSD. If used in epidemiological research, further work is required to establish a cut-off that is likely to yield a more accurate prevalence estimate in this context.

Data on the types of events described by children in the CPSS have not yet been explored; it will be necessary to establish if events are consistent with those set out in DSM-5 for PTSD and whether using this information improves the performance of the CPSS (e.g., in conjunction with a cut-off score). The increase in reported events between data collection for BIOPATH and then several months later in the subsample has also still to be explored. While there is an increase at group level, it will be of interest to check whether the events reported by children are consistent over time for events that happened prior to BIOPATH data collection. It is currently unclear why there is an increase in both events reported and PTSD symptoms, but this might relate to changing circumstances in the Beqaa region around the time of data collection. Many families reported an increase in events like army raids and evictions, and were concerned about forced return to Syria. Events like army raids could have been reported as new traumatic events, or triggered stronger memories of events that occurred during the war. The increase in PTSD symptom scores appeared to be driven by those who did not report a traumatic event, which might suggest that increased CPSS scores reflect symptoms not specific to PTSD (e.g., depression) related to changing circumstances. This is consistent with a concurrent increase in scores for the CES-DC, SDQ, and WHODAS. However, this is speculative and we cannot rule out alternative explanations including interviewer effects and differences in the context of data collection.

\subsection{SDQ + Impact supplement}


The subscale structure of the SDQ was not replicated and the subscales showed poor internal consistency $(\alpha=.26$ .66). While this might relate to the different culture and context, it should be noted that some data from UK children also fell short of standard criteria for internal consistency ( $\alpha=.58-.77$ [22]). In Arab samples, subscales were not internally consistent using parent-report in children from GAZA [30] and could not be replicated in Omani and Syrian children using teacher report [21]. This suggests that the subscales may not clearly capture distinct patterns of psychopathology in Arab populations. Factor analysis suggested that some items may have a different meaning in this population. For example, the item Gets on better with adults than other children, which is intended to measure difficulties with peer relationships, was negatively correlated with other Peer problems items, endorsed at a high frequency, and showed some cross-loading on the Prosocial factor. This suggests that it may be interpreted as a desirable trait - such as a sign of maturity or good manners - rather than as a measure of social difficulties in this population. Another study found that this item was not valid in children from Oman consistently across self-, parent-, and teacher-report versions [20]. The authors offered a similar explanation, suggesting that in a collective culture where there are fewer boundaries between relationships with the same versus different age groups, this item does not capture peer problems. In our study, interviewers reported that some items were culturally insensitive and some parents experienced it as shameful or as an accusation to be asked items such as Steals from home, school or elsewhere. Despite interviewers making it clear that these are standard items asked to everyone, some items were endorsed at very low frequencies and may not reflect the actual prevalence of these behaviours in this population.

Two of the factors identified by factor analysis included items from both internalising and externalising subscales, suggesting that this may not be a clear distinction in this population, or that some items carry a different meaning. For example, the Emotional problems item Nervous or clingy in new situations, easily loses confidence loaded with externalising behaviour problems, replicating a finding from children with learning disabilities in Oman and Saudi Arabia using the teacher-report version [31]. This is consistent with another recent study of Syrian children in Lebanon (aged 5-16 years) that suggested that anger and sadness were associated in children's descriptions of their emotions during social situations [32]. This was contrary to research based on WEIRD (Western, Educated, Industrialised, Rich, Developed) populations, where the processes involved in identifying and regulating emotions such as anger and sadness are thought to be different. While it is possible that this is an artefact (e.g., reflecting differential item response patterns), the similarities across studies and methods (including child vs. parent-report) are suggestive of differences in the way emotions are experienced or expressed in the Syrian refugee context.

Despite these issues, the Total difficulties score and Externalising subscale showed reasonable ability to discriminate between children with mental disorders and those without, achieving AUC values $(.72, .82)$ comparable to that reported in children from Yemen [8]. In particular, the Externalising subscale achieved sensitivity of $82 \%$ and specificity of $71 \%$ in detecting conduct or oppositional defiant disorder. This suggests that even with relatively poor internal consistency, these checklists of problems may nevertheless have utility in screening for clinically significant difficulties in Syrian refugee children. No data on reliability were reported from the Yemen study so it is not clear if similar issues with internal consistency were seen. The SDQ Total difficulties score and Externalising subscale could be used as a first stage of screening in a clinical setting, with further assessment to differentiate true from false positives. A negative result on the externalising scale rule outs conduct problems with a high degree of confidence. However, the Internalising subscale performed poorly, with very low specificity (22\%) driven by the majority of children scoring above cut-off. This mirrored the SCARED, where a large proportion of non-cases scored above cut-off, suggesting that the difficulties in identifying children with anxiety disorders in this population are not specific to the SCARED nor to self-report measures. The SDQ Internalising subscale is not recommended as a way to screen for internalising disorders in this context.

\subsection{Measures of functional impairment}

The WHODAS-Child self- and parent-report versions showed reasonable replication of the subscale structure and good internal consistency. Self- and parent-report versions were significantly associated with each other, as well as with the Clinical Global Impression - severity (CGI-s) score assigned by interviewer and confirmed during clinical supervision. Scoring above a cut-off of 17 on the self-report WHODAS-Child was a reasonable predictor of having a CGI-s score $\geq 4$, suggesting that the self-report WHODAS-Child may have utility in identifying children with 
more severe and impairing mental health problems in this population. The parent-report WHODAS-Child did not significantly predict CGI-s score $\geq 4$ in this context. The self-report version could potentially be combined with a symptom scale with high sensitivity as a second stage of screening, though the effectiveness of this approach has yet to be tested.

The SDQ Impact supplement is intended to be used in this way, and endorsing the screening question did significantly predict CGI-s $\geq 4$ with good specificity. However, the use of a skip rule means that only around half of parents whose child met criteria for a mental disorder completed it, resulting in low sensitivity. The screening question asks parents if they think their child has difficulties in emotions, concentration, behaviour or being able to get on with other people, so it relies on the parent conceptualising their child's difficulties in this way. It was apparent that some parents who answered No to this question subsequently requested mental health services for their child, suggesting that in this population the screening question may not be effective. However, it should be noted that the parent-report version of the WHODAS-Child was also a poor predictor of CGI-s score, suggesting that parent-report measures provide more limited insight into impairment and distress resulting from their child's mental health problems.

Many children in our sample did not attend school and this meant that the WHODAS-Child subscale relating to impairment at school was missing for many cases. While a global impairment score was calculated from the other subscales in these cases, this rests on the assumption that impairment in school is highly correlated with impairment in other settings. However, it is possible that impairment is more likely to manifest in the more structured school setting than in settings with fewer demands. Further work will be required to explore whether performance of the WHODAS-Child differs in children who do or do not attend school.

\subsection{Respondent and interviewer effects}

The WHODAS-Child was the only measure where we used both self- and parent-report versions, allowing a direct comparison between respondants. When child and parent were interviewed by the same person, there was good agreement between child and parent reports. However, where a different interviewer completed the questionnaire with child and parent the agreement was less than half the magnitude. This suggests that even when using a questionnaire with closed questions, there may be a significant interviewer effect. It also introduced a challenge to reliability, such that construct validity for the WHODAS-Child subscales was hard to replicate when different interviewers were used. We aimed to ensure that interviewers were focusing on the quality of data over the quantity of interviews completed, but it is likely that there were still differences in administration that could impact data quality. This highlights the need for improved training and supervision of interviewers to ensure that administration is consistent, and further work to identify ways in which administration differs (e.g., rephrasing questions, taking time to check understanding, rechecking answers if there are apparent inconsistencies). These are questionnaires designed to be self-completed, and it is unclear if similar challenges to reliability would occur if they were completed by the respondant without support (e.g., due to difficulty understanding questions or differences in interpretation).

There also seem to be significant respondant effects, such that parent-report measures of impairment were associated with each other, but much less with self-report and interviewer-report, a finding that has been reported previously for measures of both symptoms and impairment [33]. While it's possible that parents have less insight into some forms of impairment (e.g., at school or with peers) or distress, it's also possible that both children's and parents' perspectives capture unique information about impairment. There may be utility in combining information from self- and parent-report, but this has yet to be explored. Parent-report WHODAS-Child is significantly correlated with all measures of psychopathology and CGI-s score, suggesting that as a dimesional measure it captures information about impairment (despite its poorer performance when applying a cut-off).

\subsection{Do these tools meet needs in the Syrian refugee context?}

During this project, two specific needs for screening tools were identified by mental health professionals working with Syrian refugees in Lebanon: (1) a very brief screener that could be used by outreach volunteers to identify children with problems, and (2) measures of specific mental disorders (e.g., depression, PTSD) that would help psychotherapists differentiate these types of problems. Of the tools evaluated here, none fits the criteria for a very brief screener (e.g., 5 items) so further work is required to develop and evaluate a tool for this purpose. The 
CES-DC, SCARED, CPSS, and SDQ are designed to measure specific mental disorders; however, using cut-offs to optimise sensitivity results in unacceptably low specificity in most cases and the substantial proportion of false positives may at least partly reflect the presence of other psychopathology. Thus, they do not seem to be good candidates for differentiating different mental disorders from each other in clinical settings with Syrian refugees. The exception may be the tools with high NPV (CES-DC and SDQ Externalising subscale), in which case a negative result can rule out the presence of these problems with a high degree of confidence.

\subsection{Challenges in applying findings to other contexts}

In theory, sensitivity and specificity do not differ depending on disease prevalence. However, in practice there are various ways in which methodology influences prevalence, and in turn this has an effect on the reported sensitivity and specificity of tests [34,35]. Higher prevalence tends to mean lower specificity, though the effect on sensitivity is less predictable [35]. The way that samples are selected can result in different prevalence rates of disorders and qualitatively different types of populations, hence impacting the performance of screening tools. For example, a population with a higher prevalence might be one with more severe cases of disorder, which would make it easier to detect cases and improve the performance of a screening tool. However, what may be more likely in the Syrian refugee context is an increase in subthreshold presentations associated with challenging environmental conditions. This would result in an increase in false positives and decrease in specificity, which is what we observe in this study. If the tools are used in a population with a different prevalence of common mental disorders, and qualitative differences such as the level of adversity, then performance may differ. Caution should therefore be applied in using the cut-offs derived from this sample of vulnerable Syrian refugee children in Beqaa, Lebanon.

\subsection{Next steps}

A number of steps need to be taken to provide further data on the performance of these measures in this context. It is possible that measures perform differently in older and younger children, in boys and girls, and in children with different educational levels. Therefore testing for measurement invariance is necessary. Sensitivity to change - for example, after an intervention - has also still to be tested. Further analysis at item level is required to explore which items are most predictive of disorder, which will guide the future development of scales with improved psychometric properties. The utility of two-step approaches to screening, using measures of both symptoms and functional impairment, has also to be undertaken. Improved cut-offs that balance the number of false positives and false negatives, and therefore guide more accurate prevalence estimates in this population, will be also explored. Finally, it should be noted that while questionnaire measures have a place in providing quick ways to screen for the presence of mental disorders or level of symptoms and impairment, they do not replace in-depth clinical assessment by trained mental health professionals; the latter is required for confirmation of diagnosis in clinical practice and to provide robust prevalence estimates in epidemiological research.

\section{Acknowledgements}

Data collection for the VaST study was funded by an award from TIES/NYU as part of the 3EA I MENAT Measurement Initiative (Subaward: S4323-04). The BIOPATH study was funded by the Eunice Shriver National Institute of Child Health \& Human Development (NICHD; R01HD083387). The t-CETA study was funded by Elrha as part of the Research for Health in Humanitarian Crises (R2HC) scheme. NICHD and Elrha played no role in study design, in the collection, analysis or interpretation of data, or in the writing of the report.

We warmly thank all participating families for their participation. Fieldwork was conducted with Médecins du Monde France (MdM) in Lebanon. We thank Patricia Moghames, Nicolas Chehade, Stephanie Legoff, Nicolas Puvis, and Zeina Hassan, and all other members of the VaST, BIOPATH, and t-CETA teams for their dedication, hard work and insights. 


\section{References}

1. Faulstich, M.E., et al., Assessment of depression in childhood and adolescence: an evaluation of the Center for Epidemiological Studies Depression Scale for Children (CES-DC). Am J Psychiatry, 1986. 143(8): p. 10247.

2. Fendrich, M., M.M. Weissman, and V. Warner, Screening for depressive disorder in children and adolescents: validating the Center for Epidemiologic Studies Depression Scale for Children. Am J Epidemiol, 1990. 131(3): p. 538-51.

3. Birmaher, B., et al., The screen for child anxiety related emotional disorders (SCARED): Scale construction and psychometric characteristics. Journal of the American Academy of Child and Adolescent Psychiatry, 1997. 36(4): p. 545-553.

4. Birmaher, B., et al., Psychometric properties of the Screen for Child Anxiety Related Emotional Disorders (SCARED): a replication study. J Am Acad Child Adolesc Psychiatry, 1999. 38(10): p. 1230-6.

5. Hariz, N., et al., Reliability and validity of the Arabic Screen for Child Anxiety Related Emotional Disorders (SCARED) in a clinical sample. Psychiatry Res, 2013. 209(2): p. 222-8.

6. Foa, E.B., et al., The Child PTSD Symptom Scale: A preliminary examination of its psychometric properties. Journal of clinical child psychology, 2001. 30(3): p. 376-384.

7. Goodman, R., The Strengths and Difficulties Questionnaire: A research note. Journal of Child Psychology and Psychiatry, 1997. 38: p. 581-586.

8. Alyahri, A. and R. Goodman, Validation of the Arabic Strengths and Difficulties Questionnaire and the Development and Well-Being Assessment. East Mediterr Health J, 2006. 12 Suppl 2: p. S138-46.

9. Sheehan, D.V., et al., Reliability and validity of the Mini International Neuropsychiatric Interview for Children and Adolescents (MINI-KID). J Clin Psychiatry, 2010. 71(3): p. 313-26.

10. Scorza, P., et al., Validation of the "World Health Organization Disability Assessment Schedule for children, WHODAS-Child" in Rwanda. PLoS One, 2013. 8(3): p. e57725.

11. Goodman, R., The extended version of the Strengths and Difficulties Questionnaire as a guide to child psychiatric caseness and consequent burden. J Child Psychol Psychiatry, 1999. 40(5): p. 791-9.

12. Busner, J. and S.D. Targum, The clinical global impressions scale: applying a research tool in clinical practice. Psychiatry (Edgmont), 2007. 4(7): p. 28-37.

13. Ghubash, R., et al., The performance of the Center for Epidemiologic Study Depression Scale (CES-D) in an Arab female community. Int J Soc Psychiatry, 2000. 46(4): p. 241-9.

14. Essau, C.A., et al., Depressive symptoms among children and adolescents in Iran: a confirmatory factor analytic study of the centre for epidemiological studies depression scale for children. Child Psychiatry Hum Dev, 2013. 44(1): p. 123-36.

15. Betancourt, T., et al., Validating the Center for Epidemiological Studies Depression Scale for Children in Rwanda. J Am Acad Child Adolesc Psychiatry, 2012. 51(12): p. 1284-92.

16. Salah, E.M., et al., Screening for depressive symptoms and their associated risk factors in adolescent students in South Sinai, Egypt. Life Science Journal, 2013. 10(3): p. 433-443.

17. Kadak, M.T., et al., Psychometric properties of the Turkish version of the child PTSD symptom scale. Compr Psychiatry, 2014. 55(6): p. 1435-41.

18. Rachamim, L., et al., Validation of the Child Posttraumatic Symptom Scale in a sample of treatmentseeking Israeli youth. J Trauma Stress, 2011. 24(3): p. 356-60.

19. Kohrt, B.A., et al., Validation of cross-cultural child mental health and psychosocial research instruments: adapting the Depression Self-Rating Scale and Child PTSD Symptom Scale in Nepal. BMC Psychiatry, 2011. 11(1): p. 127.

20. Emam, M.M., et al., Psychometric properties of the Arabic self-report version of the strengths and difficulties questionnaire. Res Dev Disabil, 2016. 59: p. 211-220.

21. Tubbs Dolan, C., The strengths and difficulties of the Strengths and Difficulties Questionnaire: Crossnational measurement of children's social-emotional well-being in crisis-affected contexts. 2017, New York University: New York. 
22. Goodman, A., D.L. Lamping, and G.B. Ploubidis, When to use broader internalising and externalising subscales instead of the hypothesised five subscales on the Strengths and Difficulties Questionnaire (SDQ): data from British parents, teachers and children. J Abnorm Child Psychol, 2010. 38(8): p. 1179-91.

23. Betancourt, T.S., et al., Family-based promotion of mental health in children affected by HIV: a pilot randomized controlled trial. J Child Psychol Psychiatry, 2017. 58(8): p. 922-930.

24. Sheehan, D.V., et al., The Mini-International Neuropsychiatric Interview (M.I.N.I.): the development and validation of a structured diagnostic psychiatric interview for DSM-IV and ICD-10. J Clin Psychiatry, 1998. 59 Suppl 20: p. 22-33;quiz 34-57.

25. Kyrillos, V., et al., Assessing the mental health of Syrian refugee children and adolescents in Lebanon: Observations from the field

26. Mandrekar, J.N., Receiver operating characteristic curve in diagnostic test assessment. J Thorac Oncol, 2010. 5(9): p. 1315-6.

27. Mandrekar, J.N., Simple statistical measures for diagnostic accuracy assessment. J Thorac Oncol, 2010. 5(6): p. 763-4.

28. HealthNewsReview.org. Understanding medical tests: sensitivity, specificity, and positive predictive value. 2018 [cited 2020 16th January]; Available from: https://www.healthnewsreview.org/toolkit/tips-forunderstanding-studies/understanding-medical-tests-sensitivity-specificity-and-positive-predictive-value/.

29. Campbell, D.T. and D.W. Fiske, Convergent and discriminant validation by the multitrait-multimethod matrix. Psychol Bull, 1959. 56(2): p. 81-105.

30. Thabet, A.A., D. Stretch, and P. Vostanis, Child mental health problems in Arab children: application of the strengths and difficulties questionnaire. Int J Soc Psychiatry, 2000. 46(4): p. 266-80.

31. El-Keshky, M. and M. Emam, Emotional and behavioural difficulties in children referred for learning disabilities from two Arab countries: A cross-cultural examination of the Strengths and Difficulties Questionnaire. Res Dev Disabil, 2015. 36C: p. 459-469.

32. Kim, H.Y. and C. Tubbs Dolan, SERAIS: Social Emotional Response and Information Scenarios Evidence on Construct Validity, Measurement Invariance, and Reliability in use with Syrian Refugee Children in Lebanon. 2019, New York University: New York.

33. Weissman, M.M., H. Orvaschel, and N. Padian, Children's symptom and social functioning self-report scales. Comparison of mothers' and children's reports. J Nerv Ment Dis, 1980. 168(12): p. 736-40.

34. Leeflang, M.M., P.M. Bossuyt, and L. Irwig, Diagnostic test accuracy may vary with prevalence: implications for evidence-based diagnosis. J Clin Epidemiol, 2009. 62(1): p. 5-12.

35. Leeflang, M.M., et al., Variation of a test's sensitivity and specificity with disease prevalence. CMAJ, 2013. 185(11): p. E537-44. 


\section{PROCEDURE FOR THE TRANSLATION OF PSYCHOMETRIC MEASURES}

\section{Table of Contents}

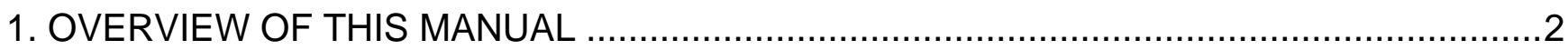

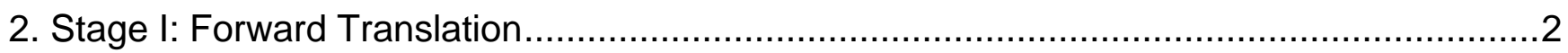

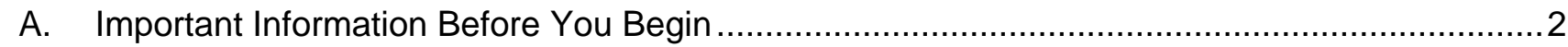

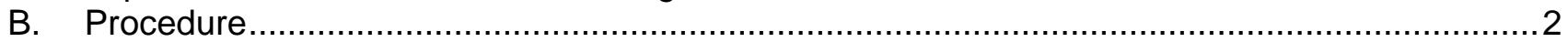

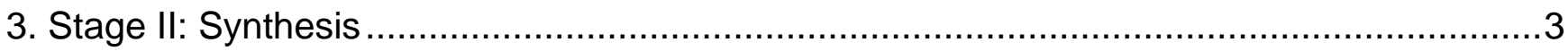

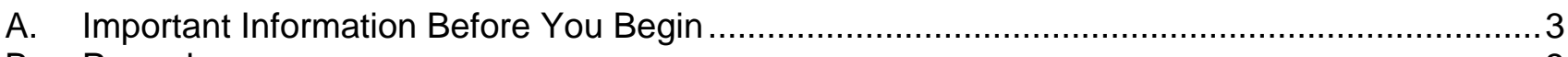

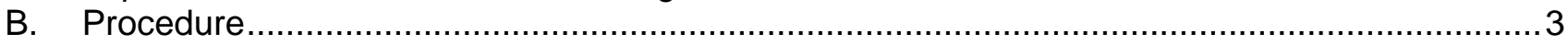

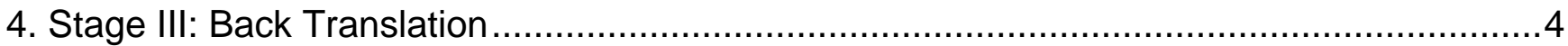

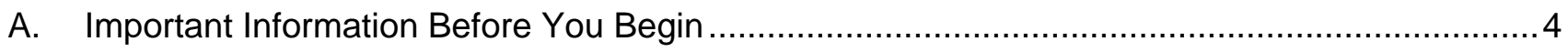

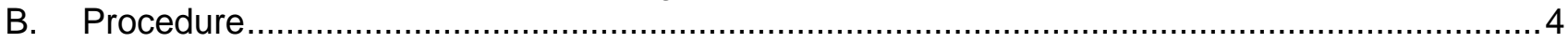

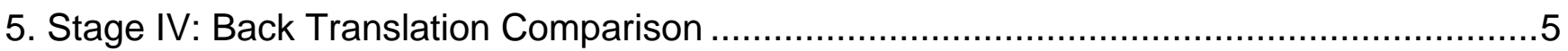

A. Important Information Before You Begin ........................................................................

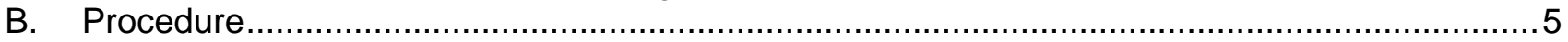

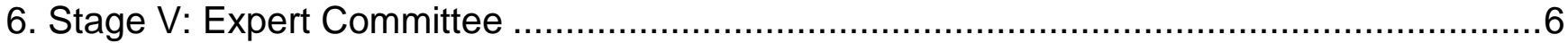

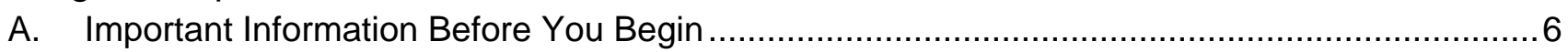

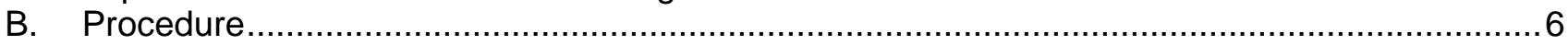

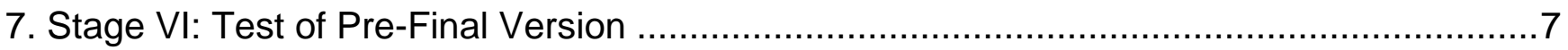

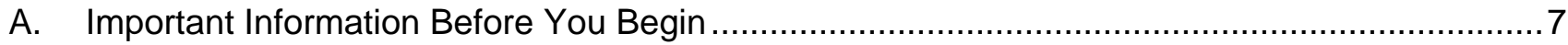

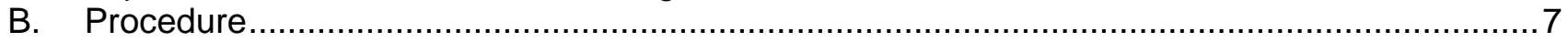

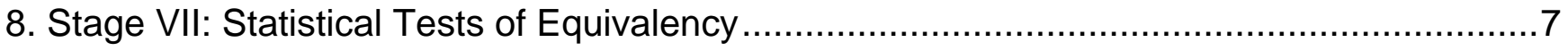

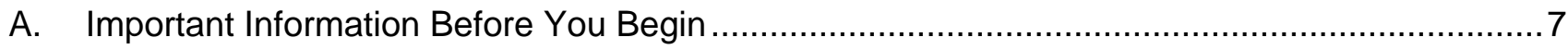

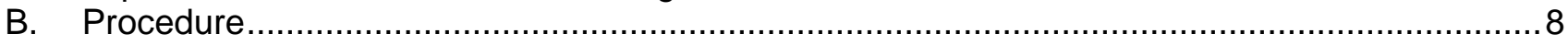

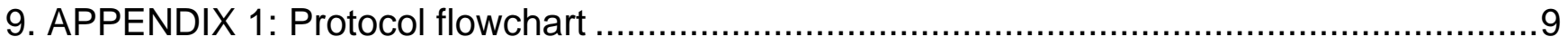

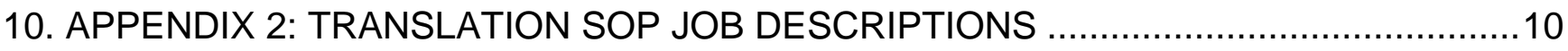

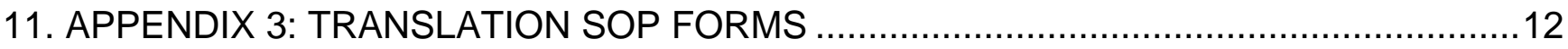




\section{OVERVIEW OF THIS MANUAL}

The purpose of this manual is to standardize the procedure of translating psychometric measures from English into Arabic. Throughout the entire translation process the "source language" is English and the "target language" is Arabic. This protocol has been established to produce measures that can assess a different target population than the population the measure was developed for. The measures to be translated are established measures used in the psychological field. All measures were developed in English and deemed valid. Throughout the entire translation process the original English measures will be referred to as the "Original Measure."

Supplementary Documents: Two supplementary documents should be used alongside this Protocol: "Translation SOP Job Descriptions" and "Translation SOP Forms." For a detailed description of each role throughout the translation process see "Translation SOP Job Descriptions." For the supplementary forms to be completed during the first five stages see, "Translation SOP Forms."

\section{Stage I: Forward Translation}

\section{A. Important Information Before You Begin}

Two translators will perform the forward translation. Translators will be fluent in both English and Arabic, but their dominant language must be Arabic.

Each translator will be assigned an ID. Translators will be assigned "Translator One" or "Translator Two" at random-there is no difference between the labels.

Translators will conduct their translations independently and should not confer on their translations.

Translators will use the provided "Form A: Stage I: Forward Translation" (translators will receive the forms from the London Team) throughout the entire forward translation. All forms should be completed electronically.

Translators should ensure that the entire form has been filled per each item; including "Measure Name" "Translator ID" "Item Number" and "Date." The measure name is the name of the entire questionnaire being translated, the Translator ID will be the assigned ID given to each translator, the "Item number" is the corresponding number of the item found on the Original Measure, and the "Date" is the date on which the translation occurred.

Translators will be translating the Original Measure from English into Arabic. Throughout the entire Forward Translation process, all items will come from the Original Measure.

\section{B. Procedure}

1. Using the "Form A: Stage I: Forward Translation", provided from the London Teamtranslators will translate the English item from Box One into Arabic. Translators will record their final Arabic translation in Box Two. 
2. Translators should record any questions or concerns about the translated item in Box Three. Translators should make note of any difficult words or phrases they encountered.

3. Translators will repeat this process until all items on the measure have been translated.

4. Translators will then send all completed electronic forms to either the Study Coordinator or the Field Work Coordinator

\section{Stage II: Synthesis}

\section{A. Important Information Before You Begin}

The purpose of this stage is to combine the two translations formed in Stage II into one comprehensive translated measure. Translator One, Translator Two, and a third, unbiased person will create a synthesized and completed translation based on the translations produced in Stage II. This third party must be fluent in both Arabic and English, preferably with Arabic as their native language.

The role of the third party person is to collaborate with both Translator One and Translator Two while providing an unbiased opinion.

Translator One and Translator Two will bring all completed forms from Stage I for each item on each measure.

Translators will use "Form B: Stage II: Synthesis of Translations" (translators will receive the forms from the London Team) throughout the entire synthesis stage. All forms should be completed electronically.

Translators should ensure that the entire form has been filled per each item, including "Measure Name" "Name" "Item Number" and "Date." The measure name is the name of the entire questionnaire being translated, "Name" is the names of all parties involved in this stage, the "Item Number" is number of the item found on the Original Measure, and the "Date" is the date on which the synthesis occurred.

\section{B. Procedure}

1. Using "Form B: Stage II: Synthesis of Translations" provided from the London Team, Translator One, Translator Two, and the third party will compare the translations until they've agreed on one sound translation per each item. The synthesized translation will be placed into Box Three.

2. If there is a disagreement on an item, translators will consult the comments section of each of their "Form A: Stage I: Forward Translation" to show the rationale behind their translation choice.

3. Translators and the third party will record any/all comments and concerns into the fourth "Comments" box. 
4. This process will be completed until every item on every measure has been successfully synthesized.

5. When all items from one measure have successfully been synthesized, the Translators and the Third Party will combine all synthesized items into one document to form the "Synthesized Translation: Translation Three."

6. Translators will then send all completed electronic forms to either the Study Coordinator or the Field Work Coordinator

\section{Stage III: Back Translation}

\section{A. Important Information Before You Begin}

Two new translators will translate the "Synthesized Translation: Translation Three" from Arabic back into English. Translators must be fluent in both Arabic and English. Both translators will be blind to the Original Measure.

Translators will be assigned an ID as either "Translator Three" or "Translator Four" at random-there is no difference between the labels.

Translators will conduct their translations independently and should not confer on their translations.

Translators will use "Form C: Stage III: Back Translation" (translators will receive the forms from the London Team) throughout the entire back-translation. All forms should be completed electronically.

Translators should ensure that the entire form has been filled per each item; including "Measure Name," "Translator ID," "Item Number," and "Date." The measure name is the name of the entire questionnaire being translated, the "Translator ID" will be the assigned ID given to each translator, the "Item number" is number of the item found on the Original Measure being translated, and the "Date" is the date on which the translation occurred.

Translators will be translating the "Synthesized Translation" produced in Stage II from Arabic into English. Throughout the entire Back Translation process, all items will come from the "Synthesized Translation."

\section{B. Procedure}

1. Using "Form C: Stage III: Back Translation" provided from the London Team, translators will translate the Arabic item from Box One into English. Translators will record their final English translation in Box Two.

2. Translators should record any questions or concerns about the translated item in Box Three. Translators should make note of any difficult words or phrases they encountered.

3. Translators will repeat this process until all items on the measure have been translated. 
4. Translators will then send all completed electronic forms to either the Study Coordinator or the Field Work Coordinator

\section{Stage IV: Back Translation Comparison}

\section{A. Important Information Before You Begin}

The aim of this stage is to compare the two back translated versions to the Original Measure to see if they are linguistically equal. Translator Three, Translator Four, and the third unbiased party will review the back-translated versions and compare them to the Original Measure. Often times, even if the translations are linguistically correct, they may not have the same meaning in the target culture; translators should be aware of this.

Translator Three and Translator Four will bring all completed forms from Stage III for each item on each measure.

Translators will use "Form D: Stage IV: Back Translation Comparison" (translators will receive the forms from the London Team) throughout the entire Back Translation Comparison process. All forms should be completed electronically.

Translators should ensure that the entire form has been filled per each item, including "Measure Name," "Name," "Item Number," and "Date." The measure name is the name of the entire questionnaire being translated, the "Name" is the names of all parties involved in this stage, the "Item Number" is number of the item found on the Original Measure and the "Date" is the date on which this comparison occurred.

The Translators and the third party will be working from the two back-translated measures formed in Stage III as well as the Original Measure. If any discrepancies are found then the Translators and third party may need to consult the "Synthesized Translation: Translation Three" formed in Stage II.

\section{B. Procedure}

1. Using "Form D: Stage IV: Back Translation Comparison" provided from the London Team, Translator Three, Translator Four, and the Third Party will compare the two back-translations to the Original Measure.

2. If there are discrepancies between the back-translations and the original item then the reason for this should be explored. A change in meaning could have arisen during the forward or back-translation process. Translators should record any questions or concerns about the translated item in Box Four. Translators should make note of any difficult words or phrases they encountered.

3. If any changes are made to the "Synthesized Translation: Translation Three" then the new version of the item must be recorded in Box Five "Translation Four: Arabic Version". (All items in Box Five will be in Arabic). Although it is important to be culturally and linguistically correct, translators should not be too quick to alter the measure much for fear of losing validity. 
4. When all items from one measure have successfully been compared and deemed appropriate and accurate, the Translators and the Third Party will combine all Arabic items into one document to form "Translation Four."

5. Translators will then send all completed electronic forms to either the Study Coordinator or the Field Work Coordinator

\section{Stage V: Expert Committee}

\section{A. Important Information Before You Begin}

The aim of the expert committee is to ensure that the translated measure is not only linguistically accurate, but culturally relevant and psychologically accurate as well. The committee will be comprised of the field work coordinator (who is likely to be the Third Party) and 3-4 experts. The committee will have access to all versions and all records throughout the entire translation procedure-if they're inclined to see them. The committee will focus on the Original Measure and "Translation Four," the latest translation. Each member of the committee needs to be fluent in both Arabic and English and familiar with each culture.

The committee will use "Form E: Stage V: Expert Committee" (see the attached "Translation Protocol Forms: Form E") to keep a record of their work. It is not necessary for every member of the committee to fill out his or her own individual form. One record per each item is sufficient for the entire group. The group may elect one individual to fill out the forms while the meeting proceeds. All forms should be completed electronically.

The recorder will ensure that the entire form is filled out per each item, including "Measure Name," "Name," "Item Number," and "Date." The measure name is the name of the entire questionnaire being translated, the "Name" is all the names of the parties involved at this stage, the "Item Number" is number of the item found on the Original Measure and the "Date" is the date on which this committee meeting occurred.

\section{B. Procedure}

1. Using "Form E: Stage V: Expert Committee" provided from the London Team the committee will begin the review process. It will be the job of the committee to compare the Original Item to the Translated Item. The committee will look for any discrepancies in the language, look for any non-equivalent items, ensure that the translated measure is culturally relevant for the target population, and that the measure is valid.

2. The committee will discuss each individual item to ensure that all of these qualifications are met. The checklist on the form will guide this discussion.

3. If there are any disagreements in the items then the committee can consult the previous forms used throughout the translation process to understand the rationale of the choice behind the translations and to provide clarity. 
4. The recorder should record any questions or concerns about the translated item in Box Three. Recorders should make note of any difficult words or phrases they encountered.

5. If the committee feels the need to change anything in the translated item they should record the new item, in Arabic, in Box Four.

6. When all items from one measure have successfully been assessed, the committee will combine all Arabic items into one document to form the "Pre-Final translation: Translation Five."

\section{Stage VI: Test of Pre-Final Version}

\section{A. Important Information Before You Begin}

The purpose of this stage is to test the translated measures with the target population in order to receive feedback about the measures.

\section{B. Procedure}

1. Project coordinators will recruit members of the target population to take the "Pre-Final Translation: Translation Five." The target population is 30-40 Syrian Refugees.

2. Project coordinators will administer the test in the same manner as they would in real data collection.

3. After the tests are completed by the participants, the test administers will ask the participants for feedback on the measures. Asking particularly for things that they didn't understand or if there were any cultural inequalities. Test administers must keep a record of all feedback given by the participants.

4. Test administers should continuously take notes throughout the test session, noting any reactions to the measures, noting what went well and what didn't, and looking for possible confounding factors.

5. After the test sessions conclude, test administers should evaluate the feedback received.

\section{Stage VII: Statistical Tests of Equivalency}

\section{A. Important Information Before You Begin}

The purpose of this stage is to run varying statistical analyses, depending on the measure itself, to ensure that the translated measure is valid.

Just because the Original Measure was valid does not mean that the translated measure will be. 
B. Procedure

1. Identify the proper statistical test needed to calculate validity for each measure.

2. Once the proper test has been identified, run the statistical analyses.

3. Determine, based on the results of the statistical analyses, whether the translated measure is valid.

4. If the measure is not valid then the expert committee shall be notified and shall discuss proper changes to be made to ensure validity.

5. Feedback gathered during Stage VI and results of statistical analysis from Stage VII of the "Pre-Final Measure: Measure Five" should be collated. This should be used to inform any further changes, resulting in a final measure "Translation Six."

6. If necessary, a final review can be carried out by members of the Expert Committee to confirm that any changes are appropriate. 


\section{APPENDIX 1: Protocol flowchart}

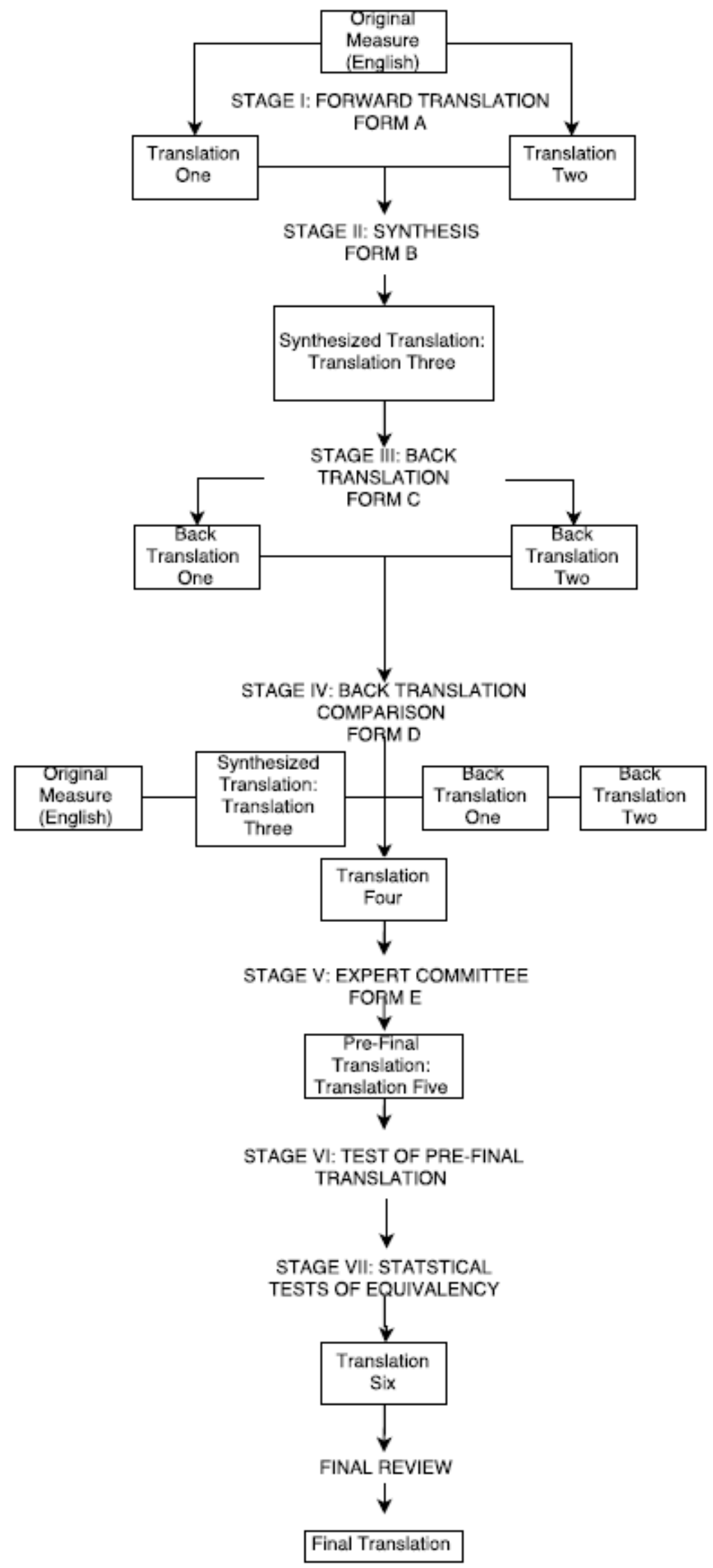




\section{APPENDIX 2: TRANSLATION SOP JOB DESCRIPTIONS}

\section{Translator One and Translator Two:}

- Translator One and Two will be students recruited from the American University of Beirut

- Translators will be selected based on their qualifications and availability

- Translators must be fluent in both English and Arabic, with their dominant language being Arabic

- Translators should be familiar with both cultures

- Translator One and Two's main role is Forward Translation; to translate Original Measures from English into Arabic

- Translators will also participate in producing a synthesized translation based off the combination of Translator One and Translator Two's work.

\section{Translator Three and Translator Four:}

- Translator Three and Translator Four will be students recruited from the American University of Beirut

- Translators will be selected based on their qualifications and availability

- Translators must be fluent in both English and Arabic

- Translators should be familiar with both cultures

- Translator Three and Four's main role is Back-Translation; to translate "Synthesized Translation: Translation Three" from Arabic into English

- Translator Three and Translator Four will also participant in the comparison of their back-translated measures to the Original Measure and the Synthesized Measure

\section{Third Party Individual:}

- It is likely that this individual will be the Field Work Coordinator, but may be another individual if deemed more appropriate

- This Third Party must be fluent in both Arabic and English

- The Third Party should be familiar with both cultures

- The Third Party's role is to act as mediator in both Stage II and Stage IV and to participate in the Expert Committee 
- The Third Party shall work with Translator One and Translator Two in Stage II to help combine Translator One and Translator Two's Forward Translation into one comprehensive synthesized translation

- The Third Party shall work with Translator Three and Translator Four in Stage IV to help compare Translator Three and Translator Four's Back-Translated Measures to the Original Measure to see if they are equivalent. If they are not, then it is the job of the Third Party to work with Translator Three and Translator Four to make the translated measures equivalent to the Original Measure; they will make any changes to the "Synthesized Translation: Translation Three" that they see fit and any changes they perform will be compiled into one final translation "Translation Four"

- The Third Party shall also participate in the "Expert Committee." As the Third Party partook in both Stage II and Stage IV; the Third Party shall be a representative of all Translators throughout the process

\section{Expert Committee:}

- The Expert Committee will be comprised of the Field Work Coordinator, the Third Party (only if the Field Work Coordinator is not acting as the Third Party), and at least three experts on the field of study

- Their task is to review the latest translated version, "Translation Four." The committee should ensure that the translation is not only linguistically equivalent, but psychologically, and culturally equivalent as well

- One person on the committee will be elected as recorder to take notes throughout the meeting and track any changes made

- All changes made will be compiled into one Pre-Final translation "Translation Five" 


\section{APPENDIX 3: TRANSLATION SOP FORMS}

\section{Table of Contents}

Form A: Stage I: Forward Translation 2

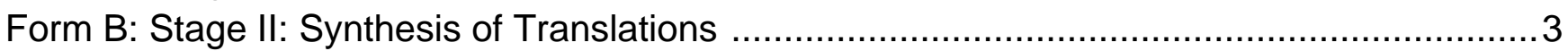

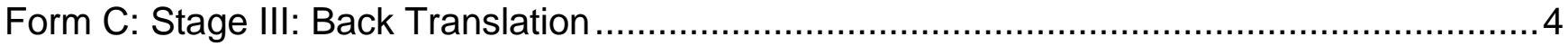

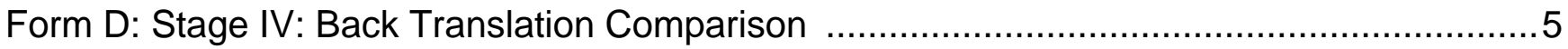

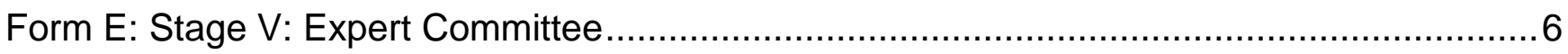




\section{Form A: Stage I: Forward Translation}

\section{Measure Name:}

\section{Translator ID:}

\section{Date:}

Item Number:

Box One: Source Language (English): Insert item from Original Measure below:

Box Two: Target Language (Arabic): Insert your translation below:

Box Three: Comments: State any questions or concerns you may have with this item below:

Item Number:

Box One: Source Language (English): Insert item from Original Measure below:

Box Two: Target Language (Arabic): Insert your translation below:

Box Three: Comments: State any questions or concerns you may have with this item below:

Item Number:

Box One: Source Language (English): Insert item from Original Measure below:

Box Two: Target Language (Arabic): Insert your translation below:

Box Three: Comments: State any questions or concerns you may have with this item below: 


\section{Form B: Stage II: Synthesis of Translations}

\section{Measure Name:}

\section{Translator ID:}

\section{Date:}

Item Number:

Box One: Translation One: Insert Translator One’s translation below:

Box Two: Translation Two: Insert Translator Two's translation below:

Box Three: Synthesis Translation: Insert the synthesized translation below:

Box Four: Comments: State any questions or concerns you may have with this item below:

Item Number:

Box One: Translation One: Insert Translator One's translation below:

Box Two: Translation Two: Insert Translator Two's translation below:

Box Three: Synthesis Translation: Insert the synthesized translation below:

Box Four: Comments: State any questions or concerns you may have with this item below: 


\section{Form C: Stage III: Back Translation}

\section{Measure Name:}

\section{Translator ID:}

\section{Date:}

Item Number:

Box One: Synthesis Translation (Arabic): Insert item from "Synthesized Translation: Translation Three" below:

Box Two: Source Language (English): Insert your translation below:

Box Three: Comments: State any questions or concerns you may have with this item below:

Item Number:

Box One: Synthesis Translation (Arabic): Insert item from "Synthesized Translation: Translation Three" below:

Box Two: Source Language (English): Insert your translation below:

Box Three: Comments: State any questions or concerns you may have with this item below: 


\title{
Form D: Stage IV: Back Translation Comparison
}

\section{Measure Name:}

\section{Translator ID:}

\section{Date:}

Item Number:

Box One: Back-Translation One (English): Insert Translator Three's back-translation below:

Box Two: Back-Translation Two (English): Insert Translator Four's back-translation below:

Box Three: Original Item (English): Insert the item from the Original Measure below:

Box Four: Comments: State any questions or concerns you may have with this item below:

Box Five: Translation Four: Arabic Version: Track any changes made during the backtranslation process below:

\author{
Item Number: \\ Box One: Back-Translation One (English): Insert Translator Three's back-translation below: \\ Box Two: Back-Translation Two (English): Insert Translator Four's back-translation below: \\ Box Three: Original Item (English): Insert the item from the Original Measure below: \\ Box Four: Comments: State any questions or concerns you may have with this item below: \\ Box Five: Translation Four: Arabic Version: Track any changes made during the back- \\ translation process below:
}




\section{Form E: Stage V: Expert Committee}

\section{Measure Name:}

\section{Translator ID:}

\section{Date:}

\begin{tabular}{|l|}
\hline Item Number: \\
\hline $\begin{array}{l}\text { Box One: Source Language (English): Insert item from the Original Measure } \\
\text { below: }\end{array}$ \\
\hline Box Two: Target Language (Arabic): Insert item from "Translation Four" below: \\
\hline $\begin{array}{l}\text { Box Three: Comments: State any questions or concerns you may have with this } \\
\text { item below: }\end{array}$
\end{tabular}
item below:

Box Four: Translation Five: Arabic Version: Track any changes made during expert committee below:

Linguistically accurate $\square$ Culturally relevant/accurate $\square$ Psychologically accurate 


\section{Clinical Global Impression - severity (CGI-s) scoring sheet}

\begin{tabular}{|l|l|l|}
\hline ID: & Age: & Gender: \\
\hline
\end{tabular}

Enter MINI KID diagnoses:

\section{Guidelines for questions}

These questions can be used if there is not already sufficient information from the clinical interview. They are suggested probes to gain sufficient information to assign a code; it is not necessary to use all questions and they should be adapted based on knowledge that the interviewer already has about the child.

\section{Questions for Children}

- Earlier, you told me about XXX [describe any impairment noted during the MINI KID]. Can you give me an example of XXX?

- $\quad$ Can you describe how frequent this XXX is? How many days out of this week? Out of this month?

- $\quad$ Can you tell me the feelings you get when you get $X X X$ ?

- What are the incidents that trigger this XXX?

- Can you think of any reason why this is happening to you?

- Do you know when this XXX started happening to you? Can you put a certain date of when this all started?

- With whom does this XXX happen the most?

- When does this XXX happen the most?

- Can you tell me what do you feel before this XXX starts? During this XXX and after this XXX is done?

- Can you describe the thoughts that you get when this XXX happen? Before? During? After?

- How did this affect your overall functioning?

- How did this affect your relationships? With your family? Parents? Siblings? Neighbours? Classmates? Friends? School Friends? Teachers? Work colleagues?

- How has this XXX been affecting your emotions/feelings (are you frustrated, sad, angry about it)?

- When this XXX happens, what does it impact as well? Do you feel that other things are influenced by your XXX? Are there things that you can't or won't do because of XXX? Give me examples.

\section{Questions for Caregivers}

- Earlier, you/your child told me about XXX [describe any impairment noted during the MINI KID]. How does XXX show on your kid?

- How do you know that this XXX is impacting his/her daily life?

- Does XXX occur in any specific time? Place? Context? With any specific person?

- How long does this XXX last? based on hours? days? weeks? Months?

- Is there anything that your kid can't do because of XXX?

- When did this XXX happen for the first time? Can you remember when was the first time that this XXX started happening?

- What do you usually do when this XXX happens with your kid?

- How does this XXX that your kid is going through affect you? the family? siblings? (list any members that the kid lives with, any other caregiver if not parent)

- Is there anything that your family can't do because of XXX? Is there anything that you do differently because of XXX?

- How does this XXX affect your kid's relationships: with his/her siblings? with his/her friends? in school? with his/her teacher? with his/her schoolmates? with his/her neighbours? with his/her community and neighbourhood friends? with his/her community and neighbourhood leaders/people/neighbours?

- Can you remember a time when this XXX did not happen with your kid? When was it? Can you explain what the potential trigger could be?

- How does this XXX affect his/her emotions? his/her behaviors? his/her attitudes and thoughts towards him/herself?

- Have you done anything to treat this XXX with your kid? did anything that you did or that your kid did help with easing this XXX or solving bits of it? 


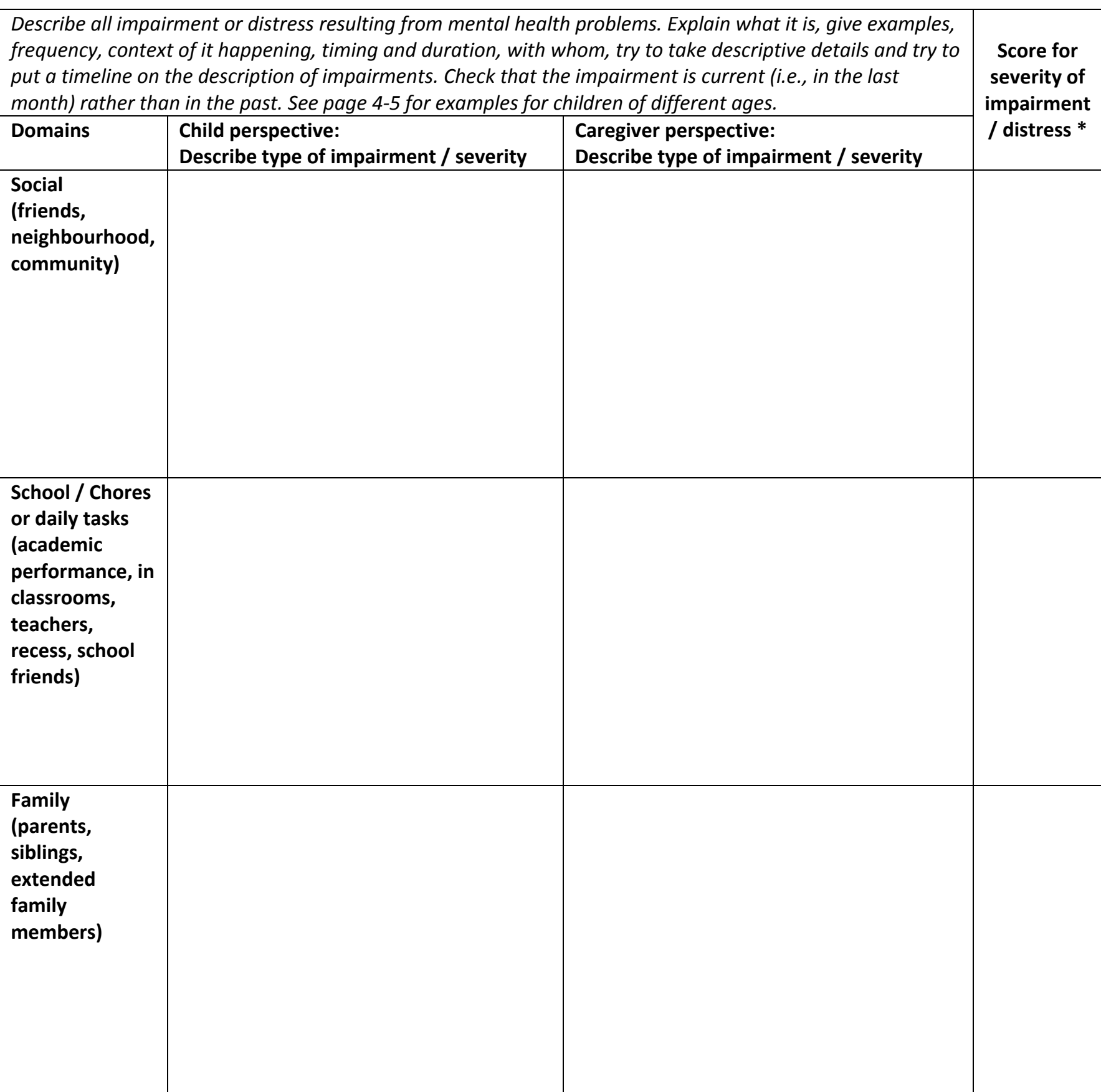

* Rate according to frequency (based on 1 month timeline) AND/OR intensity:

0-None: No impairments in this domain.

1-Mild: Several days a month, minimal impairment. Can still perform most activities.

2-Moderate: More than half the days in a month, OR less than half the days but definite impairment. Prevents some normal activities of child, but minimal disruption to family life.

3-Severe: Most of the days in a month with definite impairment (prevents some normal activities of child), OR more than half the days in a month but severe impairment (prevents normal activities of child and/or family have to go to significant lengths to accommodate).

Use the CGI-s flowchart on page 3 and clinical judgement to guide assignment of a summary score:

\begin{tabular}{|l|l|}
\hline CGI-s score: & Rationale: \\
& \\
\hline
\end{tabular}




\section{CGI-s Flowchart}

This flowchart should be used to aid the assignment of a CGI-s score, but does not replace clinical judgement. It is recommended that the CGI-s score is reviewed during clinical supervision and a consensus decision made.

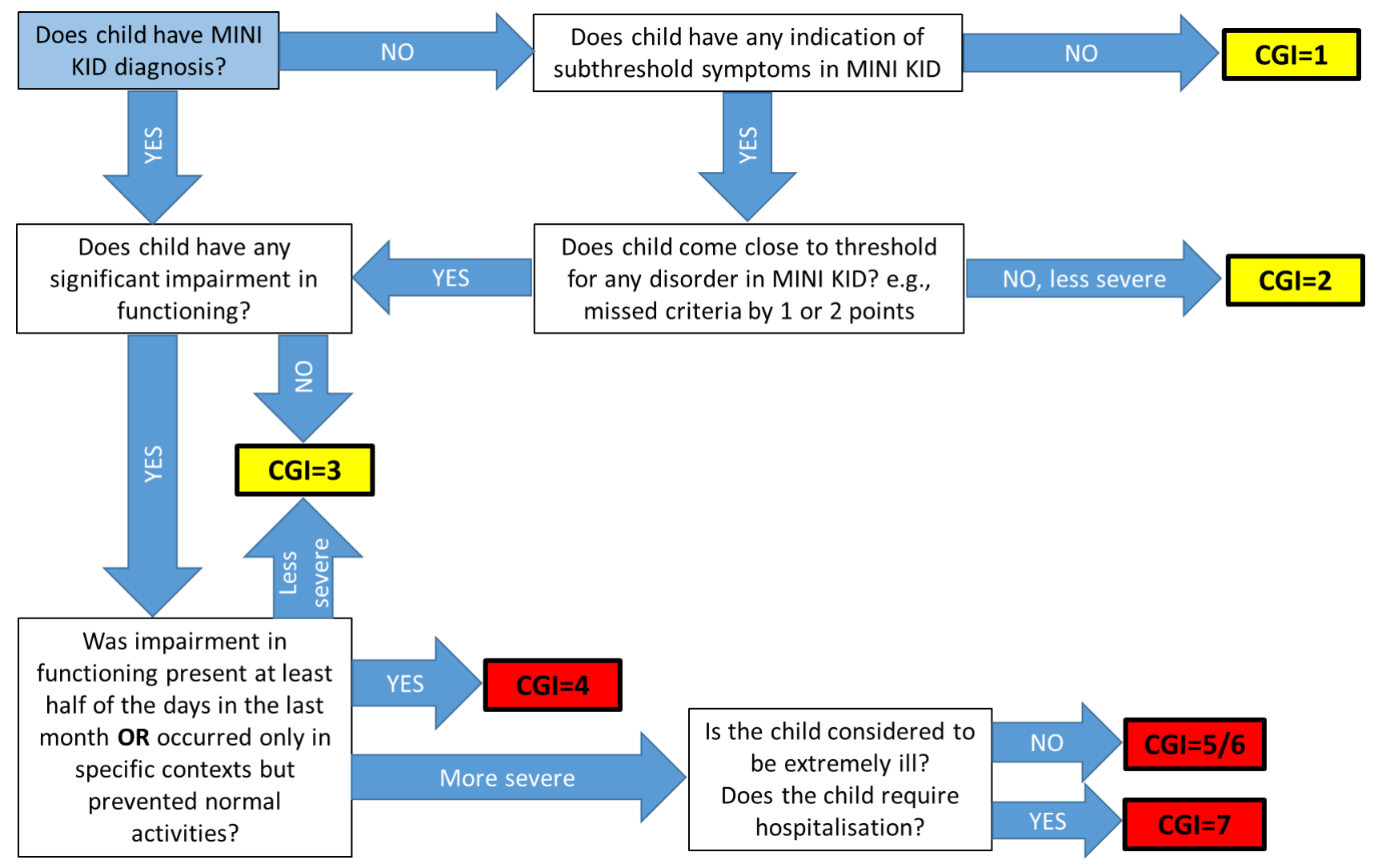


Examples of impairment to functioning in each age range

\begin{tabular}{|c|c|c|c|}
\hline Domain & 8-10 years & $11-13$ years & $14-17$ years \\
\hline $\begin{array}{l}\text { Social } \\
\text { (friends, } \\
\text { neighbourhood, } \\
\text { community) }\end{array}$ & $\begin{array}{l}\text { Isolation. Hypersensitivity and } \\
\text { irritability, e.g., crying all the } \\
\text { time. Aggressive behaviour, e.g., } \\
\text { hitting, shouting, irritability, } \\
\text { outbursts. Fighting with friends. } \\
\text { Bullying. Vandalism. }\end{array}$ & $\begin{array}{l}\text { Not participating in any social } \\
\text { groups, no interest in social } \\
\text { groups or cliques. Not being part } \\
\text { of friends. Lack of enthusiasm to } \\
\text { play with children. Isolation. } \\
\text { Staying at home and not going } \\
\text { out. Avoiding community } \\
\text { gatherings. Bullying other kids. } \\
\text { Vandalizing street, properties, } \\
\text { cars, etc. }\end{array}$ & $\begin{array}{l}\text { Defying authority (police, } \\
\text { community leaders, key actors, } \\
\text { etc.). Actively seeks to defy } \\
\text { rules, community leaders, laws. } \\
\text { Antisocial behaviour (aggressive } \\
\text { towards others, provokes fights, } \\
\text { vandalism: damage or } \\
\text { destruction of properties, theft). } \\
\text { Altercation with police. } \\
\text { Vindictive behaviour (actively } \\
\text { seeks to take revenge). Social } \\
\text { and community withdrawal: not } \\
\text { socializing with neighbourhood } \\
\text { friends, community members. }\end{array}$ \\
\hline $\begin{array}{l}\text { School / Chores } \\
\text { or daily tasks } \\
\text { (academic } \\
\text { performance, in } \\
\text { classrooms, } \\
\text { teachers, } \\
\text { recess, school } \\
\text { friends) }\end{array}$ & $\begin{array}{l}\text { Not participating in class. Crying. } \\
\text { Avoidance of recess. Sitting } \\
\text { alone during recess. Consecutive } \\
\text { absences from class. Fatigue. } \\
\text { Violence towards superiors at } \\
\text { school. School anxiety before } \\
\text { exams or homework, or anxiety } \\
\text { about chores or other } \\
\text { responsibility at home. Scared } \\
\text { of facing kids at school, } \\
\text { participating in events. Theft } \\
\text { from classmates from school } \\
\text { properties (classroom). } \\
\text { Repeated absences and } \\
\text { sicknesses (if any physical } \\
\text { causes are ruled out). }\end{array}$ & $\begin{array}{l}\text { Does not have friends (or rarely } \\
\text { have one regular friend). Sits } \\
\text { alone in recess. Sits alone in } \\
\text { classroom. Does not participate } \\
\text { in class. Does not concentrate } \\
\text { on lesson. Is unable to finish } \\
\text { homeworks/know how to do } \\
\text { homeworks or does not write } \\
\text { down homework. Is unable to } \\
\text { finish daily tasks related to his } \\
\text { age range (finish chores, house } \\
\text { tasks, study by him/herself). } \\
\text { Poor memory performance } \\
\text { (forgetful or unable to } \\
\text { memorize lessons). Opposing } \\
\text { and defiant behavior with } \\
\text { teachers in the classroom. } \\
\text { Vandalism of classroom or other } \\
\text { properties (household } \\
\text { properties, school properties). } \\
\text { Temper tantrums. Theft from } \\
\text { classmates from school } \\
\text { properties (classroom). }\end{array}$ & $\begin{array}{l}\text { Defiance and oppositional } \\
\text { conduct with authorative figures } \\
\text { (teachers, principals, etc.). Non- } \\
\text { attendance of classes. } \\
\text { Intimidation of classmates. } \\
\text { Defiance of superiors. Bullying. } \\
\text { Aggressive outbursts. Learning } \\
\text { difficulties (lack of } \\
\text { concentration, daydreaming, } \\
\text { phased, attention deficit, } \\
\text { jumping from one topic to } \\
\text { another, difficulty memorizing). } \\
\text { Theft from classmates from } \\
\text { school properties (classroom). } \\
\text { Repeated absences and } \\
\text { sicknesses (if any physical } \\
\text { causes are ruled out). Overall } \\
\text { isolation and social withdrawal: } \\
\text { Not socializing during recess. } \\
\text { Sitting alone in class. (Isolation } \\
\text { and avoidance of social contexts } \\
\text { in school, not participating in } \\
\text { activities, refusing to be part of } \\
\text { any social gathering or activity, } \\
\text { etc.). Withdrawal at home. Not } \\
\text { participating in chores. Lying } \\
\text { around all day long. Isolating } \\
\text { him/herself in his/her room. } \\
\text { Being in constant irritability and } \\
\text { distress. }\end{array}$ \\
\hline $\begin{array}{l}\text { Family } \\
\text { (parents, } \\
\text { siblings, } \\
\text { extended } \\
\text { family } \\
\text { members) }\end{array}$ & $\begin{array}{l}\text { Fighting with siblings. Physical } \\
\text { violence towards siblings. } \\
\text { Blunted affects. Areactive. } \\
\text { Isolated. Cries a lot. Angry } \\
\text { outbursts. Irritability. Isolation } \\
\text { from the rest of the family } \\
\text { members. Theft from } \\
\text { household, parents, extended } \\
\text { family members or siblings. } \\
\text { Enuresis (Diurnal or Nocturnal, } \\
\text { state frequency) }\end{array}$ & $\begin{array}{l}\text { Sibling rivalry [only if extreme } \\
\text { and outside of normal range], } \\
\text { physical violence and aggressive } \\
\text { intent towards siblings, and/or } \\
\text { parents. Isolation during family } \\
\text { gatherings and occasions. } \\
\text { Withdrawal from familial } \\
\text { activities, sibling games. } \\
\text { Oppositional and defiant } \\
\text { conduct towards parents. } \\
\text { Vandalism of household } \\
\text { properties. Impulsive reactions }\end{array}$ & $\begin{array}{l}\text { Temper tantrums. Angry or } \\
\text { resentful. Irritable. Oppositional } \\
\text { and defiant conduct with family } \\
\text { members. Bullying behavior } \\
\text { towards others in the family. } \\
\text { Physically violent (damage or } \\
\text { destruction of household items } \\
\text { or/and family). Lack of } \\
\text { participation within the family } \\
\text { (not being interactive with the } \\
\text { family members, not talking } \\
\text { much with the siblings or } \\
\text { parents, preferring to stay by }\end{array}$ \\
\hline
\end{tabular}




\begin{tabular}{|l|l|l|l|}
\hline & & $\begin{array}{l}\text { of violence, angry outbursts, } \\
\text { temper tantrums. }\end{array}$ & $\begin{array}{l}\text { the side). Isolation and } \\
\text { withdrawal from any social } \\
\text { aspect within the family (staying } \\
\text { in his/her room, not going out of } \\
\text { the house). Irritability and } \\
\text { hypersensitivity: constantly } \\
\text { crying over the most minimal } \\
\text { things for example. Angry } \\
\text { outbursts. Abusive language } \\
\text { towards siblings. Abusive } \\
\text { language towards parents. } \\
\text { Isolation and/or withdrawal } \\
\text { from family events, gatherings } \\
\text { and/or outings. }\end{array}$ \\
\hline
\end{tabular}




\section{Appendix 3: Missing Data}

This appendix describes missing data for the following measures:

1. SCARED: Screen for Child Anxiety Related Emotional Disorders;

2. CES-DC: Center for Epidemiological Studies Depression Scale for Children;

3. CPSS: Child PTSD Symptom Scale;

4. SDQ: Strengths and Difficulties Questionnaire;

5. SDQ+EXT: Stengths and Difficulties Questionnaire externalising subscale +12 items aligned with DSM-5 Conduct Disorder and Oppositional Defiant Disorder ${ }^{1}$;

6. WHODAS Child: World Health Organisation Disability Assessment Schedule for Children (child and parent report versions)

Table A3.1 summarises missing data in the BIOPATH wave 2 sample. For the majority of measures (SCARED, CES-DC, CPSS, SDQ and SDQ+EXT) there is very little missing data with fewer than $2 \%$ of cases missing data for any single item in any of the scales. The small amount of missing data at item level precludes analysis of missing data patterns. The majority of children (>97\%) have complete data and in the small number of cases with missing data, there are typically only $1-2$ items missing. The number of missing items is not associated with gender or age for these measures. The number of missing items is associated with the total scale score for the SCARED and CPSS, such that those children with more missing items have a slightly higher symptom score. However, the effect size is small (rho<.08).

The WHODAS Child, both child and parent report version, have a greater amount of missing data (approx. $65 \%$ of cases are missing data); however, this is accounted for by the subscale on functioning at school and the fact that a minority of the cohort have access to school. If items relating to school are not considered, there is a very small amount of missing data ( $99 \%$ of cases have complete WHODAS data). Gender is not associated with missing data. Age is associated with missing data, with older children having a greater number of missing items. However, this is accounted for by access to school (older children are less likely to attend school) and because it is the school subscale that is missing. Repeating analyses separately in those who do and those who do not attend school shows that there is no significant association between age and missing items. WHODAS scores are lower in those with more missing items. The WHODAS global disability score is calculated from available subscales and expressed as \% of the total possible score, so correction for those who do not go to school is built into the measure. However, it is possible that those who do not go to school have fewer opportunities to show impairment because they are in a less structured environment with fewer formal demands on them. Repeating analyses separately in those who do and do not attend school shows that there is no association between WHODAS score and number of missing items in each group This suggests a group difference in WHODAS scores (not attending school < attending school) but not a linear relationship between impairment and missing data.

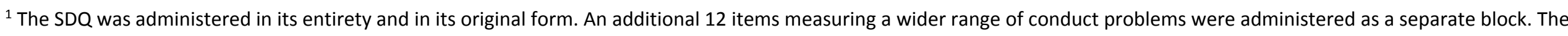
SDQ externalising subscale and the additional items were used together to determine their efficacy in predicting conduct problems. 
Table A3.1. Missing data summary for BIOPATH wave 2 sample ( $\mathrm{N}=1006$ with child-report data, $\mathrm{N}=995$ with parent-report data)

\begin{tabular}{|c|c|c|c|c|c|c|c|c|}
\hline \multirow[t]{2}{*}{ Measure } & \multirow{2}{*}{$\begin{array}{l}N \\
\text { items } \\
\text { in } \\
\text { scale }\end{array}$} & $\begin{array}{l}\text { Max. } \\
\text { missing } \\
\text { data for } \\
\text { any item } \\
\text { in scale }\end{array}$ & $\begin{array}{l}\text { Children } \\
\text { with } \\
\text { complete } \\
\text { data }\end{array}$ & $\begin{array}{l}\text { Children } \\
\text { with any } \\
\text { missing } \\
\text { data }\end{array}$ & $\begin{array}{l}\text { Max. } \\
\text { items } \\
\text { missing } \\
\text { for any } \\
\text { child }\end{array}$ & $\begin{array}{l}\text { Is gender associated with } \\
N \text { of missing items? }\end{array}$ & $\begin{array}{l}\text { Is age associated with } N \\
\text { of missing items? }\end{array}$ & $\begin{array}{l}\text { Is total score on scale }{ }^{A} \\
\text { associated with } N \text { of missing } \\
\text { items? }\end{array}$ \\
\hline & & $\begin{array}{l}N(\%) \\
\text { cases }\end{array}$ & $\begin{array}{l}N(\%) \\
\text { cases }\end{array}$ & $\begin{array}{l}N(\%) \\
\text { cases }\end{array}$ & $N$ items & $\begin{array}{c}\text { Mann-Whitney U } \\
\text { standardised test statistic }\end{array}$ & Spearman's rho & Spearman's rho \\
\hline SCARED & 18 & $12(1.2)$ & 976 (97.0) & $30(3.0)$ & 2 & $0.36, p=.719$ & $-.03, p=.382$ & $.07, p=.036$ \\
\hline CES-DC & 10 & $4(0.4)$ & 990 (98.4) & $16(1.5)$ & 2 & $0.73, p=.464$ & $-.01, p=.702$ & $-.04, p=.270$ \\
\hline CPSS & 18 & $5(0.5)$ & $980(97.4)$ & $25(2.5)$ & 7 & $1.64, p=.102$ & $.05, p=.128$ & $.08, p=.017$ \\
\hline$S D Q^{B}$ & 25 & $1(0.1)$ & 990 (99.5) & $5(0.5)$ & 2 & $1.21, p=.226$ & $.06, p=.072$ & $-.02, p=.491$ \\
\hline SDQ+EXT & 22 & $12(1.2)$ & $975(98.0)$ & $20(2.0)$ & 5 & $0.92, p=.356$ & $.12, p<.001^{D}$ & $.06, p=.063$ \\
\hline \multirow{2}{*}{$\begin{array}{l}\text { WHODAS } \\
\text { Child, child } \\
\text { report }\end{array}$} & \multirow[t]{2}{*}{25} & \multirow{2}{*}{$\begin{array}{c}632 \\
(62.8)\end{array}$} & $366(36.4)$ & $640(64.3)$ & \multirow[t]{2}{*}{14} & \multirow[t]{2}{*}{$0.13, p=.895$} & \multirow[t]{2}{*}{$.41, p<.001^{E}$} & \multirow[t]{2}{*}{$-.14, p<.001^{F}$} \\
\hline & & & $998(99.2)^{C}$ & $8(0.8)^{C}$ & & & & \\
\hline \multirow{2}{*}{$\begin{array}{l}\text { WHODAS } \\
\text { Child, parent } \\
\text { report }^{\text {B }}\end{array}$} & \multirow[t]{2}{*}{25} & \multirow{2}{*}{$\begin{array}{c}655 \\
(65.1)\end{array}$} & $344(34.6)$ & $651(65.4)$ & \multirow[t]{2}{*}{7} & \multirow[t]{2}{*}{$0.38, p=.706$} & \multirow[t]{2}{*}{$.37, p<.001^{G}$} & \multirow[t]{2}{*}{$-.09, p=.003^{H}$} \\
\hline & & & $987(99.2)^{C}$ & $8(0.8)^{C}$ & & & & \\
\hline
\end{tabular}

SCARED: Screen for Child Anxiety Related Emotional Disorders; CES-DC: Center for Epidemiological Studies Depression Scale for Children; CPSS: Child PTSD Symptom Scale; SDQ:

Strengths and Difficulties Questionnaire; SDQ+EXT: Stengths and Difficulties Questionnaire externalising subscale +12 items aligned with DSM-5 Conduct Disorder and Oppositional Defiant Disorder; WHODAS Child: World Health Organisation Disability Assessment Schedule for Children (child and parent report versions); CGI-S: Clinical Global Impression severity score. ${ }^{A}$ Total score corrected for missing data by replacing missing items (providing $<10 \%$ missing) with mean value. ${ }^{B}$ In 11 cases no parent / caregiver was available for interview; these were primarily cases where the young person had got married between baseline and follow up assessment and no longer lived with a primary caregiver. ${ }^{C}$ Excluding items relating to school. ${ }^{D}$ Accounted for by school attendance (access to school declines from age 12 years): school attendance=yes $(n=352)$, rho=.003, $p=.961$, school attendance $=n o(n=643), r h o=.03, p=.398 .{ }^{E}$ Accounted for by school attendance (access to school declines from age 12 years): school attendance=yes ( $n=373$ ), rho=.09, $p=.073$, school attendance=no $(n=633)$, rho=.05, $p=.218 .{ }^{F}$ Accounted for by school attendance (access to school declines from age 12 years): school attendance=yes ( $\left.n=372\right)$, rho $=-.01$, $\mathrm{p}=.890$, school attendance $=\mathrm{no}(\mathrm{n}=630)$, rho=-.05, $\mathrm{p}=.179 .{ }^{6}$ Accounted for by school attendance (access to school declines from age 12 years): school attendance=yes ( $\mathrm{n}=352$ ), rho $=.07, p=.193$, school attendance=no $(n=643)$, rho $=-.01, p=.876 .{ }^{~}$ Accounted for by school attendance (access to school declines from age 12 years): school attendance=yes $(n=352)$, rho $=.06, p=.265$, school attendance $=n o(n=641)$, rho $=-.03, p=.513$. 
Table A3.2 summarises missing data in the subsample of children with both questionnaire and clinical interview data. For the SCARED, CES-DC, SDQ and SDQ+EXT there was very little missing data with $2.5 \%$ or fewer cases missing data for any single item in any of the scales. The small amount of missing data at item level precludes analysis of missing data patterns. The majority of children (>93\%) have complete data and in the small number of cases with missing data, there are typically only 1-2 items missing. The CPSS had slightly more missing data, with approx. $10 \%$ of children having some missing data; again, most of these children were only missing 1 item. The number of missing items was not associated with gender or age for any of these measures. The number of missing items was not associated with total scale scores, other than for the SDQ+EXT, such that those children with more missing items have a slightly lower symptom score. This could be because parents of children with few conduct problems declined to answer some questions, or because of cultural sensitivity (e.g., around lying or stealing) parents declined to answer some questions as well as under-reporting on other questions. However, there were only 8 children with missing data who were each missing only one item, so it is hard to draw firm conclusions based on the very small amount of missing data. The number of missing items was not associated with diagnosis of a related disorder (e.g., missing data on the SCARED was not related to diagnosis of any anxiety disorder) nor with the severity of mental disorder as quantified using the Clinical Global Impression severity (CGI-s) score, which took into account the degree of functional impairment and distress.

The WHODAS Child, both child and parent report version, have a greater amount of missing data (approx. $44 \%$ of cases are missing data); however, this is accounted for by the subscale on functioning at school and the fact that only some children had access to school. If items relating to school are not considered, there is a very small amount of missing data (>98\% of cases have complete WHODAS data). Gender is not associated with missing data. Age is associated with missing data, with older children having a greater number of missing items. However, this is accounted for by access to school (older children are less likely to attend school) and because it is the school subscale that is missing. Repeating analyses separately in those who do and those who do not attend school shows that there is no significant association between age and missing items. There is no association between number of missing items and WHODAS scores; note that this differs from the result seen in the BIOPATH data (see Table A3.1). There is also no assocation with a diagnosis of any disorder nor with severity of mental disorder quantified using the CGI-s score. 
Table A3.2. Missing data summary for subsample questionnaire data and MINI KID clinical interview + consensus diagnosis data ( $N=119)$

\begin{tabular}{|c|c|c|c|c|c|c|c|c|c|c|}
\hline \multirow[t]{2}{*}{ Measure } & \multirow[t]{2}{*}{$\begin{array}{c}N \\
\text { items } \\
\text { in } \\
\text { scale }\end{array}$} & $\begin{array}{l}\text { Max. } \\
\text { missing } \\
\text { data for } \\
\text { any item } \\
\text { in scale }\end{array}$ & $\begin{array}{l}\text { Children } \\
\text { with } \\
\text { complete } \\
\text { data }\end{array}$ & $\begin{array}{l}\text { Children } \\
\text { with any } \\
\text { missing } \\
\text { data }\end{array}$ & $\begin{array}{l}\text { Max. } \\
\text { items } \\
\text { missing } \\
\text { for any } \\
\text { child }\end{array}$ & $\begin{array}{c}\text { Is gender } \\
\text { associated } \\
\text { with } N \text { of } \\
\text { missing items? }\end{array}$ & $\begin{array}{l}\text { Is age } \\
\text { associated } \\
\text { with } N \text { of } \\
\text { missing } \\
\text { items? }\end{array}$ & $\begin{array}{l}\text { Is total score } \\
\text { on scale } \\
\text { associated } \\
\text { with } N \text { of } \\
\text { missing items? }\end{array}$ & $\begin{array}{l}\text { Is diagnosis of } \\
\text { relevant } \\
\text { disorder } \\
\text { associated with } \\
N \text { of missing } \\
\text { items? }\end{array}$ & $\begin{array}{l}\text { Is severity of } \\
\text { mental disorder } \\
\text { (CGI-s score) } \\
\text { associated with } \\
N \text { of missing } \\
\text { items? }\end{array}$ \\
\hline & & $\begin{array}{l}N(\%) \\
\text { cases }\end{array}$ & $\begin{array}{l}N(\%) \\
\text { cases }\end{array}$ & $\begin{array}{l}N(\%) \\
\text { cases }\end{array}$ & $N$ items & $\begin{array}{c}\text { Mann-Whitney } \\
\text { U standardised } \\
\text { test statistic }\end{array}$ & $\begin{array}{l}\text { Spearman's } \\
\text { rho }\end{array}$ & $\begin{array}{l}\text { Spearman's } \\
\text { rho }\end{array}$ & $\begin{array}{c}\text { Independent } \\
\text { samples Kruskal- } \\
\text { Wallis Test }\end{array}$ & $\begin{array}{l}\text { Spearman's } \\
\text { rho }\end{array}$ \\
\hline SCARED & 18 & $2(1.7)$ & 114 (95.8) & $5(4.2)$ & 3 & $-0.22, p=.824$ & $.12, p=.179$ & $-.07, p=.433$ & $3.11, p=.211$ & $-.08, p=.395$ \\
\hline CES-DC & 10 & $1(0.8)$ & 117 (98.3) & $2(1.7)$ & 1 & $1.56, p=.119$ & $.12, p=.197$ & $-.11, p=.248$ & $2.52, p=.283$ & $-.18, p=.055$ \\
\hline CPSS & 18 & $3(2.5)$ & 107 (89.9) & 12 (10.1) & 4 & $-0.24, p=.814$ & $.10, p=.260$ & $.05, p=.603$ & $0.05, p=.974$ & $-.02, p=.825$ \\
\hline SDQ & 25 & $2(1.7)$ & $112(94.1)$ & $7(5.9)$ & 1 & $-0.14, p=.891$ & $-.05, p=.590$ & $-.02, p=.870$ & $0.58, p=.747$ & $.05, p=.628$ \\
\hline SDQ+EXT & 22 & $3(2.5)$ & 111 (93.3) & $8(6.7)$ & 1 & $0.27, p=.787$ & $.16, p=.082$ & $-.20, p=.028$ & $1.77, p=.413$ & $.01, p=.921$ \\
\hline \multirow{2}{*}{$\begin{array}{l}\text { WHODAS } \\
\text { Child, child } \\
\text { report }\end{array}$} & \multirow[t]{2}{*}{25} & \multirow[t]{2}{*}{$51(42.9)$} & $66(55.5)$ & $53(44.5)$ & \multirow[t]{2}{*}{8} & \multirow[t]{2}{*}{$1.78, p=.076$} & \multirow[t]{2}{*}{$.40, p<.001^{D}$} & \multirow[t]{2}{*}{$-.08, p=.380$} & \multirow[t]{2}{*}{$1.15, p=.562$} & \multirow[t]{2}{*}{$.08, p=.413$} \\
\hline & & & $118(99.2)^{C}$ & $1(0.8)^{C}$ & & & & & & \\
\hline \multirow{2}{*}{$\begin{array}{l}\text { WHODAS } \\
\text { Child, parent } \\
\text { report }\end{array}$} & \multirow[t]{2}{*}{25} & \multirow[t]{2}{*}{$48(40.3)$} & $67(56.3)$ & $52(43.7)$ & \multirow[t]{2}{*}{10} & \multirow[t]{2}{*}{$1.79, p=.073$} & \multirow[t]{2}{*}{$.39, p<.001^{E}$} & \multirow[t]{2}{*}{$.03, p=.744$} & \multirow[t]{2}{*}{$1.43, p=.489$} & \multirow[t]{2}{*}{$.06, p=.510$} \\
\hline & & & $117(98.3)^{C}$ & $2(1.7)^{C}$ & & & & & & \\
\hline
\end{tabular}

SCARED: Screen for Child Anxiety Related Emotional Disorders; CES-DC: Center for Epidemiological Studies Depression Scale for Children; CPSS: Child PTSD Symptom Scale; SDQ:

Strengths and Difficulties Questionnaire; SDQ+EXT: Stengths and Difficulties Questionnaire externalising subscale +12 items aligned with DSM-5 Conduct Disorder and Oppositional Defiant Disorder; WHODAS Child: World Health Organisation Disability Assessment Schedule for Children (child and parent report versions); CGI-S: Clinical Global Impression severity score. ${ }^{A}$ Total score corrected for missing data by replacing missing items (providing $<10 \%$ missing) with mean value. ${ }^{B}$ Relevant current disorder is: any anxiety disorder for SCARED, major depressive disorder or episode for CES-DC, PTSD for CPSS, any common mental disorder (anxiety, depression, PTSD, conduct disorder, oppositional defiant disorder) for SDQ, conduct disorder / oppositional defiant disorder for SDQ+EXT, any common mental disorder for WHODAS. ${ }^{\mathrm{C}}$ Excluding items relating to school. ${ }^{\mathrm{D}}$ Accounted for by school attendance (access to school declines from age 12 years): school attendance=yes $(n=68)$, rho=.05, $p=.702$, school attendance=no $(n=51)$, rho $=.18, p=.197$. ${ }^{E} A c c o u n t e d$ for by school attendance (access to school declines from age 12 years): school attendance=yes $(n=71)$, rho=-.05, $p=.692$, school attendance=no $(n=48), r h o=.08, p=.584$. 


\section{Appendix 4: Factor Analysis and Scale Distributions}

This appendix presents results of exploratory factor analysis (EFA) using the BIOPATH year 2 data ( $N=1006)$.

\section{CES-DC (10-item version)}

EFA resulted in one factor with eigenvalue $>1$, which explained $50.5 \%$ of the variance. All items had a factor loading $>.6$.

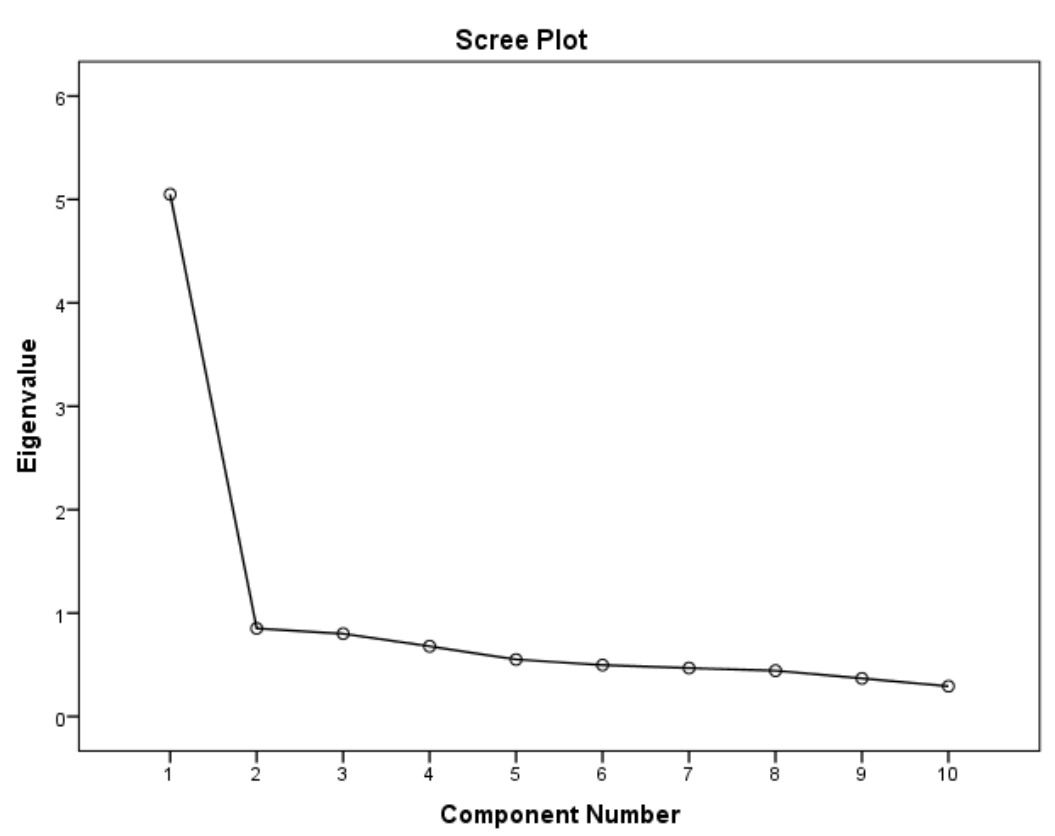

Figure A4.1. Scree plot from PCA of CES-DC 10-item version

\begin{tabular}{|l|c|}
\hline \multicolumn{1}{|c|}{ Component Matrix } \\
\hline & \multicolumn{1}{|c|}{ Component } \\
\hline & 1 \\
\hline I was bothered by things that usually don't bother me & .618 \\
\hline I wasn't able to feel happy, even when my family or friends tried to & .728 \\
help me feel better & \\
\hline I felt like I couldn't pay attention to what I was doing & .634 \\
\hline I felt down and unhappy & .785 \\
\hline I felt like I was too tired to do things & .735 \\
\hline I was happy & .676 \\
\hline I felt lonely, like I didn't have any friends & .625 \\
\hline I felt like crying & .743 \\
\hline I felt sad & .815 \\
\hline It was hard to get started doing things & .718 \\
\hline Extraction Method: Principal Component Analysis. \\
\hline a. 1 components extracted. & \\
\hline Table A4.1. Factor loadings from PCA of CES-DC 10-item version \\
\hline
\end{tabular}




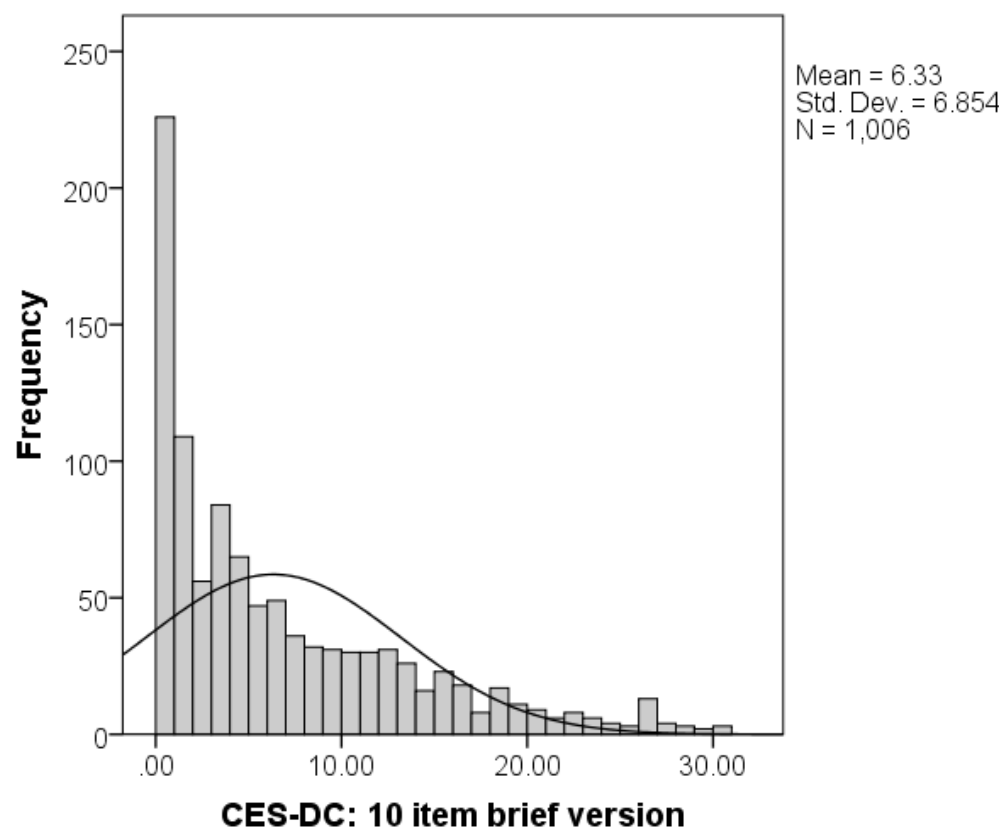

Figure A4.2. Distribution of CES-DC 10-item version in BIOPATH

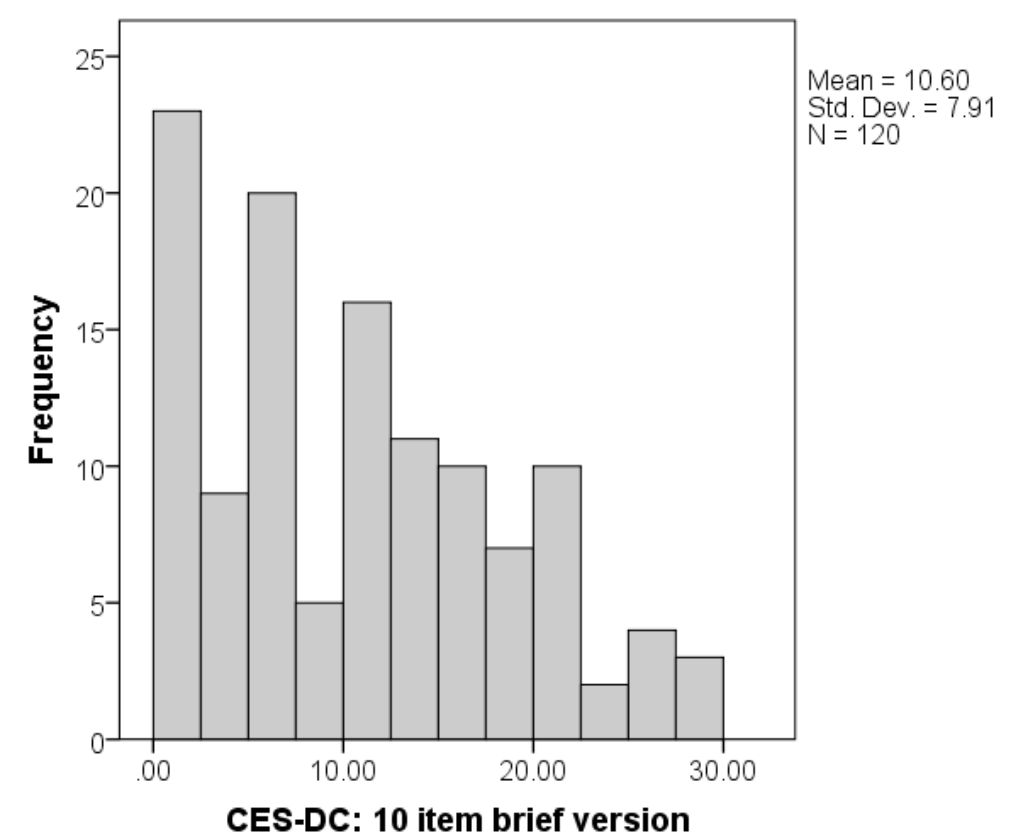

Figure A4.3. Distribution of CES-DC 10-item version in subsample 


\section{SCARED (18-item version)}

EFA resulted in four factors with eigenvalue $>1$, which explained $53.5 \%$ of the variance. All items had a factor loading $>.6$.

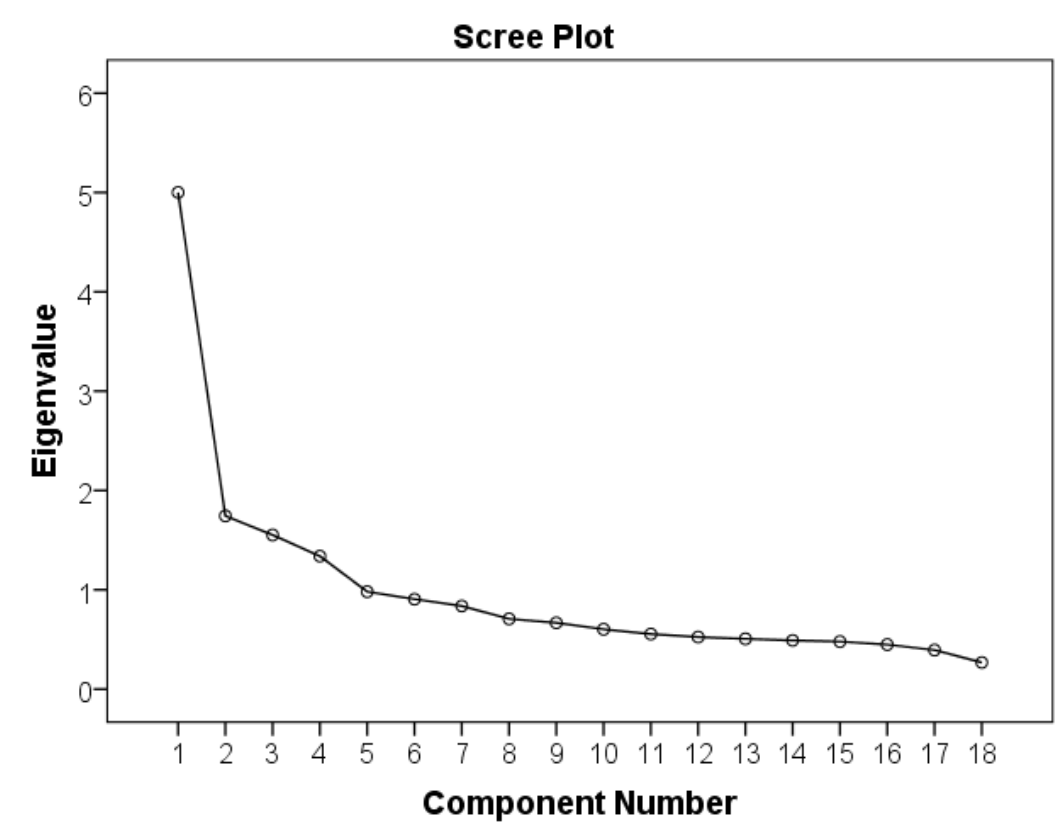

Figure A4.4. Scree plot from PCA of SCARED 18-item version

\begin{tabular}{|l|c|c|c|c|c|}
\hline \multicolumn{4}{|l}{ Rotated Component Matrix } \\
\hline
\end{tabular}

Table A4.2. Factor loadings from PCA of SCARED 18-item version

$\mathrm{PN}$, panic disorder; GD, generalised anxiety disorder; SP, separation anxiety; SC, social phobia 


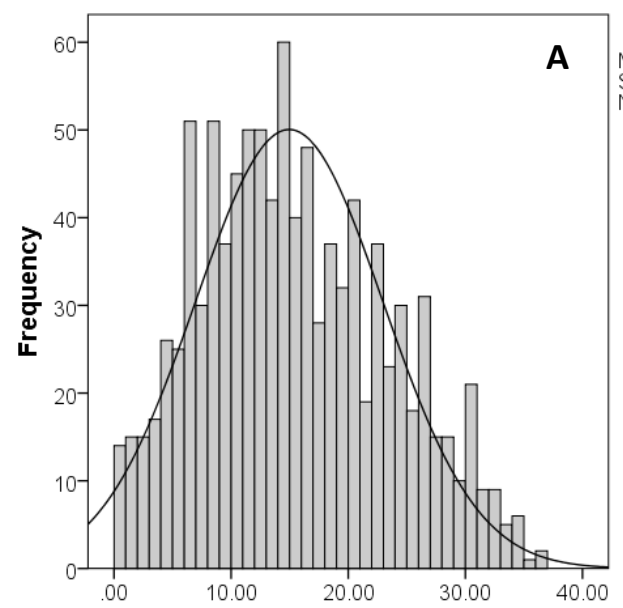

SCARED: 18 item brief version

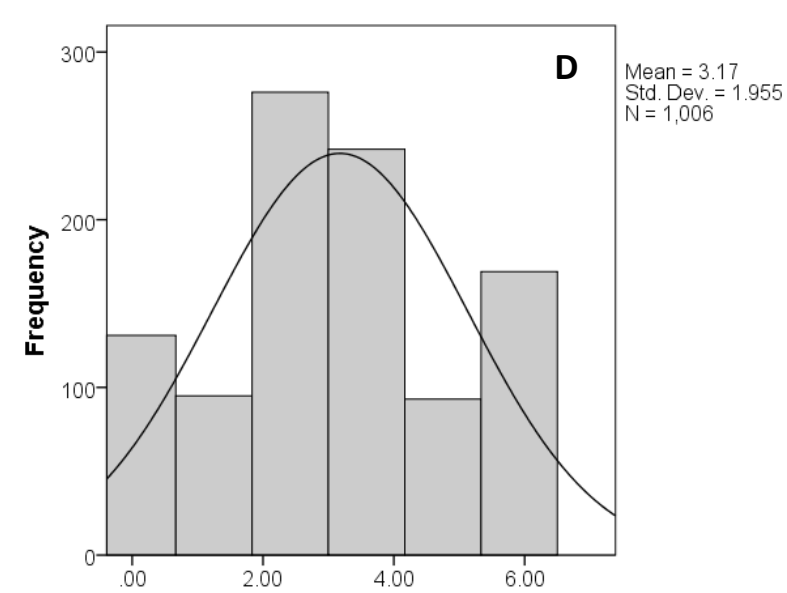

SCARED Separation Anxiety Disorder: 3
QMUL-IDRAAC-MDM Final Report Appendix 4
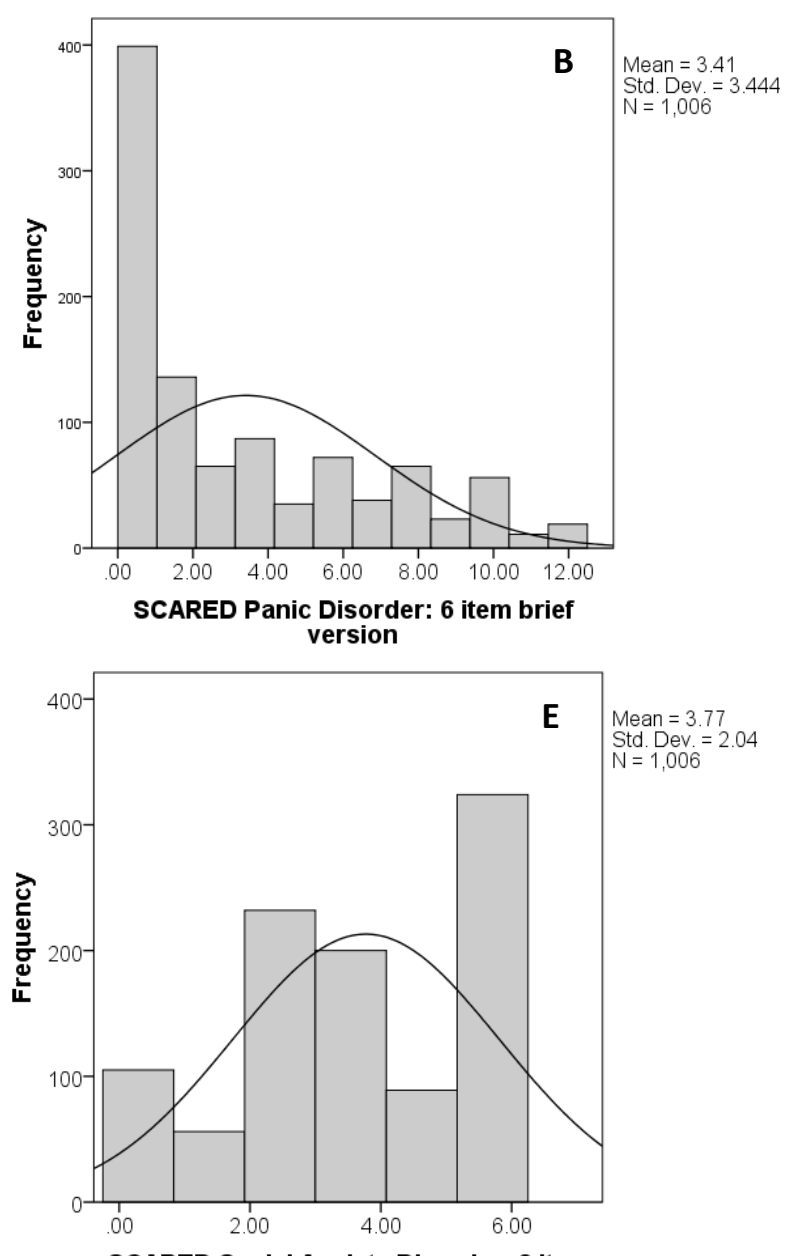

SCARED Social Anxiety Disorder: 3 item
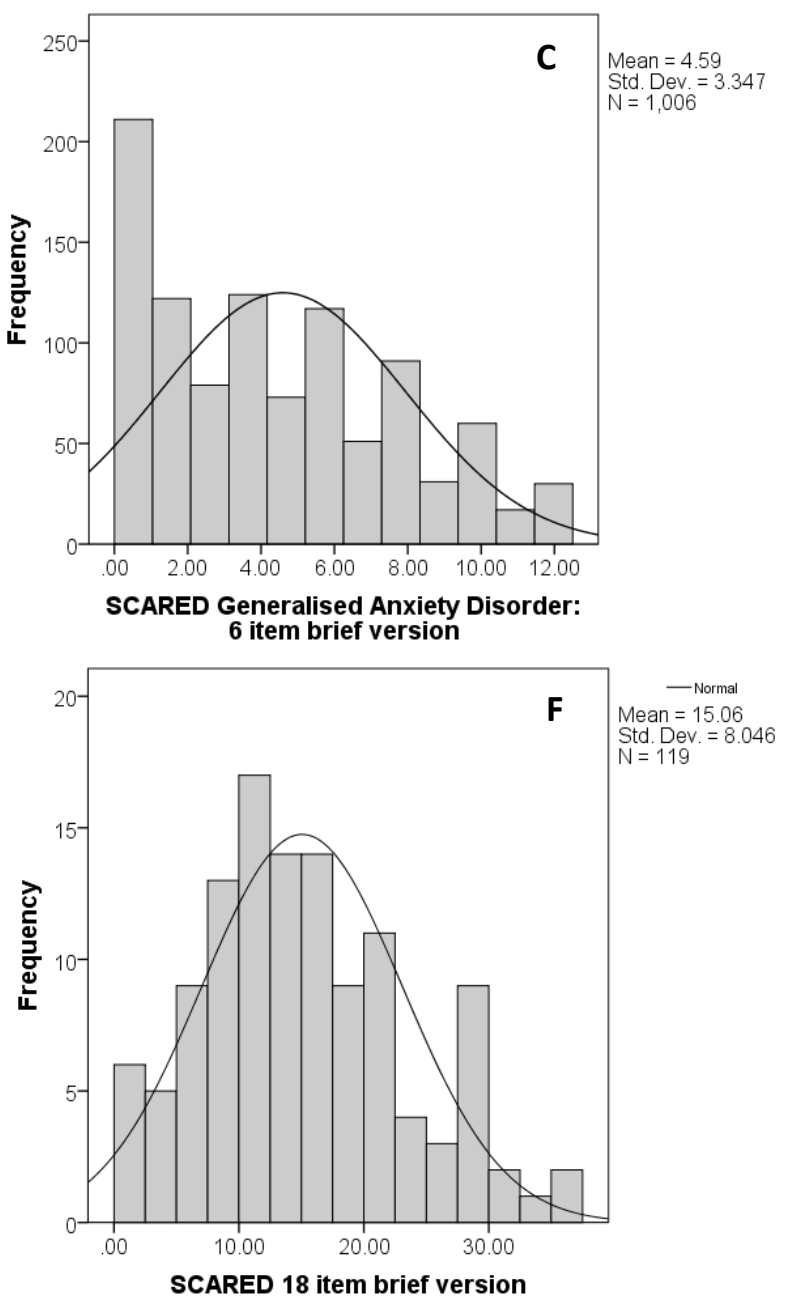

Figure A4.4. Distribution of SCARED 18-item version total score and subscales in BIOPATH (A-E) and total score in subsample (F) 


\section{CPSS (original 17-item version)}

EFA of the 17 symptom items resulted in two factors with eigenvalue $>1$, which explained $59.8 \%$ of the variance. All items had a factor loading $>.4$. The screen plot suggests that a one factor solution may also be appropriate.

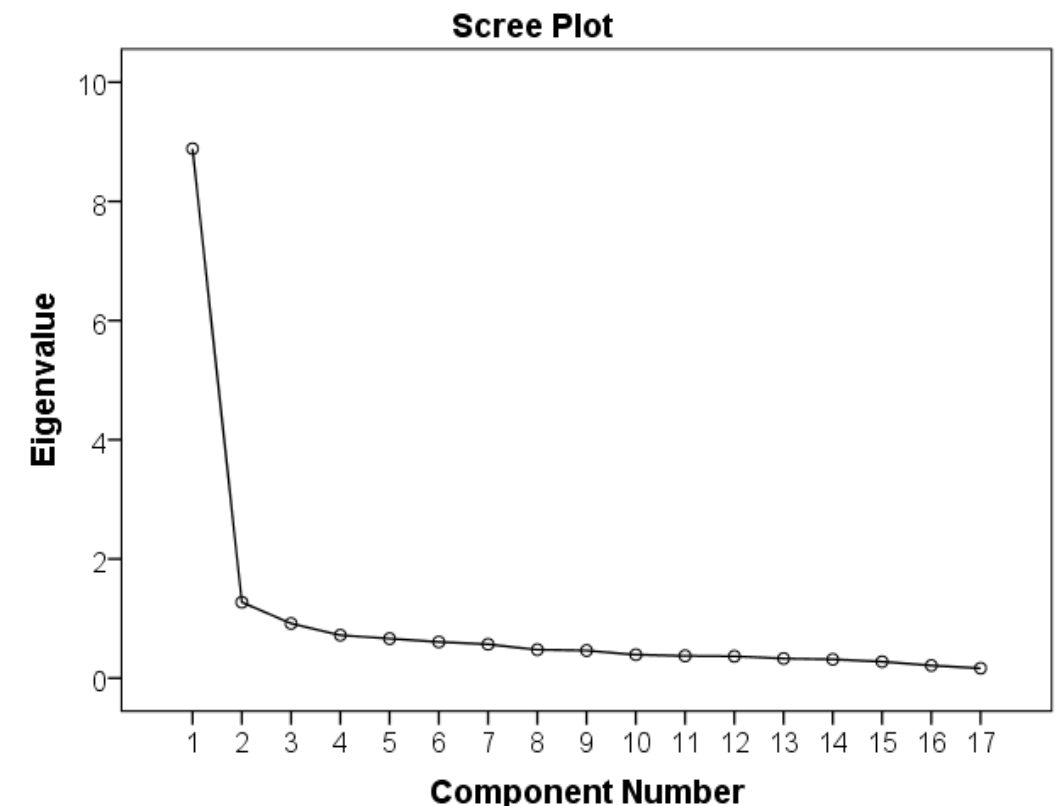

Figure A4.5. Scree plot from PCA of CPSS 17-item version

\begin{tabular}{|l|c|c|}
\hline \multicolumn{3}{|c|}{ Rotated Component Matrix } \\
\hline & \multicolumn{2}{|c|}{ Component } \\
\hline & 1 & \multicolumn{2}{|c|}{} \\
\hline Having upsetting thoughts or images about the event & .734 & .319 \\
\hline Having bad dreams or nightmares & .344 & .535 \\
\hline Acting or feeling as if the event was happening again & .658 & .432 \\
\hline Feeling upset when you think about it or hear about the event & .807 & .331 \\
\hline Having feelings in your body when you think about or hear about the & .790 & .375 \\
\hline event & & \\
\hline Trying not to think about, talk about, or have feelings about the event & .847 & .221 \\
\hline Trying to avoid activities, people, or places that remind you of the & .822 & .243 \\
\hline traumatic event & & \\
\hline Not being able to remember an important part of the upsetting event & .496 & .291 \\
\hline Having much less interest or doing things you used to do & .520 & .543 \\
\hline Not feeling close to people around you & .279 & .711 \\
\hline Not being able to have strong feelings & .387 & .745 \\
\hline Feeling as if your future plans or hopes will not come true & .355 & .603 \\
\hline Having trouble falling or staying asleep & .209 & .724 \\
\hline Feeling irritable or having fits of anger & .324 & .685 \\
\hline Having trouble concentrating & .179 & .778 \\
\hline Being overly careful (checking to see who and what is around you) & .483 & .471 \\
\hline Being jumpy or easily startled & .500 & .559 \\
\hline Extraction Method: Principal Component Analysis. & & \\
\hline Rotation Method: Varimax with Kaiser Normalization. & & \\
\hline a. Rotation converged in 3 iterations. & & \\
\hline
\end{tabular}

Table A4.3. Factor loadings from PCA of CPSS 17-item version 

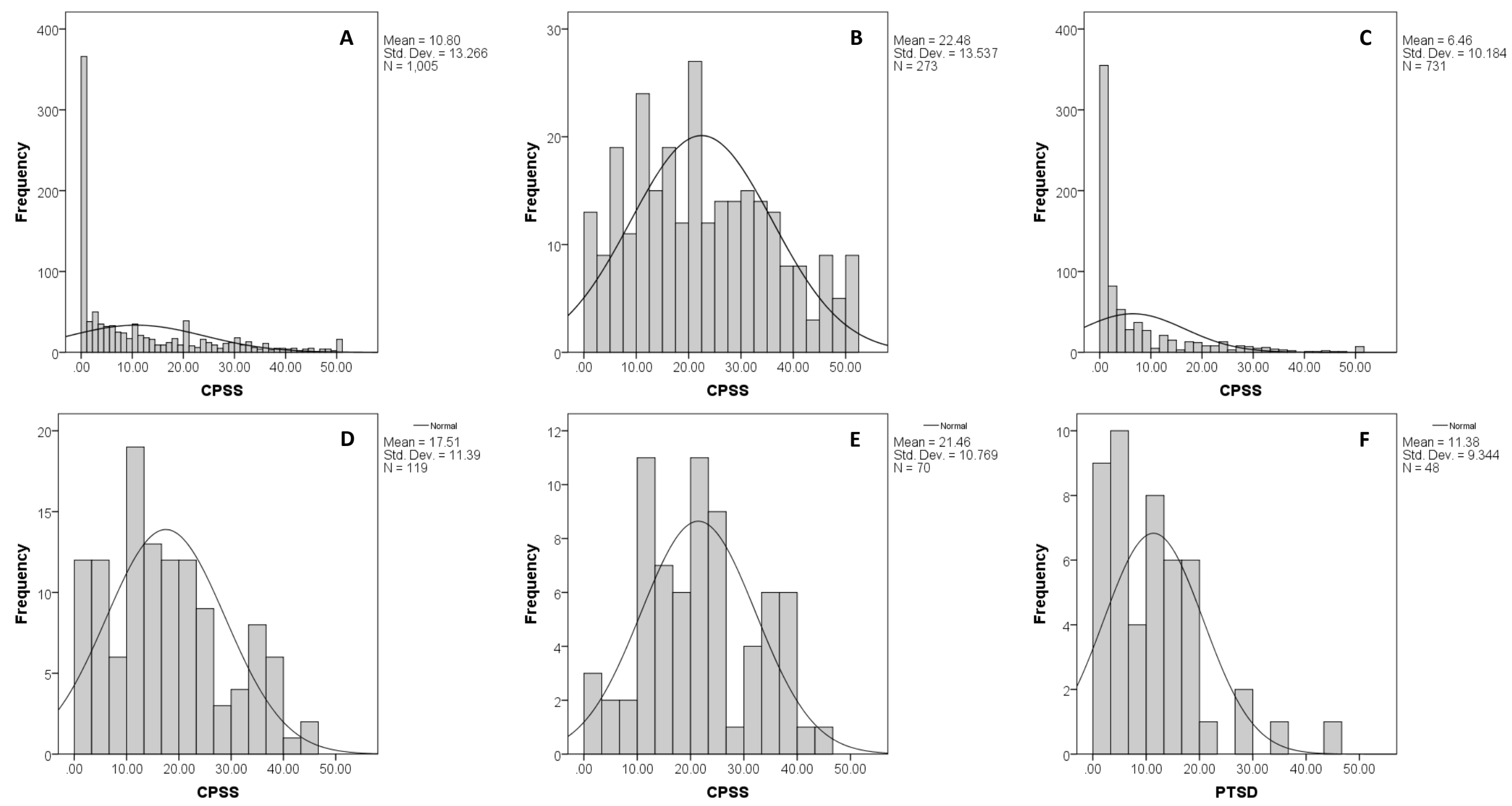

Figure A4.6. Distribution of CPSS in BIOPATH: all children (A), those reporting an event (B), and those not reporting an event (C); and in subsample: all children (D), those reporting an event $(E)$, and those not reporting an event $(F)$ 


\section{SDQ + Impact supplement}

EFA of the 25 symptom items from the SDQ resulted in seven factors with eigenvalue $>1$, which explained $49.6 \%$ of the variance. All but two items had a factor loading >.4. EFA of the 5 items from the SDQ Impact supplement resulted in a one factor solution, which explained $54.0 \%$ of the variance.
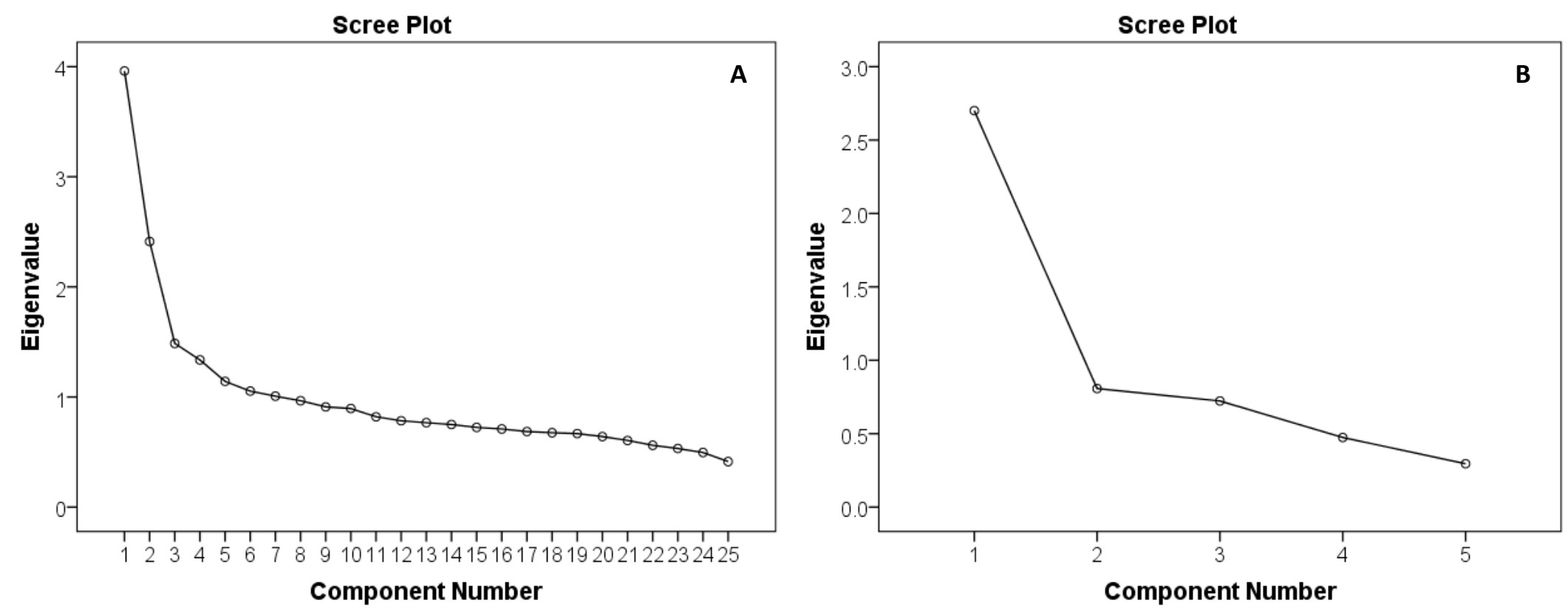

Figure A4.7. Scree plot from PCA of: (A) SDQ symptom items and (B) SDQ Impact supplement 


\section{Rotated Component Matrix ${ }^{a}$}

\begin{tabular}{|c|c|c|c|c|c|c|c|c|c|}
\hline \multirow{2}{*}{ 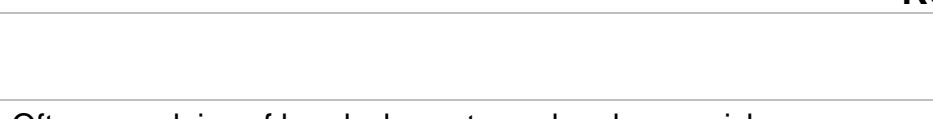 } & \multirow[t]{2}{*}{5 subscales } & \multirow{2}{*}{$\begin{array}{l}\text { Internalising / } \\
\text { externalising }\end{array}$} & \multicolumn{7}{|c|}{ Component } \\
\hline & & & 1 & 2 & 3 & 4 & 5 & 6 & 7 \\
\hline Often complains of headaches, stomach-aches or sickness & Emo & Int & .037 & .530 & .000 & .171 & .179 & -.035 & .106 \\
\hline Many worries, often seems worried & Emo & Int & .325 & .637 & -.014 & -.020 & -.022 & .060 & -.043 \\
\hline Often unhappy, down-hearted or tearful & Emo & Int & .258 & .640 & .130 & .110 & .020 & .074 & -.087 \\
\hline Nervous or clingy in new situations, easily loses confidence & Emo & Int & .648 & .290 & -.117 & .119 & .060 & .024 & .166 \\
\hline Many fears, easily scared & Emo & Int & .111 & .563 & .077 & -.252 & .093 & .349 & -.093 \\
\hline Rather solitary, tends to play alone & Peer & Int & -.051 & .602 & -.203 & .085 & -.019 & -.131 & .137 \\
\hline Has at least one good friend & Peer & Int & -.042 & .254 & .087 & .649 & -.010 & .140 & .047 \\
\hline Generally liked by other children & Peer & Int & -.063 & .032 & -.072 & .654 & .180 & .173 & -.056 \\
\hline Picked on or bullied by other children & Peer & Int & .139 & .309 & -.067 & .119 & .555 & .050 & .068 \\
\hline Gets on better with adults than with other children & Peer & Int & .257 & -.046 & .372 & -.017 & -.044 & -.065 & .507 \\
\hline Often has temper tantrums or hot tempers & Con & Ext & 673 & .286 & -.060 & .106 & .017 & -.103 & .180 \\
\hline Generally obedient, usually does what adults request & Con & Ext & .383 & -.113 & -.402 & .306 & -.042 & .326 & .165 \\
\hline Often fights with other children or bullies them & Con & Ext & .420 & .114 & -.067 & .133 & .491 & -.066 & .030 \\
\hline Often lies or cheats & Con & Ext & .173 & -.017 & .024 & .170 & .563 & .243 & .221 \\
\hline Steals from home, school or elsewhere & Con & Ext & -.068 & -.038 & -.038 & -.082 & .681 & .032 & -.160 \\
\hline Restless, overactive, cannot stay still for long & Hyp & Ext & .677 & -.047 & .099 & -.147 & .051 & .155 & -.116 \\
\hline Constantly fidgeting or squirming & Hyp & Ext & .652 & .166 & .091 & -.133 & .180 & .133 & -.071 \\
\hline Easily distracted, concentration wanders & Hyp & Ext & .131 & .366 & .053 & -.081 & .093 & .555 & .190 \\
\hline Thinks things out before acting & Hyp & Ext & -.014 & -.077 & -.162 & .254 & .181 & .574 & .115 \\
\hline Sees tasks through to the end, good attention span & Hyp & Ext & .078 & -.008 & -.191 & .168 & -.016 & .594 & -.164 \\
\hline Considerate of other people's feelings & Pro & & -.097 & .017 & .592 & .106 & -.080 & -.167 & -.198 \\
\hline Shares readily with other children (treats, toys, pencils etc.) & Pro & & .067 & -.112 & .262 & -.009 & -.042 & -.080 & -.728 \\
\hline Helpful if someone is hurt, upset or feeling ill & Pro & & .066 & -.049 & .672 & -.031 & .049 & -.091 & .004 \\
\hline Kind to younger children & Pro & & -.122 & .055 & .421 & -.514 & -.018 & .060 & -.006 \\
\hline Often volunteers to help others (parents, teachers, other children) & Pro & & .035 & -.016 & .627 & -.120 & -.083 & .006 & .044 \\
\hline \multicolumn{10}{|l|}{$\begin{array}{l}\text { Extraction Method: Principal Component Analysis. } \\
\text { Rotation Method: Varimax with Kaiser Normalization. }\end{array}$} \\
\hline Is. & & & & & & & & & \\
\hline
\end{tabular}

\section{Table A4.4. Factor loadings from PCA of SDQ 25 symptoms items}

Emo: Emotional problems; Peer: Peer problems; Con: Conduct problems; Hyp: Hyperactivity; Pro: Prosocial; Int: Internalising; Ext: Externalising 


\section{Component Matrix ${ }^{a}$}

\begin{tabular}{|l|c|}
\hline & Component \\
\hline & 1 \\
\hline Do the difficulties upset or distress your child? & .643 \\
\hline Do the difficulties interfere with Home life? & .777 \\
\hline Do the difficulties interfere Friendships? & .816 \\
\hline Do the difficulties interfere Classroom learning? & .580 \\
\hline Do the difficulties interfere Leisure activities? & .826 \\
\hline Extraction Method: Principal Component Analysis. \\
\hline a. 1 components extracted. \\
\hline
\end{tabular}

Table A4.5. Factor loadings from PCA of SDQ Impact supplement 


\section{EA Consortium}

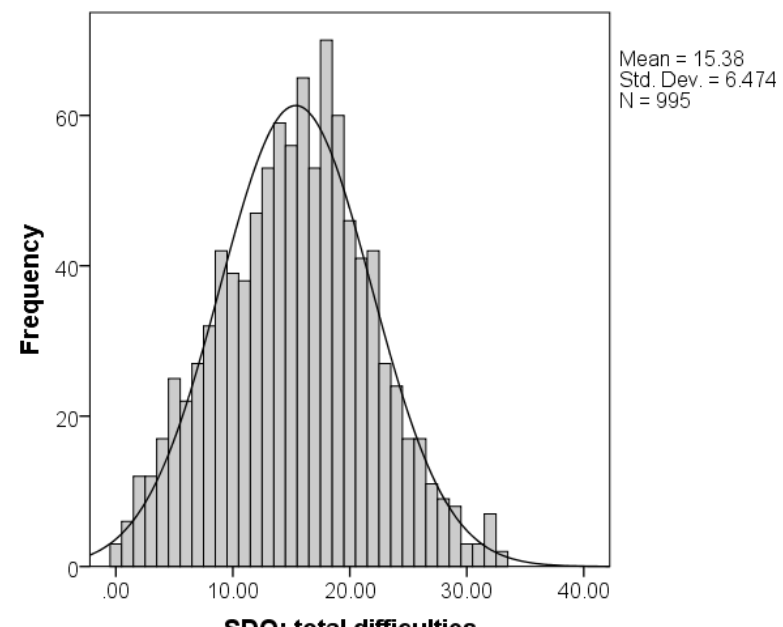

SDQ: total difficulties

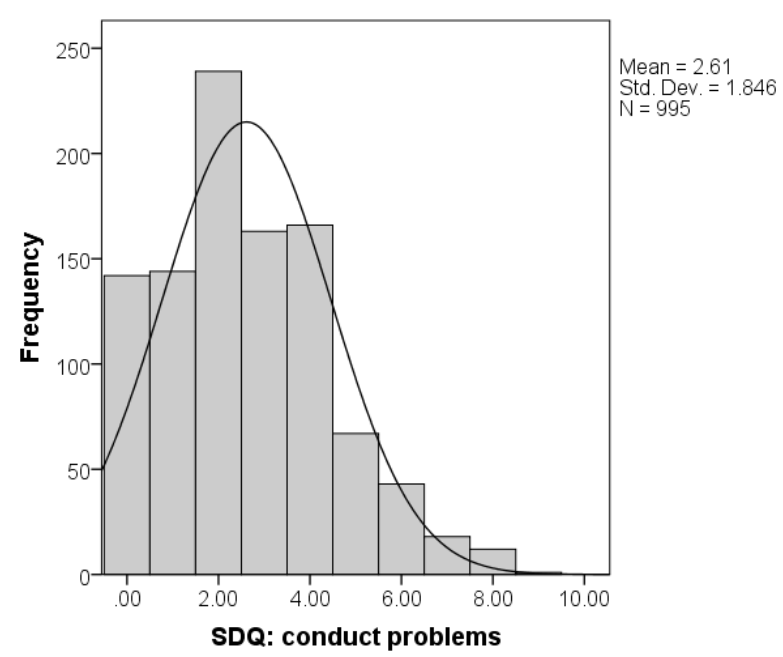

QMUL-IDRAAC-MDM Final Report Appendix 4
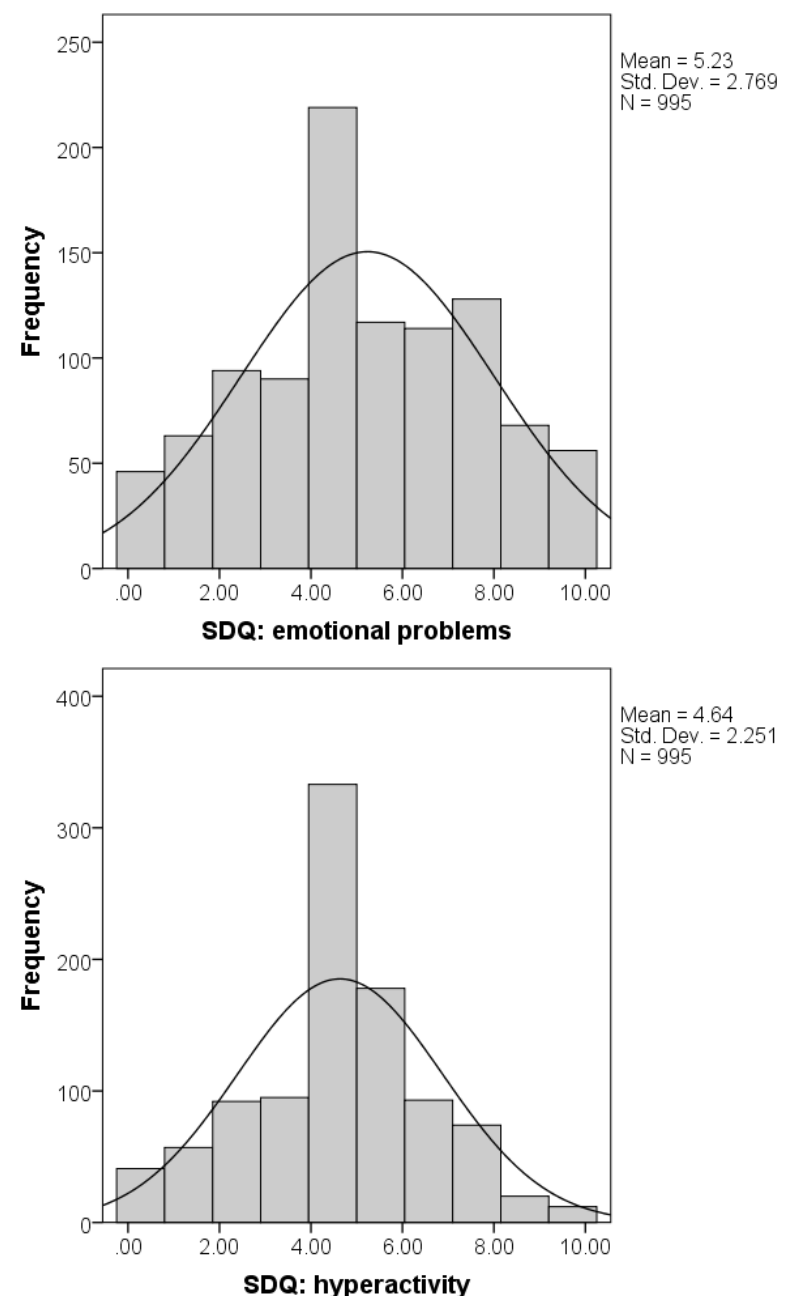
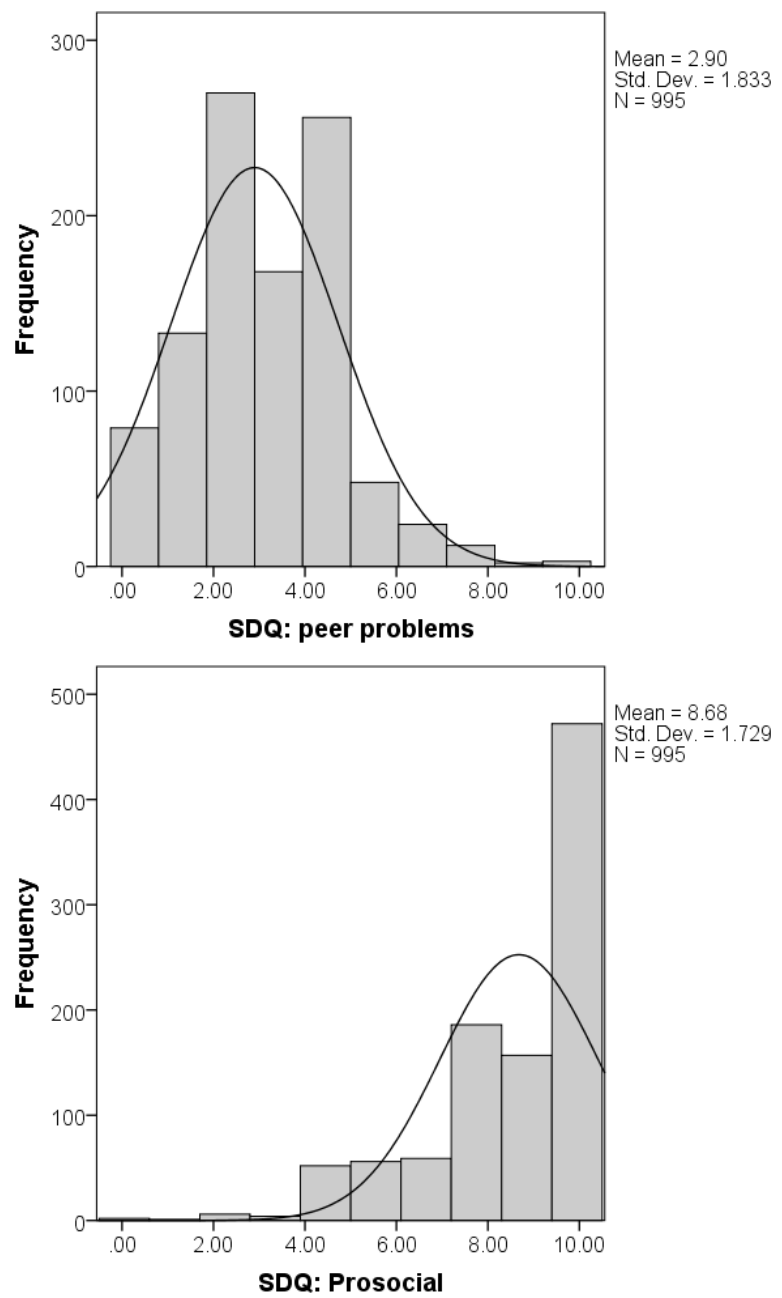

Figure A4.8. Distribution of SDQ total difficulties and five subscales in BIOPATH 


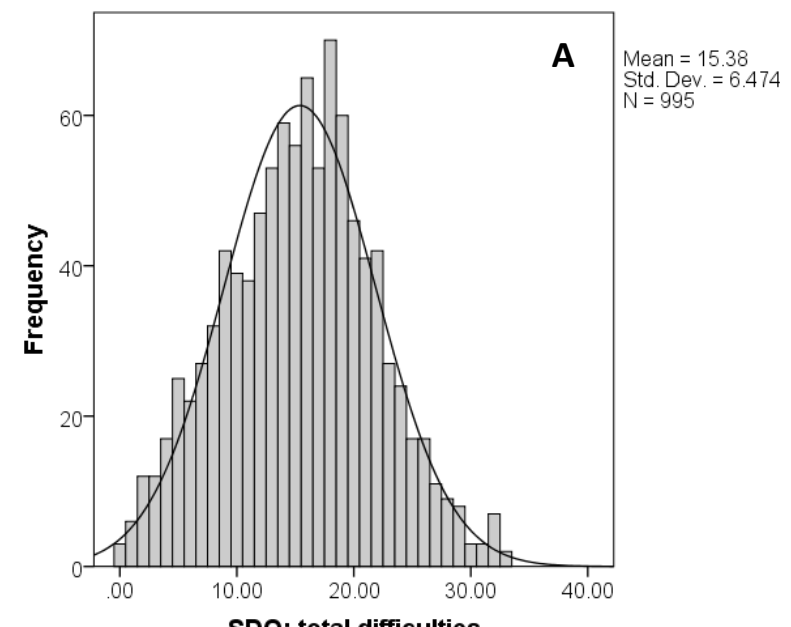

SDQ: total difficulties

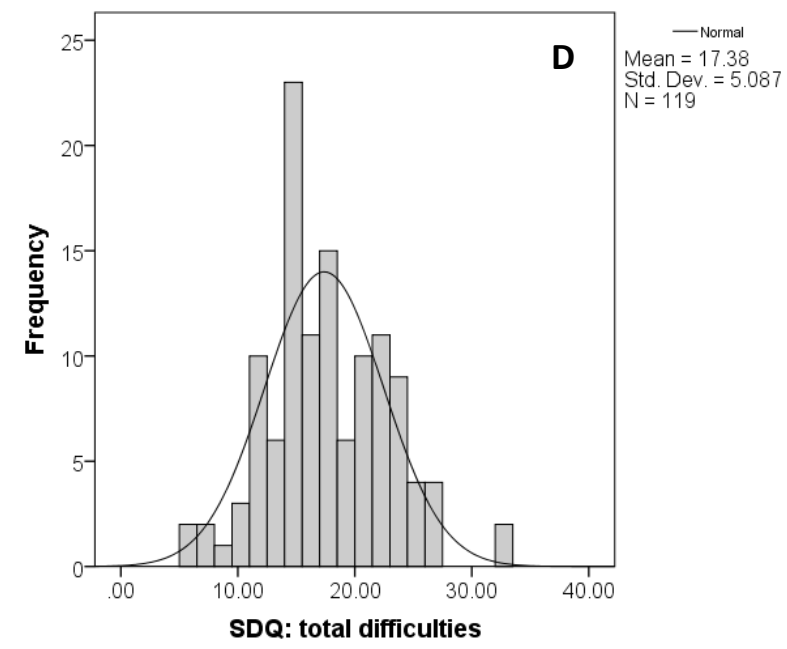

QMUL-IDRAAC-MDM Final Report Appendix 4
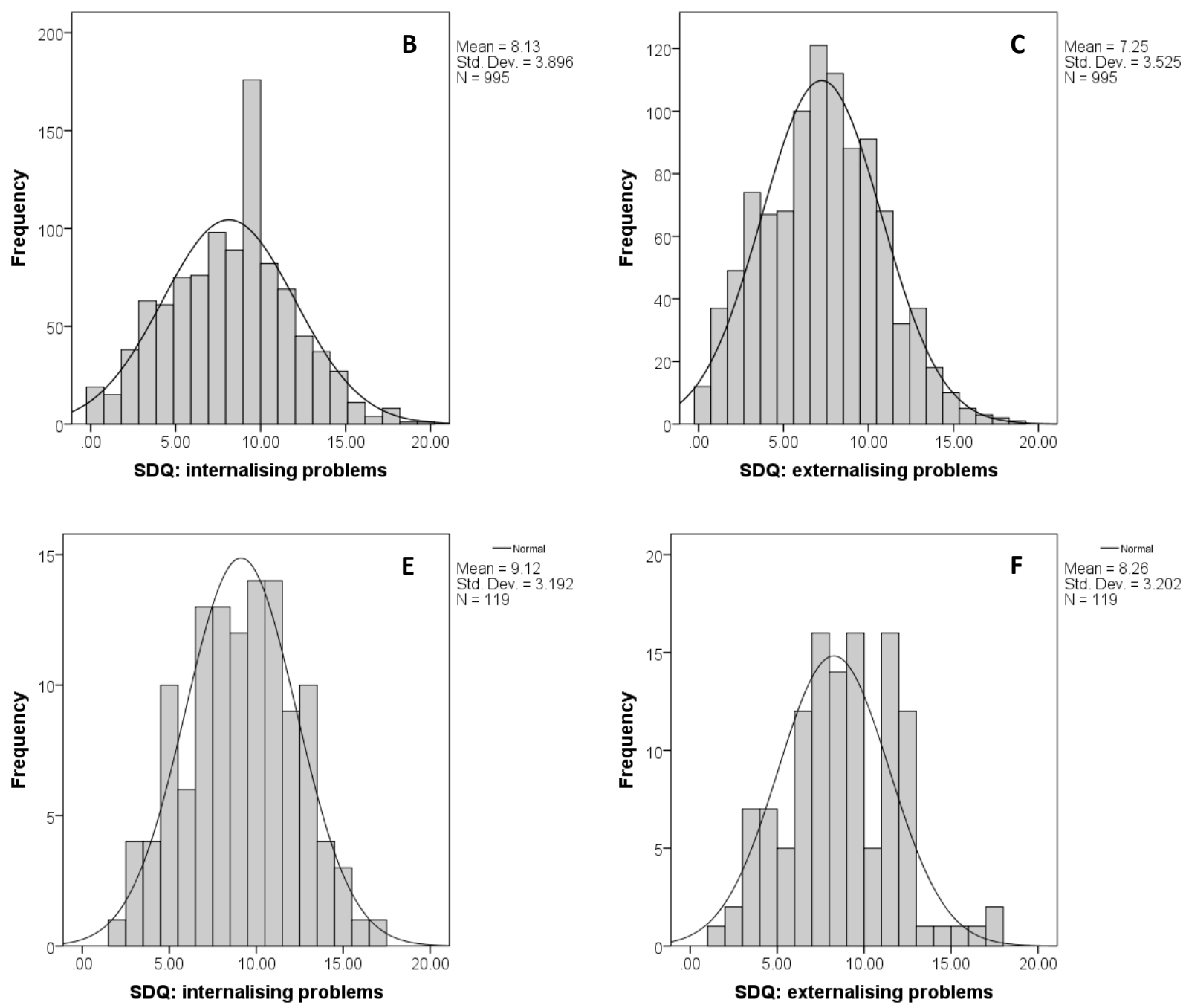

Figure A4.9. Distribution of SDQ total difficulties and internalising and externalising subscale scores in BIOPATH (A-C) and subsample (D-F) 

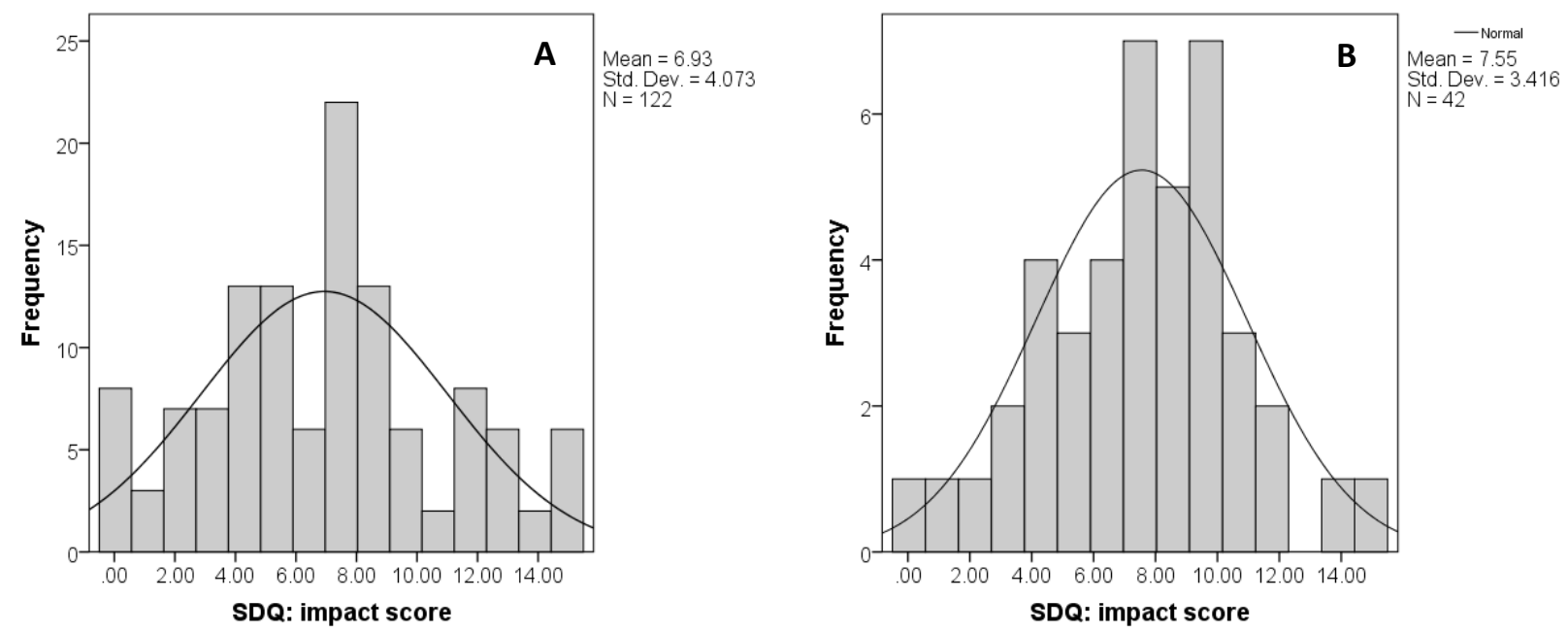

Figure A4.10. Distribution of SDQ impact score in BIOPATH (A) and subsample (B) 


\section{WHODAS Child}

EFA using all self-report items resulted in a matrix that was not positive definite; this was probably due to the large amount of missing data for the school items.

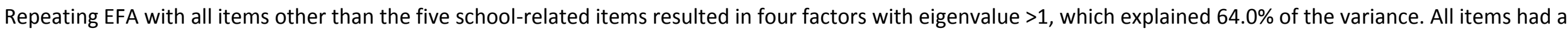
factor loading $>.4$.

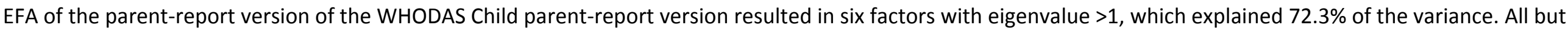
two items had a factor loading $>.4$.
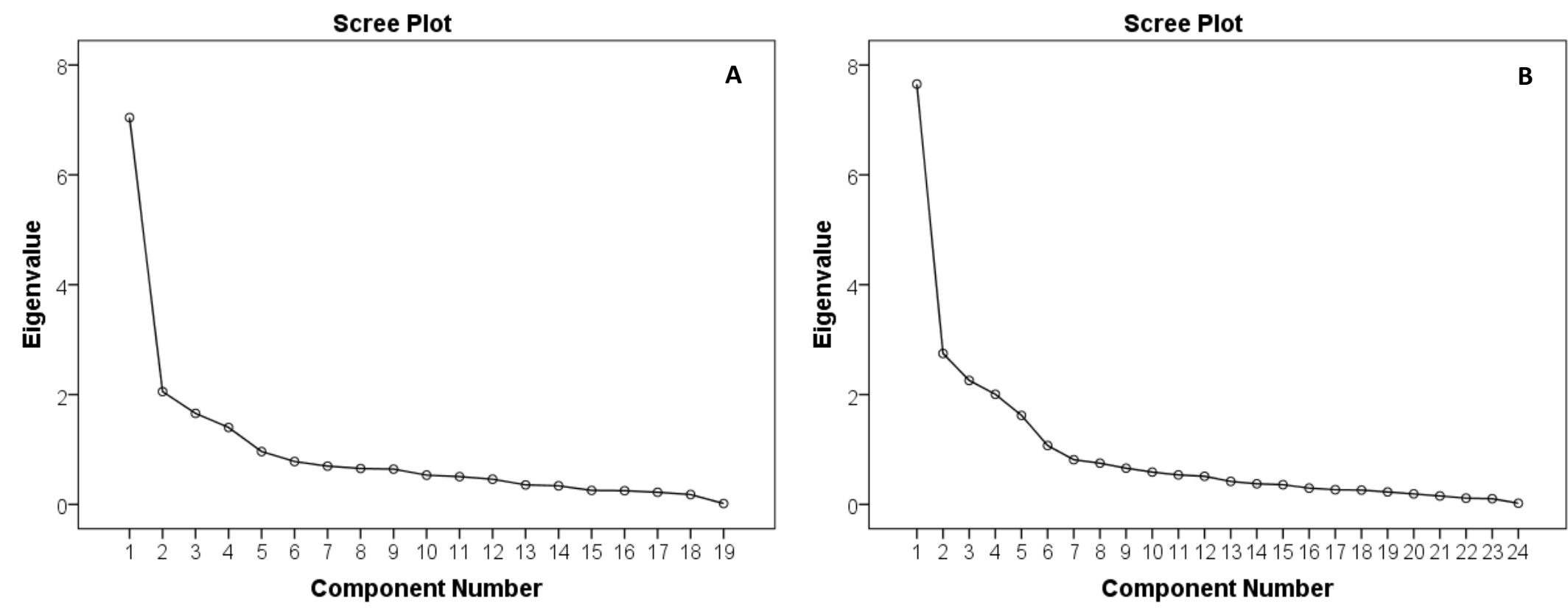

Figure A4.11. Scree plot from PCA of: (A) Self-report version and (B) Parent-report version

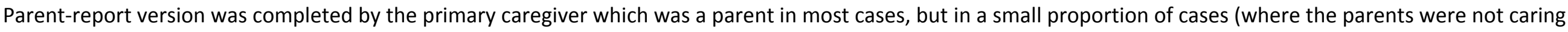
for the child) was another family member. 


\section{Rotated Component Matrix ${ }^{a}$}

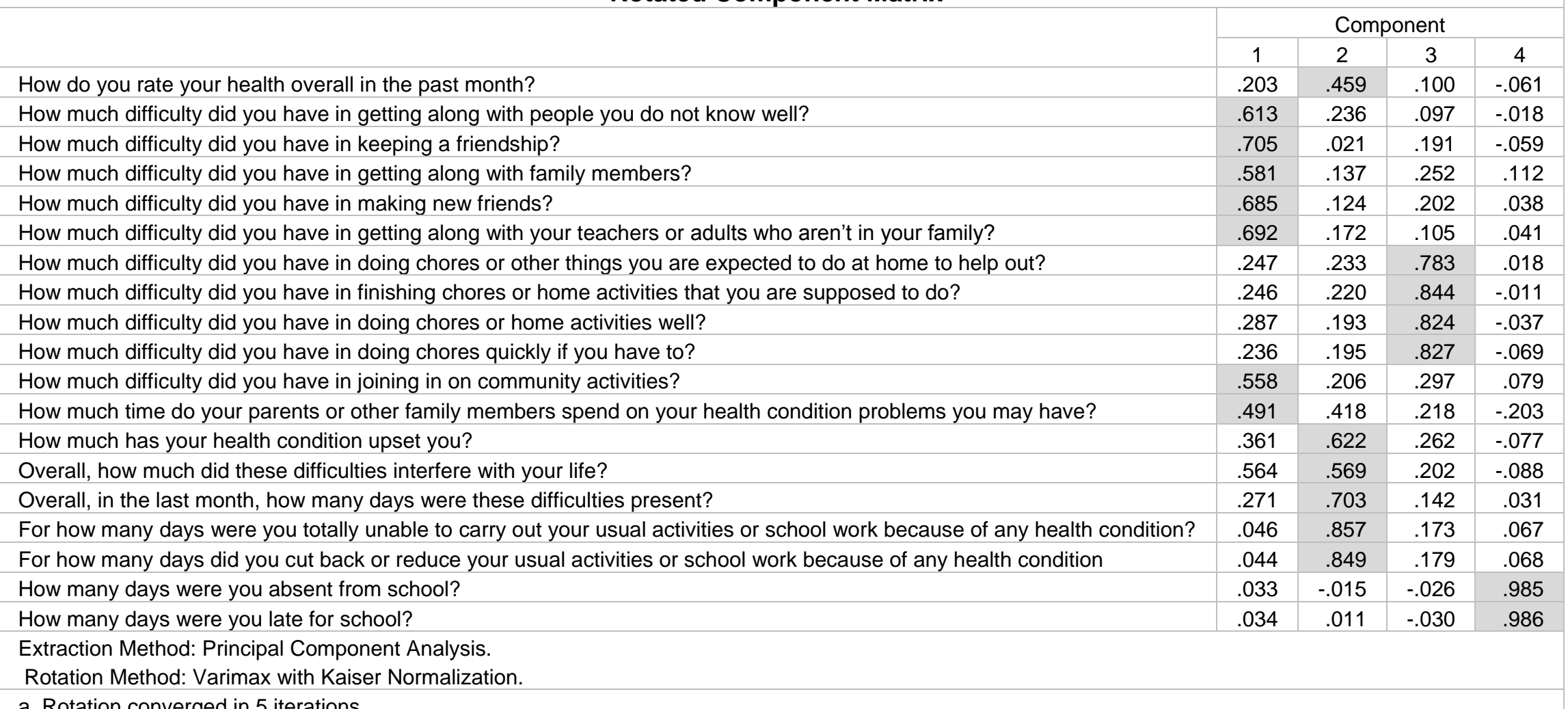

\section{Table A4.6. Factor loadings from PCA of WHODAS Child self-report version items}


Rotated Component Matrix ${ }^{a}$

\begin{tabular}{|c|c|c|c|c|c|c|}
\hline & \multicolumn{6}{|c|}{ Component } \\
\hline & 1 & 2 & 3 & 4 & 5 & 6 \\
\hline How do you rate your childs health overall in the past month? & 139 & 093 & .170 & 655 & -.061 & -.135 \\
\hline Difficulty in getting along with people he/she does not know well & .057 & .081 & .760 & .059 & .009 & .101 \\
\hline Difficulty in keeping a friendship & .101 & 202 & .729 & .089 & -.022 & .054 \\
\hline Difficulty in getting along with family members & .203 & 192 & .563 & .264 & .057 & -.026 \\
\hline Difficulty in making new friends & .270 & 128 & .751 & 125 & .005 & .038 \\
\hline Difficulty in getting along with teachers or adults who aren't in your family & .236 & .105 & .683 & .076 & -.029 & .082 \\
\hline Difficulty in doing chores or helping out at home & .133 & 859 & .205 & 126 & -.008 & .060 \\
\hline Difficulty in finishing chores or home activities & .138 & .886 & .191 & .130 & .001 & .059 \\
\hline Difficulty in doing chores or home activities well & .065 & 888 & .176 & 132 & .009 & .085 \\
\hline Difficulty in doing chores quickly & .064 & .866 & .114 & .084 & -.025 & .086 \\
\hline Difficulty in doing regular school assignments & .888 & .024 & .174 & .050 & .023 & .096 \\
\hline Difficulty in studying for important school tests & .893 & .118 & .137 & .137 & .014 & .085 \\
\hline Difficulty in completing all their school assignments & .923 & .083 & .155 & .081 & .012 & .075 \\
\hline Difficulty in completing school work on time & .880 & .142 & .121 & .148 & .008 & .067 \\
\hline Difficulty following rules or fitting in at school & .700 & .042 & .316 & .132 & -.077 & .094 \\
\hline Difficulty joining in community activities & .378 & .233 & .353 & .166 & .071 & .033 \\
\hline Time spent by family on child's health problems & .085 & .109 & .063 & .751 & -.047 & .273 \\
\hline How much has child's health condition upset him/her? & .061 & .098 & .070 & .810 & .014 & .283 \\
\hline How much did these difficulties interfere with his/her life? & .188 & .143 & .214 & .753 & -.017 & .242 \\
\hline How many days were these difficulties present? & .236 & .212 & .247 & .427 & .045 & .442 \\
\hline How many days was your child unable to carry out his/her usual activities because of health? & .117 & 125 & .068 & 244 & .011 & .833 \\
\hline How many days did they reduce usual activities due to health? & .119 & .056 & .080 & .177 & .024 & .871 \\
\hline Days absent from school? & .026 & -.005 & .005 & -.051 & .990 & .020 \\
\hline Days late for school? & -.015 & -.012 & .010 & -.032 & .992 & .023 \\
\hline
\end{tabular}

Extraction Method: Principal Component Analysis.

Rotation Method: Varimax with Kaiser Normalization.

a. Rotation converged in 6 iterations.

\section{Table A4.6. Factor loadings from PCA of WHODAS Child parent-report version items}



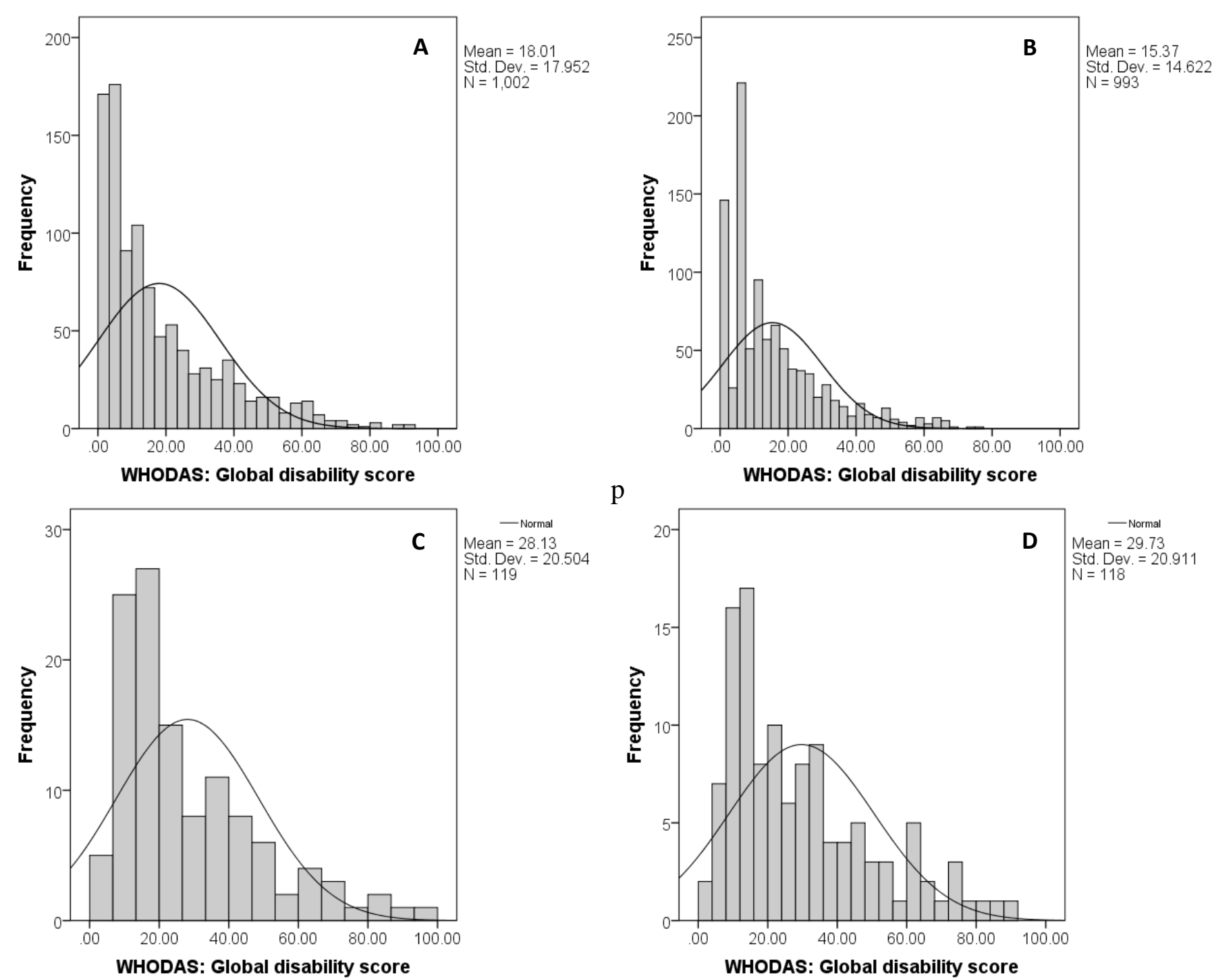

Figure A4.12. Distribution of WHODAS Child global disability score in BIOPATH for self-report (A) and parent-report (B) versions, and in subsample for self-report (C) and parent-report (D) versions 

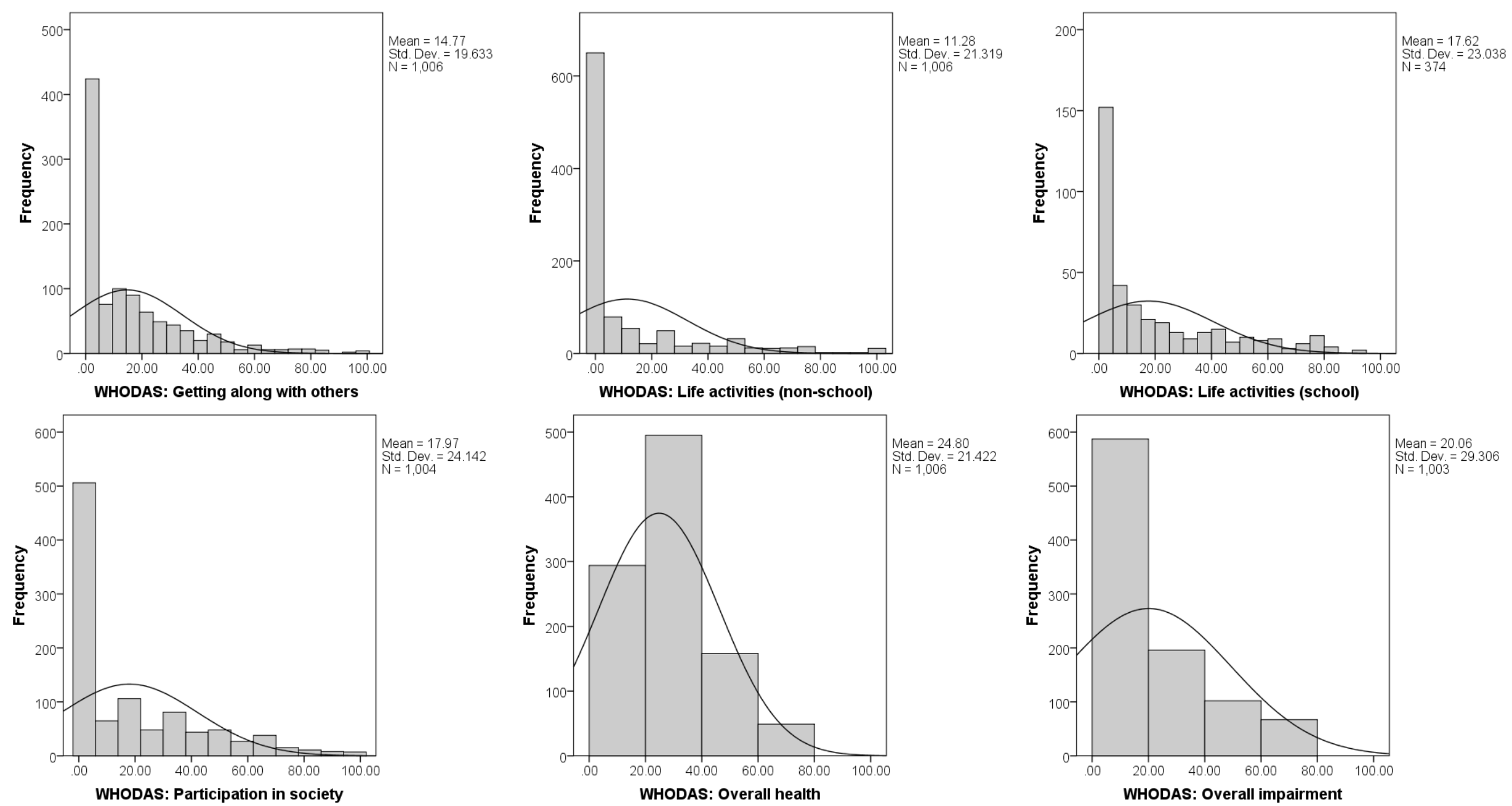

Figure A4.13. Distribution of WHODAS Child subscale scores in BIOPATH for self-report version 

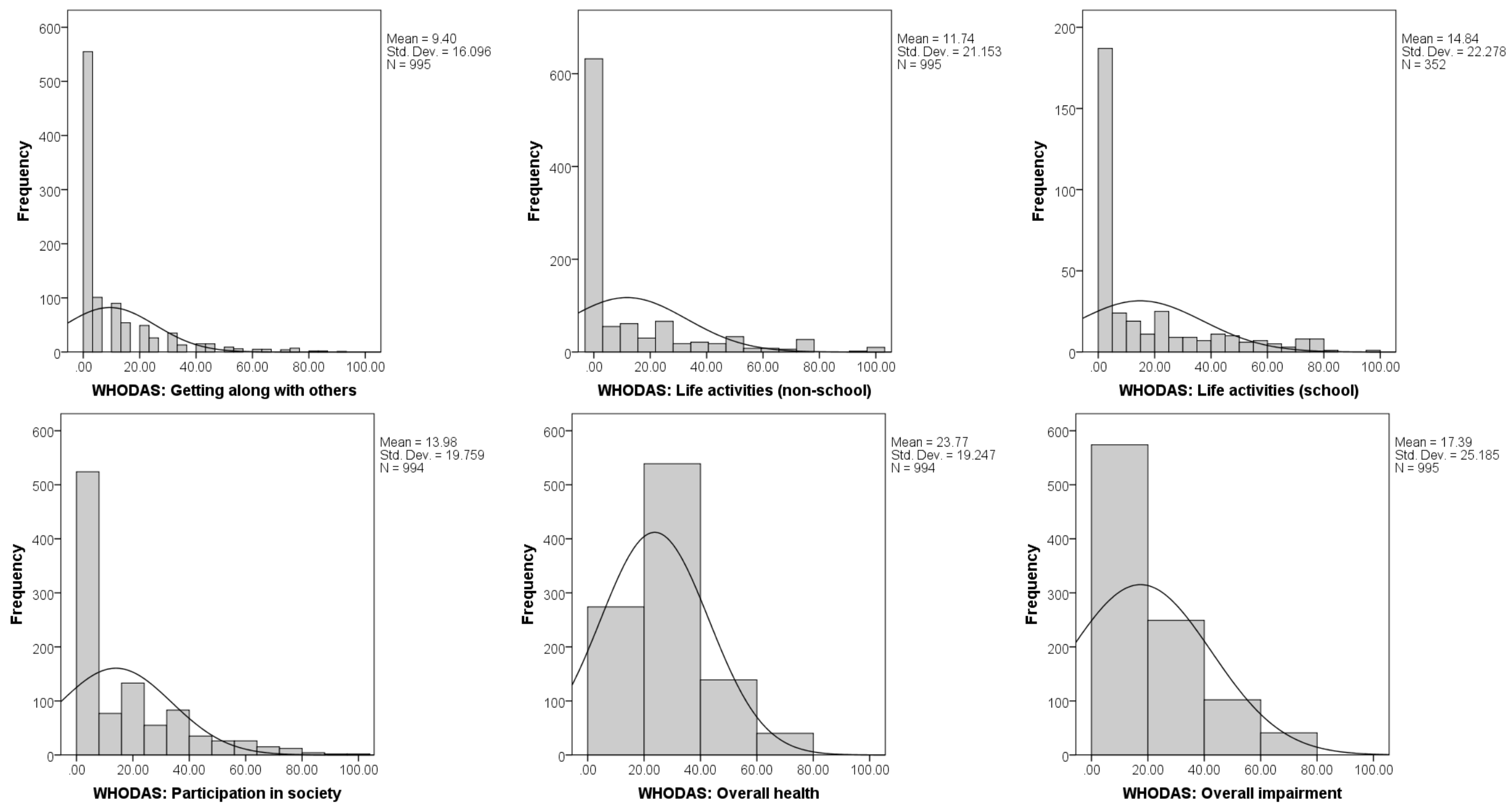

Figure A4.13. Distribution of WHODAS Child subscale scores in BIOPATH for parent-report version 


\section{WHODAS Child inter-rater reliability}

The correlations between different respondants - child self-report and parent-report of the child's difficulties - are reported in Tables 7 and 8 . Table 7 shows results from the BIOPATH sample, where different interviewers completed the WHODAS with the child and parent in each family. Correlations between subscales range between .25 and .77 for self-report WHODAS (blue highlighting), and between .19 and .73 for parent-report WHODAS (green highlighting). These intercorrelations are also reflected in the high Cronbach's alpha $(\alpha=.82 / .76)$ for the five subscales that make up the Global disability score. Using a multitrait-multimethod approach, correlations between self-report and parent-report (gold highlighting) on the subscales were significant, though of small effect size (.04-.23), showing weak evidence of convergent validity. For the two Life activities subscales, the correlation between self- and parent report for the subscale was consistently greater than the cross-scale cross-informant correlations (e.g., between self-report Life activites (school) and parent-report for each of the other subscales). However, for the other subscales, the pattern was less consistent. Overall, this demonstrates weak evidence of convergent and discriminant validity in the BIOPATH sample.

\begin{tabular}{|c|c|c|c|c|c|c|c|c|c|c|c|c|c|c|c|}
\hline & & \multicolumn{7}{|c|}{ Self-report } & \multicolumn{7}{|c|}{ Parent-report } \\
\hline & & GD & GA & $\begin{array}{c}\text { LA } \\
\text { (non-school) }\end{array}$ & $\begin{array}{c}\text { LA } \\
\text { (school) }\end{array}$ & PS & $\mathrm{OH}$ & Ol & GD & GA & $\begin{array}{c}\text { LA } \\
\text { (non-school) }\end{array}$ & $\begin{array}{c}\text { LA } \\
\text { (school) }\end{array}$ & PS & $\mathrm{OH}$ & $\mathrm{Ol}$ \\
\hline \multirow{7}{*}{ 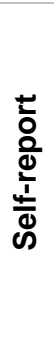 } & GD & 1.000 & $.701^{\star \star}$ & $.600^{\star \star}$ & $.627^{\star \star}$ & $.850^{\star \star}$ & $.629^{\star \star}$ & $.817^{\star \star}$ & $.233^{* *}$ & $.176^{\star *}$ & $.192^{\star \star \star}$ & .081 & $.107^{\star \star}$ & $.286^{\star *}$ & $.080^{*}$ \\
\hline & GA & $.701^{* *}$ & 1.000 & $.455^{\star *}$ & $.490^{* *}$ & $.547^{\star \star}$ & $.257^{\star \star}$ & $.512^{* *}$ & $.147^{\star \star}$ & $.139^{* *}$ & $.148^{* *}$ & .055 & .058 & $.182^{* \star}$ & .020 \\
\hline & LA (non-school) & $.600^{\star *}$ & $.455^{\star *}$ & 1.000 & $.419^{\star *}$ & $.512^{* *}$ & $.253^{\star *}$ & $.432^{* *}$ & $.157^{\star \star}$ & $.154^{\star \star}$ & $.181^{\star \star}$ & -.012 & $.081^{*}$ & $.146^{* *}$ & .040 \\
\hline & LA (school) & $.627^{* *}$ & $.490^{* *}$ & $.419^{* *}$ & 1.000 & $.449^{* *}$ & $.258^{* *}$ & $.412^{* *}$ & .098 & .100 & $.149^{* *}$ & $.183^{* *}$ & -.005 & .085 & .016 \\
\hline & PS & $.850^{* *}$ & $.547^{* \star}$ & $.512^{* *}$ & $.449^{* *}$ & 1.000 & $.376^{\star *}$ & $.771^{\star *}$ & $.172^{* *}$ & $.106^{* *}$ & $.173^{* *}$ & .016 & $.077^{\star}$ & $.235^{* *}$ & .058 \\
\hline & $\mathrm{OH}$ & $.629^{* *}$ & $.257^{\star *}$ & $.253^{* *}$ & $.258^{* *}$ & $.376^{* *}$ & 1.000 & $.360^{\star *}$ & $.154^{* *}$ & $.124^{* *}$ & .058 & .025 & $.073^{*}$ & $.225^{* \star}$ & .062 \\
\hline & Ol & $.817^{* *}$ & $.512^{* *}$ & $.432^{* *}$ & $.412^{* *}$ & $.771^{* *}$ & $.360^{* *}$ & 1.000 & $.160^{* *}$ & $.112^{* \star}$ & $.129^{* *}$ & .028 & .060 & $.239^{* *}$ & .041 \\
\hline \multirow{7}{*}{$\begin{array}{l}\frac{T}{0} \\
\frac{0}{0} \\
\frac{1}{2} \\
\frac{0}{0} \\
\frac{0}{\pi} \\
0\end{array}$} & GD & $.233^{* *}$ & $.147^{\star \star}$ & $.157^{\star \star}$ & .098 & $.172^{* *}$ & $.154^{\star \star}$ & $.160^{\star \star}$ & 1.000 & $.575^{\star \star}$ & $.527^{* *}$ & $.555^{\star \star}$ & $.775^{\star \star}$ & $.645^{\star \star}$ & $.786^{* *}$ \\
\hline & $\mathrm{GA}$ & $.176^{* *}$ & $.139^{* *}$ & $.154^{* *}$ & .100 & $.106^{* *}$ & $.124^{* *}$ & $.112^{* *}$ & $.575^{\star *}$ & 1.000 & $.328^{* *}$ & $.394^{* *}$ & $.319^{* *}$ & $.266^{* *}$ & $.373^{* *}$ \\
\hline & LA (non-school) & $.192^{* *}$ & $.148^{* *}$ & $.181^{\star \star}$ & $.149^{* *}$ & $.173^{* *}$ & .058 & $.129^{* *}$ & $.527^{\star *}$ & $.328^{* *}$ & 1.000 & $.303^{* \star}$ & $.312^{* \star}$ & $.199^{* *}$ & $.270^{* *}$ \\
\hline & LA (school) & .081 & .055 & -.012 & $.183^{* *}$ & .016 & .025 & .028 & $.555^{\star \star}$ & $.394^{* *}$ & $.303^{* *}$ & 1.000 & $.358^{* \star}$ & $.189^{* *}$ & $.352^{* *}$ \\
\hline & PS & $.107^{* *}$ & .058 & $.081^{*}$ & -.005 & $.077^{*}$ & $.073^{*}$ & .060 & $.775^{\star *}$ & $.319^{* *}$ & $.312^{* *}$ & $.358^{* *}$ & 1.000 & $.383^{* *}$ & $.734^{* *}$ \\
\hline & $\mathrm{OH}$ & $.286^{\star *}$ & $.182^{* \star}$ & $.146^{* *}$ & .085 & $.235^{* *}$ & $.225^{\star *}$ & $.239^{\star \star}$ & $.645^{\star \star}$ & $.266^{* *}$ & $.199^{* *}$ & $.189^{* *}$ & $.383^{* *}$ & 1.000 & $.335^{* \star}$ \\
\hline & Ol & $.080^{*}$ & .020 & .040 & .016 & .058 & .062 & .041 & $.786^{\star *}$ & $.373^{* *}$ & $.270^{* *}$ & $.352^{* *}$ & $.734^{* *}$ & $.335^{* *}$ & 1.000 \\
\hline
\end{tabular}

Table A4.7. Correlations between self-report and parent-report WHODAS Child subscales in the BIOPATH sample

GD, Global disability; GA, Getting along with others; LA, Life activities; PS, Participation in society; OH, Overall health; Ol, Overall impairment

Blue highlighted cells: correlations between subscales of WHODAS self-report version. Green highlighted cells: correlations between subscales of WHODAS parent-report version. Gold highlighted cells: correlations between self-report and parent-report for each WHODAS subscale. Orange highlighted cells: cross-subscale cross-respondant correlations. ${ }^{* *} p<.001, * p<.05$ 


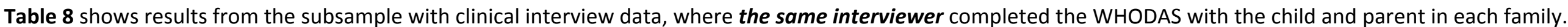

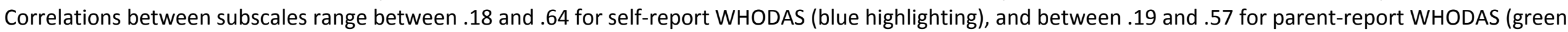

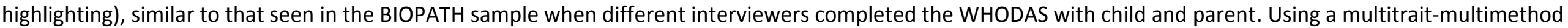

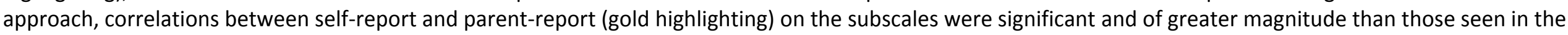

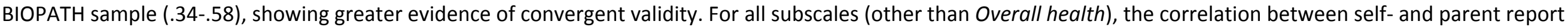

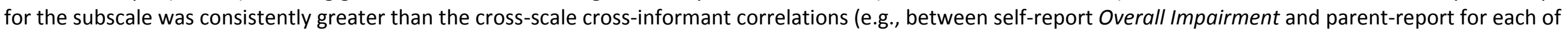

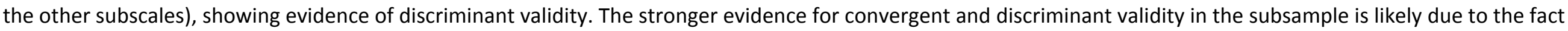

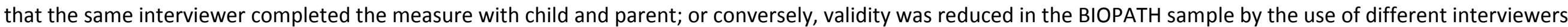
to complete the measure with child and parent.

\begin{tabular}{|c|c|c|c|c|c|c|c|c|c|c|c|c|c|c|c|}
\hline & & \multicolumn{7}{|c|}{ Self-report } & \multicolumn{7}{|c|}{ Parent-report } \\
\hline & & GD & GA & $\begin{array}{c}\text { LA } \\
\text { (non-school) }\end{array}$ & $\begin{array}{c}\text { LA } \\
\text { (school) }\end{array}$ & PS & $\mathrm{OH}$ & Ol & GD & GA & $\begin{array}{c}\text { LA } \\
\text { (non-school) }\end{array}$ & $\begin{array}{c}\text { LA } \\
\text { (school) }\end{array}$ & PS & $\mathrm{OH}$ & Ol \\
\hline \multirow{7}{*}{$\begin{array}{l}\frac{T}{0} \\
\frac{0}{0} \\
\frac{\grave{1}}{0} \\
\frac{1}{0} \\
\text { c) }\end{array}$} & GD & 1.000 & $.728^{\star *}$ & $.724^{\star *}$ & $.621^{* *}$ & $.750^{\star *}$ & $.469^{* *}$ & $.827^{\star \star}$ & $.576^{\star *}$ & $.448^{* *}$ & $.518^{* *}$ & $.309^{* *}$ & $.396^{\star *}$ & $.323^{\star \star}$ & $.537^{*}$ \\
\hline & GA & $.728^{* *}$ & 1.000 & $.439^{* *}$ & $.468^{* *}$ & $.521^{* \star}$ & .175 & $.562^{* *}$ & $.458^{* *}$ & $.500^{* *}$ & $.311^{* *}$ & .166 & $.286^{* *}$ & $.322^{* \star}$ & $.481^{* *}$ \\
\hline & LA (non-school) & $.724^{* *}$ & $.439^{* *}$ & 1.000 & $.452^{* *}$ & $.478^{* *}$ & $.303^{* *}$ & $.548^{* *}$ & $.492^{* *}$ & $.337^{* \star}$ & $.582^{* *}$ & .230 & $.290^{* *}$ & $.191^{*}$ & $.402^{*}$ \\
\hline & LA (school) & $.621^{* *}$ & $.468^{* *}$ & $.452^{* *}$ & 1.000 & $.479^{* *}$ & $.241^{*}$ & $.395^{* *}$ & .181 & .169 & .134 & $.339^{* *}$ & -.023 & .164 & $.240^{*}$ \\
\hline & PS & $.750^{* *}$ & $.521^{* *}$ & $.478^{* *}$ & $.479^{* *}$ & 1.000 & $.275^{* *}$ & $.642^{* *}$ & $.456^{* *}$ & $.302^{* \star}$ & $.410^{* *}$ & $.295^{*}$ & $.510^{* *}$ & $.353^{* *}$ & $.419^{* *}$ \\
\hline & $\mathrm{OH}$ & $.469^{* *}$ & .175 & $.303^{* *}$ & $.241^{*}$ & $.275^{* *}$ & 1.000 & $.410^{* *}$ & $.192^{*}$ & .119 & $.210^{*}$ & .135 & .112 & $.292^{* *}$ & $.192^{*}$ \\
\hline & $\mathrm{Ol}$ & $.827^{* \star}$ & $.562^{* *}$ & $.548^{* *}$ & $.395^{* *}$ & $.642^{* *}$ & $.410^{* *}$ & 1.000 & $.505^{\star \star}$ & $.403^{* \star}$ & $.417^{* *}$ & .208 & $.324^{* \star}$ & $.256^{* \star}$ & $.546^{*}$ \\
\hline \multirow{7}{*}{$\begin{array}{l}\frac{T}{0} \\
\frac{0}{0} \\
\frac{1}{1} \\
\frac{0}{0} \\
\frac{0}{0} \\
0\end{array}$} & GD & $.576^{* *}$ & $.458^{* *}$ & $.492^{* *}$ & .181 & $.456^{* *}$ & $.192^{*}$ & $.505^{* \star}$ & 1.000 & $.704^{* \star}$ & $.562^{* *}$ & $.575^{* *}$ & $.676^{* *}$ & $.540^{* *}$ & $.765^{\star \star}$ \\
\hline & GA & $.448^{* *}$ & $.500^{* *}$ & $.337^{\star *}$ & .169 & $.302^{* *}$ & .119 & $.403^{* *}$ & $.704^{* *}$ & 1.000 & $.312^{\star *}$ & $.239^{*}$ & $.320^{\star *}$ & $.254^{\star \star}$ & $.377^{*}$ \\
\hline & LA (non-school) & $.518^{\star *}$ & $.311^{\star *}$ & $.582^{\star *}$ & .134 & $.410^{\star *}$ & $.210^{*}$ & $.417^{\star *}$ & $.562^{* *}$ & $.312^{* *}$ & 1.000 & .190 & $.308^{\star *}$ & $.326^{\star *}$ & $.458^{*}$ \\
\hline & LA (school) & $.309^{* *}$ & .166 & .230 & $.339^{* *}$ & $.295^{\star}$ & .135 & .208 & $.575^{\star *}$ & $.239^{*}$ & .190 & 1.000 & $.365^{\star *}$ & $.354^{\star \star}$ & $.454^{*}$ \\
\hline & PS & $.396^{* *}$ & $.286^{* *}$ & $.290^{* *}$ & -.023 & $.510^{* *}$ & .112 & $.324^{* *}$ & $.676^{* *}$ & $.320^{* *}$ & $.308^{* *}$ & $.365^{* *}$ & 1.000 & $.378^{* *}$ & $.565^{*}$ \\
\hline & $\mathrm{OH}$ & $.323^{* *}$ & $.322^{* *}$ & $.191^{*}$ & .164 & $.353^{* *}$ & $.292^{* *}$ & $.256^{* *}$ & $.540^{* *}$ & $.254^{* *}$ & $.326^{* *}$ & $.354^{* *}$ & $.378^{* *}$ & 1.000 & $.386^{*}$ \\
\hline & $\mathrm{Ol}$ & $.537^{* \star}$ & $.481^{* *}$ & $.402^{* *}$ & $.240^{\star}$ & $.419^{\star *}$ & $.192^{*}$ & $.546^{* *}$ & $.765^{* \star}$ & $.377^{\star \star}$ & $.458^{* *}$ & $.454^{* *}$ & $.565^{\star *}$ & $.386^{* *}$ & 1.000 \\
\hline
\end{tabular}

Table A4.8. Correlations between self-report and parent-report WHODAS Child subscales in the subsample with clinical interview data

GD, Global disability; GA, Getting along with others; LA, Life activities; PS, Participation in society; OH, Overall health; OI, Overall impairment

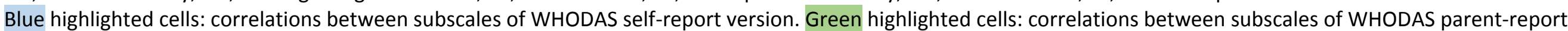

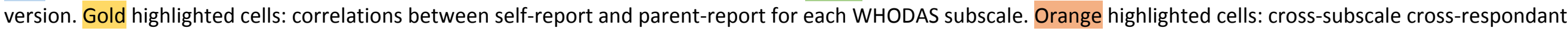
correlations. $* * \mathrm{p}<.001, * \mathrm{p}<.05$ 


\section{Appendix 5: Power analysis}

A-priori sample size calculation was performed using g*power 3.1.9.2 [25], MedCalc for Windows Version 18.10.2 (MedCalc Software, Ostend, Belgium) or estimated based on relevant literature.

\section{Cronbach's alpha}

A sample size of $\mathrm{N}=300$ is necessary to accurately measure a value of 0.7 with a 10 -item scale. ${ }^{1}$ The BIOPATH sample size of $\mathrm{N}=1006$ was therefore sufficient to establish Cronbach's alpha.

\section{Factor analysis}

For Exploratory Factor Analysis a sample of $\mathrm{N}=800$ is required to extract up to 3 factors from a 10 -item scale, $\mathrm{N}=500$ for a 15 -item scale, or $\mathrm{N}=450$ from a 20 -item scale, and to extract 4 factors requires $\mathrm{N}=600$ from a 20-item scale or $\mathrm{N}=500$ from a 25 -item scale. ${ }^{1}$ The BIOPATH sample size of $\mathrm{N}=1006$ should therefore have been sufficient for EFA.

\section{Test-retest reliability, inter-rater reliability, multi-trait multi-method analysis}

A sample size of $\mathrm{N}=23$ is required to detect a correlation coefficient of 0.5 with alpha $=.05$ and power $=$ 0.8 . Due to a delay in the start of data collection for the VaST study and because of difficulties in scheduling assessments during the t-CETA study, there were only $\mathrm{N}=13$ cases where two assessments were completed in a period of $<2$ months and $\mathrm{N}=9$ cases where two asseessments were completed in a period of $<1$ month. This was insufficient to examine the test-retest reliability of the effects of different raters. Multi-trait multi-method analysis was used with the WHODAS data: the BIOPATH sample size of $\mathrm{N}=1006$ and the subsample size of $\mathrm{N}=119$ was therefore sufficient for this correlational analysis.

\section{ROC curve analysis}

A sample size of $\mathrm{N}=105$ ( $\mathrm{n}=21$ positive cases and $\mathrm{n}=84$ negative cases) is required to detect an $\mathrm{AUC}$ of .70 with alpha $=.05$ and power $=0.8$, assuming prevalence of $20 \%$. A sample size of $N=76$ ( $n=23$ positive cases and $n=53$ negative cases) is required to detect an AUC of .70 with alpha $=.05$ and power $=0.8$, assuming prevalence of $30 \%$. A sample size of $N=68$ ( $n=27$ positive cases and $n=41$ negative cases) is required to detect an AUC of .70 with alpha $=.05$ and power $=0.8$, assuming prevalence of $40 \%$. The subsample size of $\mathrm{N}=119$ was therefore sufficient to establish a clinically relevant AUC for the measures included in the report.

\footnotetext{
${ }^{1}$ Rouquette \& Falissard, Sample size requirements for the internal validation of psychiatric scales. Int J Methods Psychiatr Res, 2011. 20(4): p. 235-49.
} 